MAISA CABETE PEREIRA SALVETTI

Estudo de viabilidade e desenvolvimento de sistema de telemedicina para o acidente vascular cerebral agudo na região de Ribeirão Preto - SP - Brasil

Ribeirão Preto

2018 


\section{FACULDADE DE MEDICINA DE RIBEIRÃO PRETO DA UNIVERSIDADE DE SÃO PAULO}

\section{MAISA CABETE PEREIRA SALVETTI}

Estudo de viabilidade e desenvolvimento de sistema de telemedicina para o acidente vascular cerebral agudo na região de Ribeirão Preto - SP - Brasil

Dissertação submetida para obtenção de grau de Mestre no programa de Mestrado Profissional em Gestão de Organizações de Saúde da Faculdade de Medicina de Ribeirão Preto da Universidade de São Paulo - USP.

Orientador: Prof. Dr. Altacílio Aparecido Nunes

*Versão corrigida. A original encontra-se disponível no Serviço de Pós-Graduação da FMRP-USP

Ribeirão Preto 
Autorizo a reprodução e a divulgação total ou parcial deste trabalho, por qualquer meio convencional ou eletrônico, para fins de estudo e pesquisa, desde que citada a fonte.

FICHA CATALOGRÁFICA

Salvetti, Maisa Cabete Pereira.

Estudo de viabilidade e desenvolvimento de sistema de telemedicina para o acidente vascular cerebral agudo na região de Ribeirão Preto - SP Brasil. Ribeirão Preto, 2018. 72 f.: il.

Dissertação de Mestrado apresentada à Faculdade de Medicina de Ribeirão Preto da Universidade de São Paulo. Área de concentração: Gestão de Organizações de Saúde.

Orientador: Nunes, Altacílio Aparecido.

1. Acidente Vascular Cerebral (AVC). 2. Telemedicina. 3. Tele-AVC. 4. Brasil. 5. Países em desenvolvimento. 6. Prontuário eletrônico. 7. Sistema Único de Saúde. 


\section{DEDICATÓRIA}

Aos meus pais, Antonio Carlos Pereira e Maria Claudia Ramos Cabete Pereira, pela inestimável dedicação de suas vidas à minha.

À minha filha Cecília, gerada junto a este projeto, que trouxe inesperadas, inimagináveis alegrias, e ao meu esposo, Thales Salvetti, meu contraponto, cujo amor constantemente traz novos significados a minha vida. 


\section{AGRADECIMENTOS}

Ao meu orientador, Prof. Dr. Altacílio Aparecido Nunes, pela oportunidade oferecida de realização deste Mestrado e todo o suporte em seu desenvolvimento, que trouxe conhecimentos essenciais e abriu portas para novo campo de atuação profissional.

Ao prof. Dr. Octávio Marques Pontes-Neto, pelas oportunidades oferecidas, aprendizado constante e acima de tudo, pelo exemplo de dedicação à produção e divulgação de conhecimento científico e de empenho na melhoria da assistência.

Ao prof. Dr. Antônio Pazin Filho, pela análise do projeto de pesquisa e preciosas contribuições críticas, com primorosa didática.

Aos professores Drs. Ayrton Custódio Moreira e Margaret de Castro, que em minha iniciação científica da graduação foram verdadeiros mestres, construindo sólida pedra fundamental sobre a qual se constrói meu conhecimento científico.

À equipe de desenvolvimento da Figlabs, nas pessoas do Rogério Bulha Siqueira e Juan Herbert Chuctaya Humari, que com excelência no conhecimento técnico e visão de inovação foram fundamentais no desenvolvimento do sistema de telemedicina.

Ao Hospital das Clínicas da Faculdade de Medicina de Ribeirão Preto da Universidade de São Paulo, pelo apoio neste projeto e pelos anos de formação.

Aos colegas Frederico Fernandes Aléssio Alves, Millene Rodrigues Camilo, Clara Monteiro Antunes Barreira, Rui Kleber do Vale Martins Filho, Pedro Cougo Pinto e Francisco Antunes Dias, por suas contribuições no desenvolvimento inicial deste projeto, apoio na sua realização e aprendizado no trabalho conjunto desde a nossa formação em neurologia.

A minha tia e mentora, Soraia Ramos Cabette Fábio, pelo apoio em diversas fases de minha vida e pelo exemplo pessoal e profissional.

Ao amigo Antônio Carlos Mattar, inspiração que me levou à Medicina e que sempre será exemplo de competência, profissionalismo e paixão por esta Arte. 


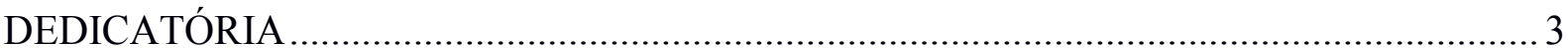

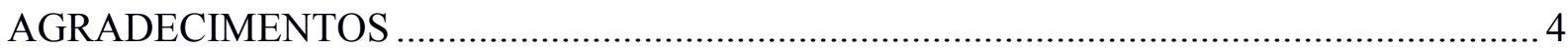

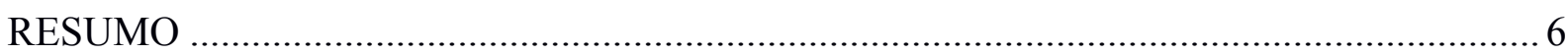

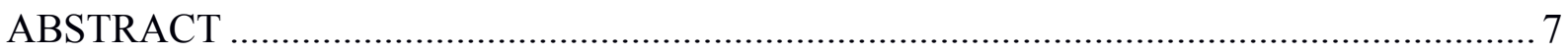

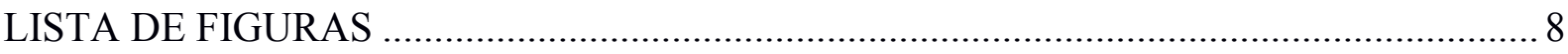

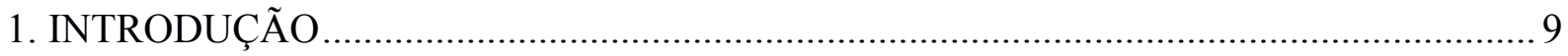

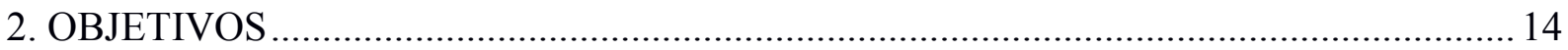

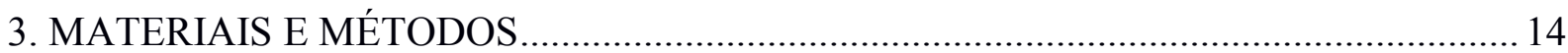

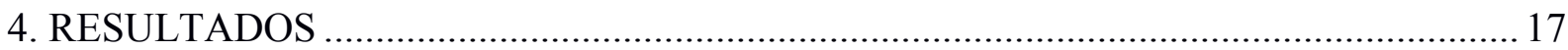

4.1 Análise demográfica da macrorregião de saúde de Ribeirão Preto ................................ 17

4.2 epidemiologia e Rede de atendimento do AVC na macrorregião de Ribeirão Preto ..... 18

4.3 Análise dos aspectos éticos e jurídicos da telemedicina para o avc .............................. 22

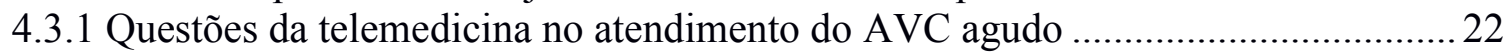

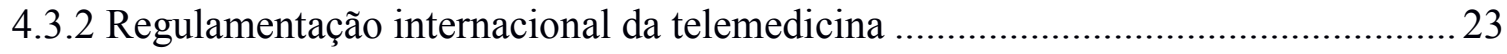

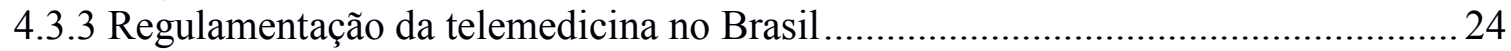

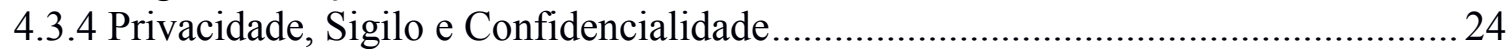

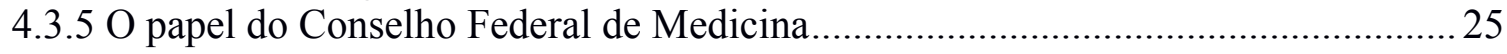

4.3.6 Normas, Resoluções e Pareceres relativos à Telemedicina ....................................26

4.3.7 Considerações éticas pertinentes ao projeto de pesquisa........................................ 30

4.4 FINANCIAMENTO e CUSTOS DA TELEMEDICINA PARA O AVC NO BRASIL30

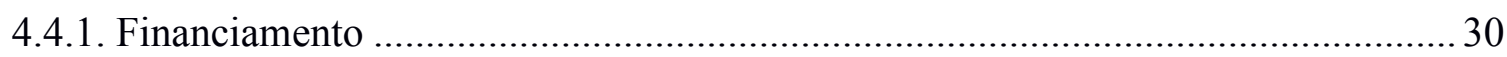

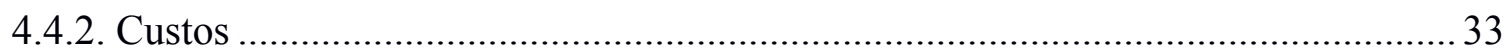

4.5 DESENVOLVIMENTO DO SISTEMA DE REGISTRO ELETRÔNICO E

VIDEOCONFERÊNCIA PARA O ATENDIMENTO DO AVC - TELEAVC................... 38

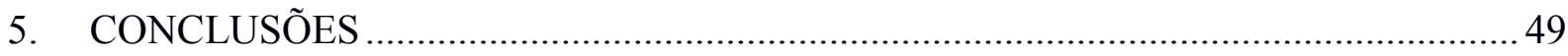

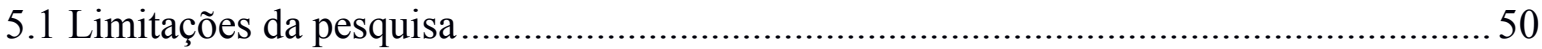

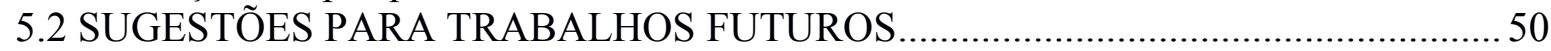

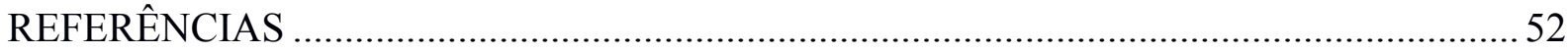

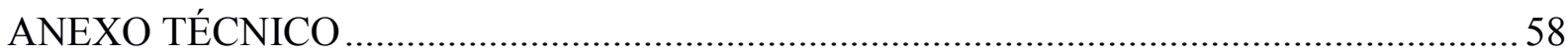




\section{RESUMO}

SALVETTI, Maisa Cabete Pereira. Estudo de viabilidade e desenvolvimento de sistema de telemedicina para o acidente vascular cerebral agudo na região de Ribeirão Preto - SP Brasil. 2018. 72f. Dissertação (Mestrado Profissional em Gestão de Organizações de Saúde). Faculdade de Medicina de Ribeirão Preto, Universidade de São Paulo. Ribeirão Preto, 2018.

O Acidente Vascular Cerebral (AVC) é uma doença prevalente e incapacitante, cujo atendimento no Brasil é insuficiente e concentrado em poucos centros de alta complexidade. A telemedicina possibilita assistência à saúde através do uso de tecnologias de comunicação entre dois ou mais profissionais, ou entre o profissional e o paciente, que estejam em locais distintos, permitindo aumento do acesso a tratamentos especializados, podendo ser útil na assistência do AVC agudo. Os objetivos deste estudo foram avaliar a viabilidade de uma rede de telemedicina para o AVC no Sistema Único de Saúde na região de Ribeirão Preto e desenvolver um sistema de telemedicina para o AVC. Para a análise da viabilidade, foram realizados o levantamento de indicadores demográficos e epidemiológicos da população de municípios que constituem o Departamento Regional de Saúde de Ribeirão Preto (DRS XIII) e uma análise técnica e econômica relacionada à estrutura necessária. O sistema de registro eletrônico e videoconferência foi desenvolvido por equipe multiprofissional, baseado em diretrizes nacionais para sistemas de informação em saúde e protocolos padronizados para o atendimento do AVC agudo. Concluiu-se que uma rede de telemedicina entre o Hospital das Clínicas de Ribeirão Preto e os outros hospitais que possuem os pré-requisitos para cadastramento como Unidade de AVC no DRS XIII será estratégica para a expansão do atendimento qualificado do AVC na região, e sua viabilidade depende do cadastro destes serviços junto ao Ministério da Saúde, financiamento dos equipamentos e treinamento das equipes assistenciais. O sistema de telemedicina desenvolvido possibilitará o registro seguro dos atendimentos, a educação permanente das equipes e base de dados para pesquisas clínicas, contribuindo para a concretização desta e de outras redes de telemedicina brasileiras.

Palavras-chave: Acidente Vascular Cerebral (AVC). Telemedicina. Tele-AVC. Brasil. Países em desenvolvimento. Prontuário eletrônico. Sistema Único de Saúde. 


\begin{abstract}
SALVETTI, Maisa Cabete Pereira. Feasibility study and development of a telemedicine system for acute stroke in the region of Ribeirão Preto - SP - Brazil. 2018. 72p. Thesis (Professional Masters in Health Organizations Management). Ribeirão Preto Medical School, University of São Paulo. Ribeirão Preto, 2018.
\end{abstract}

Stroke is a prevalent and disabling disease, whith insufficient treatment in Brazil, where is concentrated in a few high complexity centers. Telemedicine enables health care through communication technology between two or more professionals, or between the professionals and patients, in different locations, allowing increased access to specialized treatments, therefore useful in acute stroke treatment. This study objectives were to evaluate the feasibility of a public stroke telemedicine network at Ribeirão Preto region and to develop a stroke telemedicine eletronic system. For feasibility study, populational demographic and epidemiological indicators were compiled for the cities that constitute the Regional Health Department of Ribeirão Preto (DRS XIII) and a technical and economic analysis related to the necessary structure was performed. The electronical record and videoconference system was developed by a multiprofessional team, based on national guidelines for health information systems and standardized protocols for acute stroke care. A telemedicine network between the Hospital das Clínicas of Ribeirão Preto and the other hospitals that meet criteria for enrollment as Stroke Units in DRS XIII will be strategic for the expansion of regional qualified stroke care. Its viability depends on the registration of these services at the Health Ministry, equipment financing and assistance teams training. The developed telestroke system will enable the secure record of calls, the permanent education of the teams and a database for clinical research, contributing to the realization of this and other telemedicine networks.

Keywords: Stroke. Telemedicine. Telestroke. Brazil. Developing countries. Electronic medical record. Public Health System. 


\section{LISTA DE FIGURAS}

Figura 1: Distribuição geográfica dos departamentos regionais de saúde do Estado de São

Paulo. Fonte: Secretaria do estado da saúde de SP (site).

Figura 2: Sub-regiões e municípios do departamento regional de saúde de Ribeirão Preto.

Fonte: Departamento Regional de Saúde de Ribeirão Preto - DRS XIII (site). ...................... 18

Figura 3: Distância em quilômetros entre Ribeirão Preto e os municípios do DRS XIII. ....... 19

Figura 4: Distância em quilômetros entre os municípios do DRS XIII e o centro com

Tomografia Computadorizada disponível mais próximo.

Figura 5: proposta comercial Polycom equipamentos de videoconferência - valores de abril de

2015.

Figura 6: impressão de tela da página inicial do site do sistema de telemedicina para o AVC39

Figura 7: Impressão da tela da segunda aba do site do sistema de telemedicina para o AVC -

Avaliação Local

Figura 8: Impressão da tela da terceira aba do site do sistema de telemedicina para o AVC, denominada Avaliação Neurológica.

Figura 9: Impressão da tela do sítio eletrônico de telemedicina para o AVC, demonstrando a realização passo-a-passo da National Institute of Health Stroke Scale. Ao passar o mouse sobre item (ex. 1a), o usuário recebe a orientação de como realizar a avaliação.

Figura 10: Impressão da tela demonstrando orientações para avaliação do item 9 da National

Institute of Health Stroke Scale.

Figura 11: impressão da tela da aba "Trombolítico" do site de telemedicina para o AVC ...... 43

Figura 12: impressão da tela do site de telemedicina para o AVC, demonstrando lista de contraindicações ao trombolítico para conferência.

Figura 13: impressão da tela "Evolução" do site de telemedicina para o AVC .......................45

Figura 14: impressão da tela do site de telemedicina para o AVC - aba alta hospitalar. ......... 47 Figura 15: Opções para seleção de diagnóstico etiológico do AVC isquêmico - indeterminado,

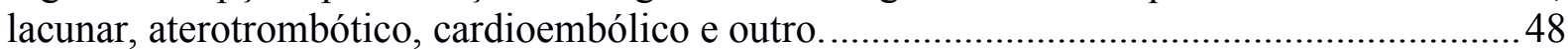

Figura 16: Metodologia de desenvolvimento de softwares com OpenEHR ..........................59

Figura 17: Nível clínico (conhecimento) e técnico no desenho de um sistema de saúde com

OpenEHR

Figura 18: Diagrama contextual da metodologia utilizada na aplicação do openEHR no

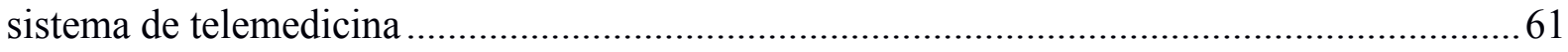

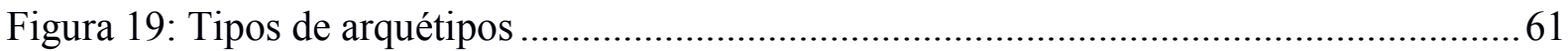

Figura 20: Desenho de arquétipo Qualidade (desenhado no Archetype Editor) ......................63

Figura 21: Desenho de linguagem ADL gerado pela ferramenta Archetype ...........................64

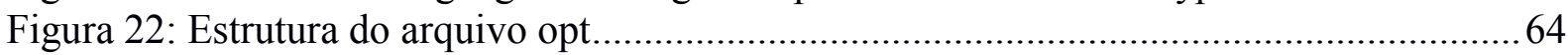

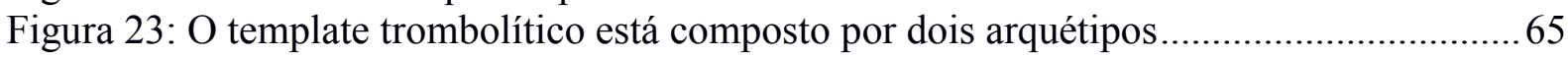

Figura 24: Exporte do arquivo do template para um operational template ............................65

Figura 25: À esquerda, encontra-se o template em xml (opt) e à direita, sua versão em arquivo

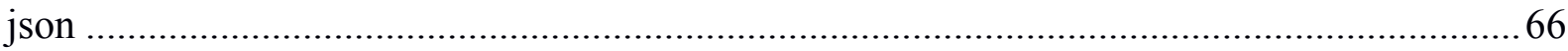

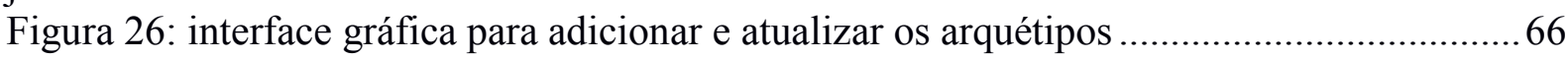

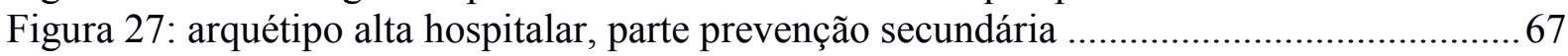

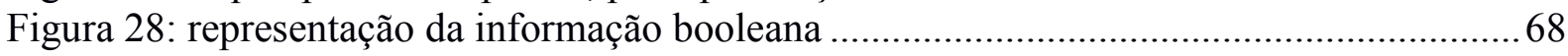

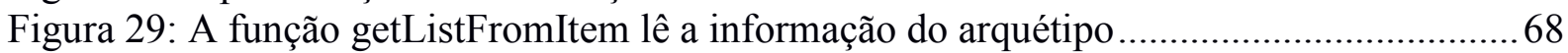

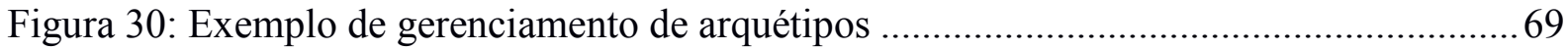




\section{INTRODUÇÃO}

As doenças cerebrovasculares foram a segunda causa de morte e a terceira causa de incapacidade no mundo em 2015 (WORLD HEALTH ORGANIZATION (WHO), 2016a, 2016b). Entretanto, sua distribuição global é desproporcional, com a maioria dos óbitos ocorrendo nos países em desenvolvimento (DONNAN, 2011). No Brasil, alguns estudos epidemiológicos mostram que a taxa média de incidência do Acidente Vascular Cerebral (AVC) encontra-se entre 87 a 168 por 100 mil habitantes (MINELLI; FEN; MINELLI, 2007; CABRAL et al., 2009).

Dentre os tipos de AVC, 80 a 85\% são de etiologia isquêmica, e o único tratamento atualmente disponível na fase hiperaguda do AVC isquêmico com comprovado impacto no desfecho funcional é o uso de trombolítico endovenoso em até 4,5 horas do início dos sintomas (WAHLGREN et al., 2008). Entretanto, dentre os pacientes admitidos em um hospital, em torno de $29,7 \%$ se encontram na janela de tempo de 4,5 horas, sendo que o medicamento é de fato administrado em apenas $27 \%$ destes - ou seja, apenas $7 \%$ dos casos admitidos com suspeita de AVC (SCHWAMM et al., 2013). Até o ano de 2012, dentre os 214 países e territórios independentes apenas $54(25 \%)$ usavam o trombolítico para tratamento dos seus pacientes com AVC hiperagudo, sendo que a maioria desses eram países desenvolvidos (CULEBRAS, 2013).

O Brasil é conhecido por seus contrastes, e no campo do atendimento ao AVC agudo isso também acontece. Dentro de um mesmo país há centros com atendimento de excelência em emergências neurológicas, capazes de atender e tratar agudamente os pacientes vítimas de AVC com taxas de sucesso semelhantes ao de países desenvolvidos, e áreas carentes de recursos básicos de atendimentos de emergência. Até mesmo dentro da mesma cidade, como evidenciado em estudo de georreferenciamento do AVC em São Paulo, existem diferenças no risco e na mortalidade pelo $\mathrm{AVC}$, sendo piores nas regiões com menores índices de desenvolvimento humano (IDH) (KAUP et al., 2015). Ainda em São Paulo, uma análise da mortalidade por AVC entre os anos de 1996 e 2011 demonstrou que, apesar de ter ocorrido uma redução global neste período, esta ocorreu principalmente na população de alta renda, e a diferença do risco de AVC entre as populações de alta e baixa renda dobrou (FERNANDES et al., 2015). 
Contrastando com centros acadêmicos que desenvolvem pesquisas de nível internacional, a maioria da população simplesmente desconhece a doença, seus fatores de risco, formas de prevenção e tratamento (PONTES-NETO et al., 2008).

As dimensões territoriais brasileiras, a pequena quantidade de hospitais capacitados para o tratamento adequado do AVC e as grandes distâncias que separam a maioria da população dos municípios de médio e pequeno porte destes hospitais são fatores que causam grande impacto na quantidade de brasileiros que conseguem chegar ao hospital adequado e no tempo certo para o tratamento trombolítico. Em junho de 2008, apenas 35 centros de tratamento de AVC estavam ativos no Brasil (MARTINS et al., 2013).

Com a finalidade de modificar o grande impacto econômico e social do AVC no Brasil, em 2008 a Coordenação Geral de Urgência e Emergência do Ministério da Saúde iniciou a organização do Projeto Nacional de Atendimento ao Acidente Vascular Cerebral (BRASIL. MINISTÉRIO DA SAÚDE., 2009). Dentro deste projeto, a telemedicina foi proposta como ferramenta para dar suporte à realização do tratamento trombolítico em hospitais sem especialistas em AVC e também ao SAMU, auxiliando, quando necessário, no reconhecimento dos casos elegíveis para o tratamento e no encaminhamento do paciente ao hospital mais adequado.

No caminho de fornecer subsídios à concretização da Rede Nacional de Atendimento ao AVC, em abril de 2012 o Ministério da Saúde publicou as Portarias Nº 664 e 665 GM/MS, aprovando um Protocolo Clínico com Diretrizes Terapêuticas para Trombólise no Acidente Vascular Cerebral (AVC) Isquêmico agudo e a Linha de Cuidados ao paciente com AVC, associada ao respectivo incentivo financeiro para fomentar sua instalação dentro do Sistema Único de Saúde (SUS) (BRASIL. MINISTÉRIO DA SAÚDE., 2012a, 2012b). Em seu artigo $5^{\circ}$, parágrafo V, a Portaria $n^{\circ} 665$ (alterado pela portaria $n^{\circ} 880$ de 2015, posteriormente) define também que um centro de referência para o atendimento ao paciente com AVC “deve fornecer cobertura de atendimento neurológico, disponível em até 30 (trinta) minutos da admissão do paciente (plantão presencial, sobreaviso à distância ou suporte neurológico especializado por meio da telemedicina/telessaúde)".

A telemedicina compreende todo serviço de assistência à saúde prestado através do uso de tecnologia de comunicação e troca de informações entre profissionais de saúde, ou entre o profissional de saúde e o paciente, que estejam em locais físicos distintos (MEDEIROS DE BUSTOS et al., 2009). É uma prolífica estratégia em saúde, que envolve 
comunicação e ampla troca de informações, com fins diagnósticos, terapêuticos e de monitorização de pacientes e condições clínicas, podendo contar até com intervenções à distância, além de servir de canal aberto à troca de experiência entre os profissionais de saúde e educação continuada dos mesmos.

No Brasil, o marco da telemedicina foi a implementação dos programas "Institutos do Milênio - Estação Digital Médica” (EDM-Milênio), em 2005, coordenado pelo CNPq (Conselho Nacional de Desenvolvimento Científico e Tecnológico), e o Projeto de Telemática e Telemedicina em apoio à Atenção Primária no Brasil, do Ministério da Saúde, ambos voltados para a educação em atenção de saúde primária. Outro importante marco foi a criação do projeto da Rede Universitária de Telemedicina (RUTE) da RNP (Rede Nacional de Ensino e Pesquisa), em 2006, com o objetivo de identificar e criar infraestrutura de videoconferência entre hospitais universitários (WEN, 2008).

A telemedicina pode ser aplicada a várias especialidades médicas, dentre as quais se encontra a neurologia vascular, então chamada "tele-AVC", ou telestroke. A proposta do telestroke surgiu nos Estados Unidos em 1999, apenas alguns anos após a aprovação do tratamento trombolítico, com a identificação da necessidade do desenvolvimento de novos paradigmas para melhorar o tratamento do AVC em todos os cenários, tanto rural como urbano, considerando o importante fator limitante do tempo para o tratamento trombolítico e a necessidade de conexões entre os centros com expertise em AVC e áreas mais remotas. A situação do atendimento ao AVC nos Estados Unidos naquela época era semelhante à brasileira atual, em que cerca de 50\% dos pacientes chegavam aos hospitais fora da janela de trombólise e a porcentagem de pacientes com AVC tratada com trombolítico era $<1,5 \%$ nacionalmente. Neste contexto, a telemedicina foi vista como uma tecnologia que poderia ser utilizada para integrar todas as informações médicas necessárias (avaliação clínica, neurorradiologia, resultados laboratoriais) para levar atendimento neurológico de alto nível a locais desassistidos (LEVINE; GORMAN, 1999).

Após o início da telemedicina para o AVC, sua utilidade já foi comprovada por vários estudos (AUDEBERT; SCHWAMM, 2009; TATLISUMAK; SOINILA; KASTE, 2009) e em 2009 a American Heart Association publicou suas diretrizes recomendando a implementação da telemedicina nas redes de atenção ao AVC (SCHWAMM et al., 2009), entendendo-a como necessária para que o cuidado do AVC não aconteça em ilhas, mas sim em uma cadeia de sobrevivência integrada e coordenada. 
A aplicação do tele-AVC já foi demonstrada em várias das etapas da linha de cuidado do paciente com AVC, dentre elas (AUDEBERT; SCHWAMM, 2009; SCHWAMM et al., 2009):

(1) No atendimento pré-hospitalar, com o contato das equipes das ambulâncias diretamente com as equipes de neurologistas dos centros de $\mathrm{AVC}$, melhorando a qualidade da triagem e impactando tanto em redução do tempo de encaminhamento do doente ao centro de AVC tanto na triagem, evitando encaminhamentos desnecessários;

(2) No tratamento hiperagudo, com suporte de equipes experientes em neurologia vascular durante o tratamento trombolítico;

(3) No suporte hospitalar durante a internação, orientando exames necessários, auxiliando em indicações cirúrgicas e de procedimentos (indicando ou evitando transferências entre unidades hospitalares) e contribuindo para a melhor definição da prevenção secundária para cada caso antes da alta;

(4) Aumentando a possibilidade de recrutamento de pacientes para estudos clínicos multicêntricos mesmo em hospitais não acadêmicos;

(5) Na educação continuada de equipes de atendimento e de pacientes;

(6) Na reabilitação dos pacientes, tanto pelo contato direto da equipe de reabilitação com o paciente (KOH et al., 2015).

Em 2012, foi publicado um estudo que realizou uma ampla pesquisa com os serviços de tele-AVC ativos nos Estados Unidos naquele momento (SILVA et al., 2012). Muitos hospitais consultados relataram como motivações para iniciar um serviço de telemedicina o fato de já estarem recebendo solicitações de auxílio de condução dos pacientes em outros hospitais menores, com dificuldade em manejar os casos sem conseguir visualizar o paciente ou as imagens radiológicas, além do que, considerando que estes pacientes acabavam sendo transferidos para o hospital central, e a telemedicina seria um modo de triá-los ou iniciar a condução destes pacientes antes de sua chegada. Outro motivo relatado foi a busca pela redução da disparidade entre serviços de saúde dentro de uma área. Ainda neste estudo, as principais barreiras e dificuldades relatadas pelos serviços de tele-AVC foram desafios no credenciamento, falta de suporte tecnológico nos hospitais satélites, falta de recursos 
financeiros para início e manutenção do programa e de regras de reembolso e pagamento e a aceitação dos médicos dos hospitais satélites.

$\mathrm{Na}$ Europa, um estudo conduzido na Catalunha avaliou o impacto da implantação de um sistema de tele-AVC em um sistema público de saúde de uma cidade cerca de $70 \mathrm{~km}$ distante do centro especializado em AVC mais próximo, e mostrou resultados animadores: a taxa de transferências para o centro de referência caiu de 17 para $10 \%$, a proporção de pacientes avaliados por um neurologista especialista em AVC subiu de 17 para 38\%; houve um aumento na taxa de tratamento agudo do AVC (trombólise endovenosa aumentou de 30 para $68 \%$ dos pacientes agudos), com uma diminuição do intervalo entre sintoma e tratamento de 210 para 162 minutos, e sem aumento de taxas de complicações associadas à intervenção. Houve uma boa aceitação do sistema pelos profissionais de saúde envolvidos no projeto (PEDRAGOSA et al., 2009).

No Brasil, a inclusão da telemedicina como estratégia alternativa para o suporte neurológico especializado ao paciente com AVC baseia-se essencialmente nas evidências científicas sobre o benefício do uso desse recurso tecnológico em outros países, pois nacionalmente ainda é incipiente, tanto no âmbito federal quanto no estado de São Paulo, sendo restrita, no SUS, a duas redes de atendimento, uma na região metropolitana de Porto Alegre - RS (MARTINS et al., 2013) e outra em São Paulo - SP (STEINMAN et al., 2015).

Em Porto Alegre, como parte de um piloto conduzido para implementação de uma rede de atendimento ao AVC, a telemedicina foi usada para o atendimento do AVC hiperagudo em um município vizinho, com cerca de 320.000 habitantes, e foi capaz de tratar, dentro do primeiro ano de funcionamento, 35 pacientes, sendo que destes, 57\% ficaram sem sequelas ou com sequelas mínimas, sendo funcionalmente independentes (MARTINS et al., 2013).

Tendo em vista o impacto das doenças cerebrovasculares na qualidade de vida no País e as dificuldades ao atendimento agudo do AVC na macrorregião de Ribeirão Preto, apesar de a mesma albergar um importante centro de pesquisa e assistência a doenças cerebrovasculares do país, são necessárias novas estratégias de integração e implantação da atenção ao cuidado no AVC agudo. Considerou-se, então, a proposta de organização de uma rede de telemedicina na região de Ribeirão Preto, entre o Hospital das Clínicas da Faculdade de Medicina de Ribeirão Preto e hospitais de nível secundário da região. Para tanto, como primeiro objetivo desta pesquisa, foram analisados os recursos disponíveis e a rede de 
urgências e emergências da região para definir o desenho desta rede de atendimento ao AVC.

Dentro do planejamento desta rede de telemedicina, deve ser considerado o recurso tecnológico necessário, bem como seu custo. Em uma primeira avaliação das opções comerciais disponíveis no País e utilizadas até o momento em serviços de telemedicina nacionais, observou-se que as opções disponíveis eram limitadas a equipamentos e softwares de videoconferência, em sua maioria com custo elevado e sem interação com prontuário eletrônico ou sistema de registro de dados dos pacientes avaliados. Portanto, foi identificada uma segunda necessidade, a de desenvolver um sistema de telemedicina para o AVC que integrasse a videoconferência e uma plataforma de registro eletrônico de dados (como um prontuário eletrônico compartilhado em tempo real), que fosse de baixo custo e com capacidade de integração aos sistemas de informação do SUS, sendo, portanto, o segundo objetivo desta pesquisa.

\section{OBJETIVOS}

- Determinar a viabilidade da implantação de uma rede de telemedicina para o AVC entre o Hospital das Clínicas de Ribeirão Preto - USP e hospitais de nível secundário do departamento regional de saúde XIII (DRS XIII) da macrorregião de Ribeirão Preto.

- Desenvolver um sistema informatizado de registro eletrônico e videoconferência, de baixo custo, direcionado ao atendimento do AVC agudo.

\section{MATERIAIS E MÉTODOS}

Para a análise da viabilidade da rede de telemedicina para o AVC na região de Ribeirão Preto serão realizados os seguintes passos: primeiro, o levantamento de indicadores demográficos e epidemiológicos da população de municípios que constituem o Departamento Regional de Saúde de Ribeirão Preto (DRS XIII); em seguida, uma análise técnica 
relacionada à estrutura necessária. Foram realizadas as seguintes estratégias de pesquisa para os tópicos listados:

- Dados demográficos do DRS XIII (população, municípios e distâncias): consultas aos sites do IBGE, Secretaria Estadual de Saúde de São Paulo e dados geográficos de mapas disponíveis no Google Maps ${ }^{\circledR}$.

- Avaliação epidemiológica do AVC no Brasil e na macrorregião de Ribeirão Preto: consultas à base de dados PubMed ${ }^{\circledR}$, ao DATASUS (DATASUS $\rightarrow$ informações de saúde $\rightarrow$ epidemiológicas e mortalidade) e dados dos casos atendidos no Hospital das Clínicas da Faculdade de Medicina de Ribeirão Preto (projeto REAVER - Registro Epidemiológicos dos Acidentes Vasculares Encefálicos de Ribeirão Preto).

- Rede de atendimento em AVC disponível na macrorregião de Ribeirão Preto pelo SUS (organização da DRS, equipamentos disponíveis, leitos de UTI e centros de referência para neurologia e AVC) por acesso às informações do DATASUS $\rightarrow$ Rede Assistencial $\rightarrow$ macrorregião de saúde de Ribeirão Preto.

- Legislação pertinente a telemedicina e sistemas de informática em saúde: revisão de portarias do Ministério da Saúde, do Conselho Federal de Medicina e publicações científicas relativas ao tema (busca via Google e PubMed®);

- Alternativas de financiamento: pesquisa de programas de financiamento governamental, políticas públicas de atendimento do AVC e possibilidades de financiamento de programa de telemedicina.

- Experiências brasileiras em telemedicina no Sistema Único de Saúde: consultas a publicações acadêmicas no tema.

- Custos: após consultoria realizada com empresa incubadora de tecnologias de informação relacionadas à saúde (Figlabs $\left.{ }^{\circledR}\right)$, foram definidos os equipamentos necessários para estruturação de rede de telemedicina e realizados orçamentos em empresas do ramo e também separadamente por custo individualizado de equipamento ou serviço. Foram analisados modelos de custeio e financiamento de redes de tele-AVC existentes e realizada projeção de custos imediatos para o início do funcionamento do sistema.

O sistema de registro eletrônico e videoconferência para o AVC foi desenvolvido por equipe multiprofissional, composta de engenheiros e médicos neurologistas, seguindo as recomendações da portaria do Ministério da Saúde $N^{0} 2.073$, de 31 de agosto de 2011, que regulamenta o uso de padrões de interoperabilidade e informação em saúde para sistemas de 
informação em saúde no âmbito do Sistema Único de Saúde, nos níveis Municipal, Distrital, Estadual e Federal, e para os sistemas privados e do setor de saúde suplementar. Os padrões de interoperabilidade e de informação em saúde são o conjunto mínimo de premissas, políticas e especificações técnicas que disciplinam o intercâmbio de informações entre os sistemas de saúde Municipais, Distrital, Estaduais e Federal, estabelecendo condições de interação com os entes federativos e a sociedade (BRASIL. MINISTÉRIO DA SAÚDE., 2011a). Portanto, conforme a portaria, o sistema utilizou:

1. Para a garantia de segurança e integridade de informações será adotado o padrão WS-Security para criptografia e assinatura digital das informações.

2. Os Web Services são identificados por um URI (Uniform Resource Identifier) e são descritos e definidos usando WSDL (Web Service Description Language).

3. Para a definição do Registro Eletrônico em Saúde (RES) será utilizado o modelo de referência OpenEHR, disponível em http:// www. openehr. org / home. html.

4. Para estabelecer a interoperabilidade entre sistemas, com vistas à integração dos resultados e solicitações de exames, será utilizado o padrão HL7 - Health Level 7.

5. Para codificação de termos clínicos, exames laboratoriais e mapeamento das terminologias nacionais e internacionais em uso no país, visando suportar a interoperabilidade semântica entre os sistemas será utilizado o padrão LOINC (Logical Observation Identifiers Names and Codes).

Além da portaria 2.073/2011 do MS serão observadas as recomendações da resolução $\mathrm{n}^{\mathrm{o}}$ 1.821/07 do Conselho Federal de Medicina (CFM), que "aprova as normas técnicas concernentes à digitalização e uso dos sistemas informatizados para a guarda e manuseio dos documentos dos prontuários dos pacientes, autorizando a eliminação do papel e a troca de informação identificada em saúde"(CONSELHO FEDERAL DE MEDICINA, 2007), e as disposições da resolução $\mathrm{n}^{\circ} 1.643 / 2002$ do CFM, que define e disciplina a prestação de serviços através da Telemedicina (CONSELHO FEDERAL DE MEDICINA, 2002).

Estão disponíveis, no ANEXO TÉCNICO desta dissertação, descrição detalhada e passos técnicos utilizados para o desenvolvimento do sistema. 


\section{RESULTADOS}

\subsection{ANÁLISE DEMOGRÁFICA DA MACRORREGIÃO DE SAÚDE DE RIBEIRÃO PRETO}

O departamento regional de saúde XIII (DRS XIII) da macrorregião de Ribeirão Preto localiza-se na região nordeste do estado de São Paulo (figura 1), abrange 26 municípios, com uma população total de aproximadamente 1.433.463 habitantes (IBGE, 2013, apud CAPELI, 2014).

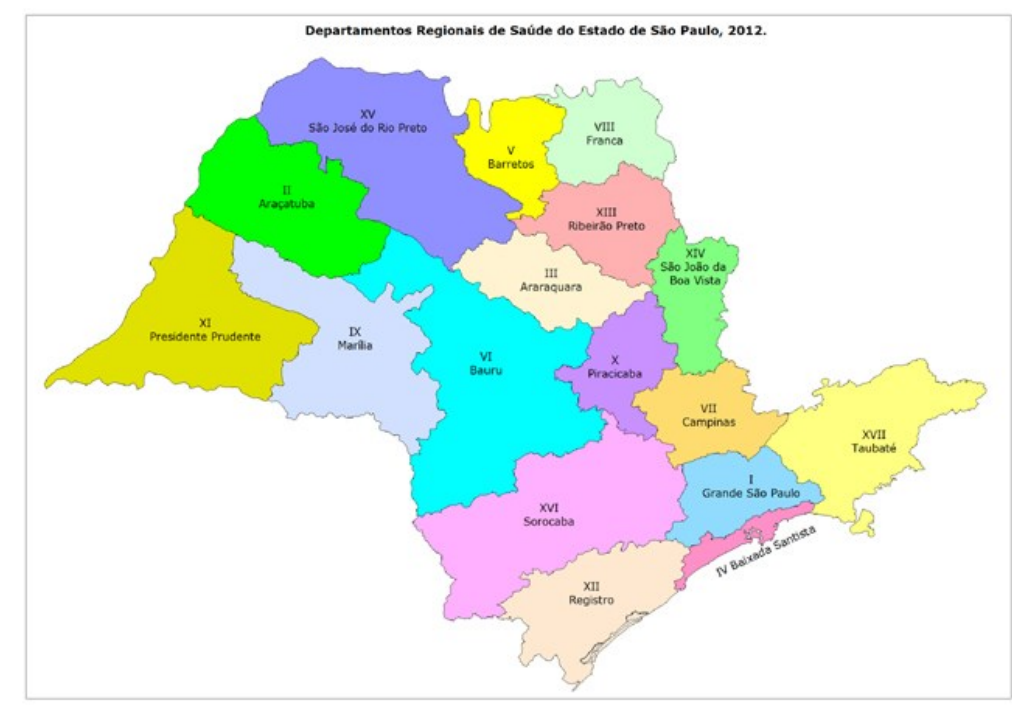

Figura 1: Distribuição geográfica dos departamentos regionais de saúde do Estado de São Paulo. Fonte: Secretaria do estado da saúde de SP (site).

Estes municípios são divididos em 3 sub-regiões (figura 2):

- Aquífero Guarany (10 municípios - 826.472 habitantes): Cravinhos, Guatapará, Jardinópolis, Luiz Antônio, Ribeirão Preto, Santa Rita do Passa Quatro, Santa Rosa do Viterbo, São Simão, Serra Azul, e Serrana.

- Horizonte Verde (9 municípios - 401.348 habitantes): Barrinha, Dumont, Guariba, Jaboticabal, Monte Alto, Pitangueiras, Pontal, Pradópolis, e Sertãozinho. 
- Vale das Cachoeiras (7 municípios - 129.345 habitantes): Altinópolis, Batatais, Brodowski, Cajuru, Cássia dos Coqueiros, Santa Cruz da Esperança, e Santo Antônio da Alegria.

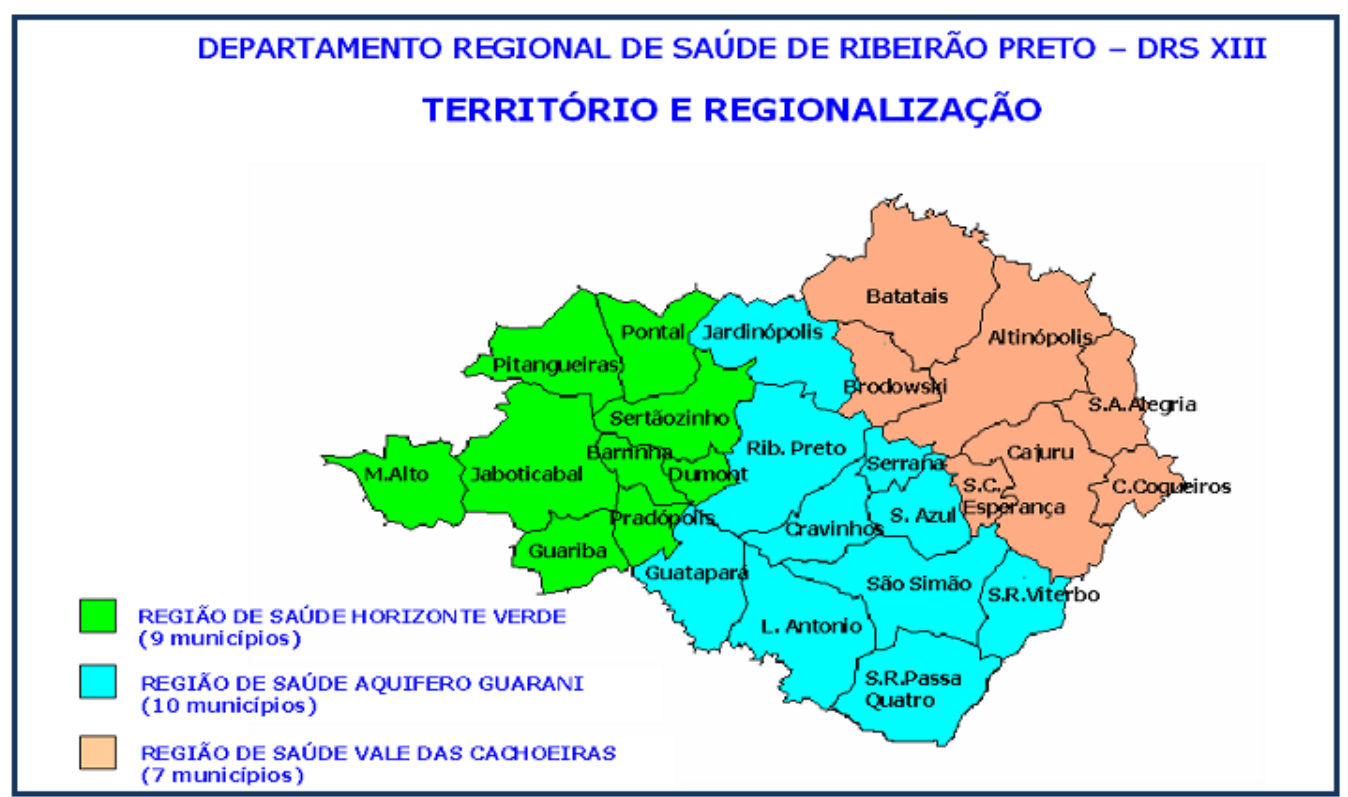

Figura 2: Sub-regiões e municípios do departamento regional de saúde de Ribeirão Preto. Fonte: Departamento Regional de Saúde de Ribeirão Preto - DRS XIII (site).

A região do DRS XIII ocupa 3,7\% da área territorial do Estado de São Paulo, possui uma das menores densidades demográficas do estado, abrangendo 22 municípios com menos de 50 mil habitantes, 02 municípios com 50 a 100 mil habitantes, 01 município com 100 a 200 mil habitantes e 01 município com mais de 500 mil habitantes. O município sede e os municípios de Sertãozinho, Jaboticabal, Monte Alto e Serrana concentram 66,7\% da população dessa região.

\subsection{EPIDEMIOLOGIA $\mathrm{E}$ REDE DE ATENDIMENTO DO AVC NA MACRORREGIÃO DE RIBEIRÃO PRETO}


Ao analisar a organização da DRS XIII, observa-se uma evidente heterogeneidade na distribuição de leitos e serviços para o atendimento dos pacientes. A região de saúde dispõe de cerca de 770 leitos para internações clínicas (entre enfermaria e unidade de terapia intensiva), sendo que 282 destes (37\%) se concentram no complexo do Hospital das Clínicas da Faculdade de Medicina de Ribeirão Preto - HCFMRP-USP (DATASUS, 2013). Quando há suspeita do diagnóstico de $\mathrm{AVC}$, estes casos são classificados como portadores de necessidade de intervenção imediata com suporte avançado médico e encaminhamento para o serviço de referência mais próximo, sendo que na DRS XIII, o HCFMRP-USP é o único centro de referência vinculado ao SUS que disponibiliza o tratamento trombolítico, admitindo cerca de 600 pacientes com AVC por ano. Analisando as distâncias dos municípios do DRS XIII até o HCFMRP, verifica-se que o município de residência interfere nas chances do paciente com AVC agudo de receber o tratamento correto no tempo correto. Conforme observamos na figura 3, alguns municípios ficam até $90 \mathrm{~km}$ de distância do centro de tratamento.

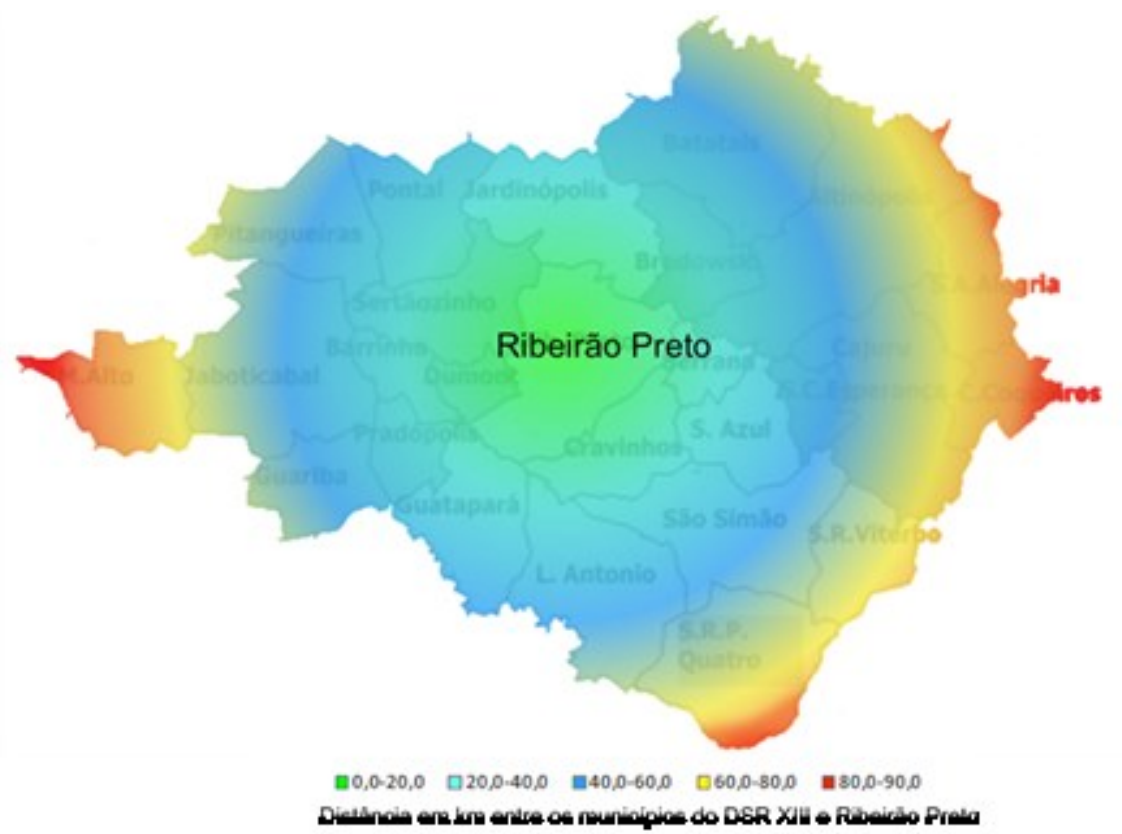

Figura 3: Distância em quilômetros entre Ribeirão Preto e os municípios do DRS XIII.

Uma análise dos atendimentos por AVC ocorridos em 2016 na Unidade de Emergência do HCFMRP demonstra que foram internados, neste ano, 597 pacientes, sendo $82 \%$ com AVC isquêmico. Foram submetidos à trombólise 125 pacientes, o que corresponde a 29\% dos pacientes com suspeita de AVCi admitidos no HCFMRP, entretanto somente a 7\% dos 1800 casos internados com doenças cerebrovasculares na região. Estes índices poderiam 
ser melhorados com a ampliação da disponibilidade de equipe de profissionais de saúde e serviços capacitados para o manejo do paciente com suspeita de AVC - necessariamente com acesso à tomografia computadorizada. Na DRS XIII, somente cinco municípios, além da cidade de Ribeirão Preto, dispõem deste recurso para pacientes atendidos pelo SUS: Batatais, Jaboticabal, Monte Alto, Serrana e Sertãozinho. Estas cidades não estão localizadas de maneira proporcional e equidistante as 21 demais, mas sim distribuídas no noroeste da macrorregião (Figura 4); registram em torno de 150 internações anuais por doenças cerebrovasculares, mas sem evidências de intervenções em fase hiperaguda do AVC, como o uso do trombolítico.

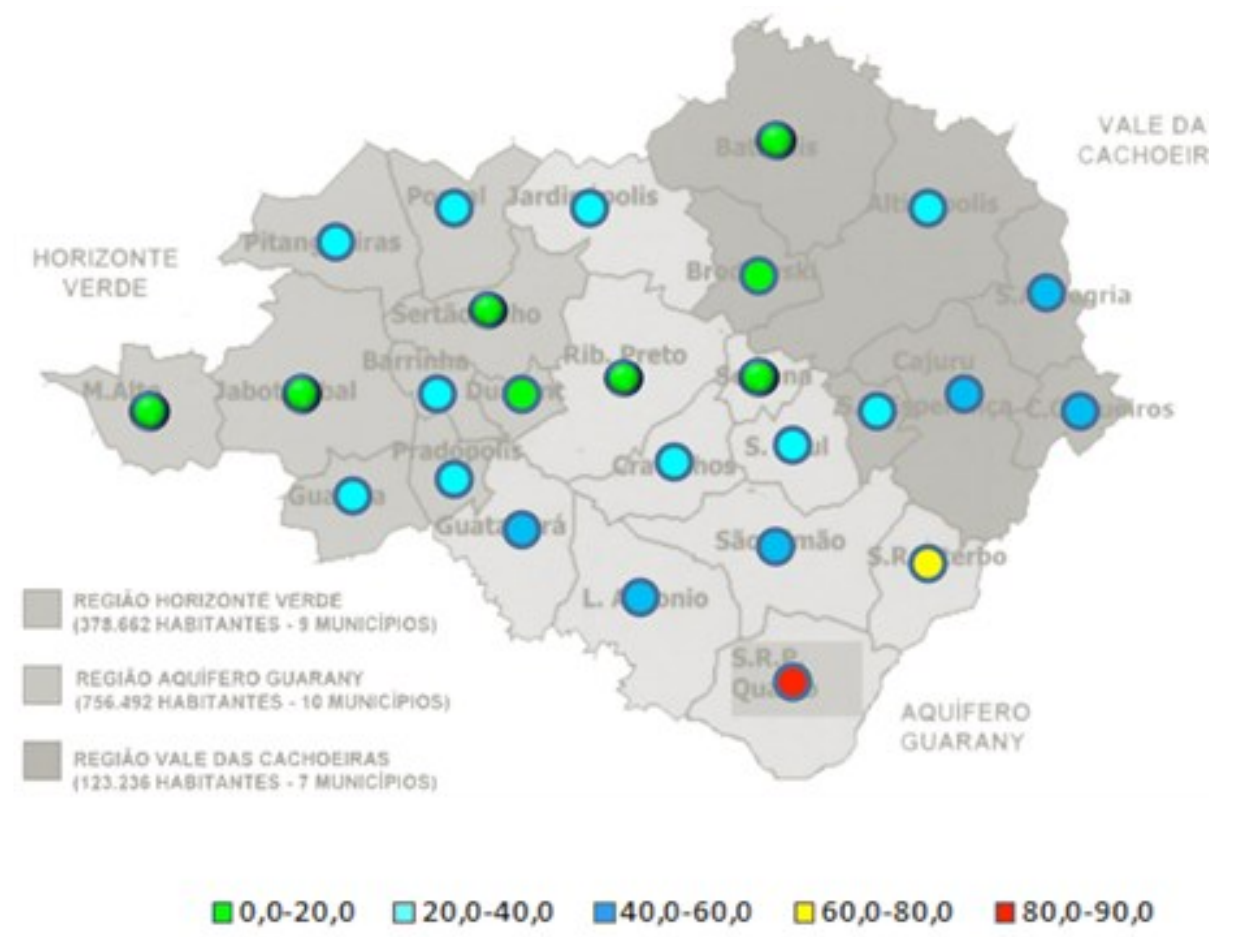

Distância em km entre os municípios do DSR XIII e os centros com CT

Figura 4: Distância em quilômetros entre os municípios do DRS XIII e o centro com Tomografia Computadorizada disponível mais próximo.

Apesar da publicação das portarias nos 664 e 665 GM/MS em 2012 ter aprovado o reembolso do tratamento trombolítico pelo SUS e a criação de unidades de AVC com seu respectivo incentivo financeiro, em toda a DRS XIII apenas a Unidade de Emergência do HCFMRP está habilitada como Unidade de AVC até a presente data. 
Analisando os critérios para habilitação de Unidades de AVC dispostos na portaria $\mathrm{n}^{\mathrm{o}}$ 665/2012, atualizada pela portaria nº00 em 2015 (BRASIL. MINISTÉRIO DA SAÚDE., 2015a), temos que os requisitos mínimos são:

I - realizar atendimento de urgência vinte e quatro horas por dia, todos os dias da semana, inclusive finais de semana;

II - realizar exame de tomografia computadorizada de crânio nas vinte e quatro horas do dia;

III - dispor de equipe treinada em urgência para atendimento aos pacientes com AVC, composta por médico, enfermeiro, técnicos de enfermagem e coordenada por neurologista com título de especialista em neurologia reconhecido pelo Conselho Federal de Medicina (CFM) ou Conselho Regional de Medicina (CRM) ou residência médica em Neurologia reconhecida pelo Ministério da Educação (MEC);

IV - disponibilizar protocolos clínicos e assistenciais escritos;

$\mathrm{V}$ - fornecer cobertura de atendimento neurológico, disponível em até 30 (trinta) minutos da admissão do paciente (plantão presencial, sobreaviso à distância ou suporte neurológico especializado por meio da telemedicina/telessaúde);

VI - possuir leitos monitorados para o atendimento ao AVC agudo, com médico vinte e quatro horas por dia e equipe treinada para o atendimento, podendo ser no serviço de urgência ou Unidade de Terapia Intensiva (UTI);

VII - possuir Unidade de Tratamento Intensivo (UTI);

VIII - realizar serviço de laboratório clínico em tempo integral;

IX - dispor de equipe neurocirúrgica 24 (vinte e quatro) horas/dia, seja ela própria, presencial ou disponível em até duas horas, ou referenciada, disponível em até duas horas;

$\mathrm{X}$ - realizar tratamento hemoterápico para possíveis complicações hemorrágicas.

Considerando os recursos estruturais atuais dos hospitais do DRS XIII, temos, contando apenas com as habilitações ativas e fora do município de Ribeirão Preto, quatro hospitais que preenchem os critérios para habilitação de Unidade de AVC pelo SUS, sendo estes: Irmandade de Misericórdia do Hospital da Santa Casa de Monte Alto, Irmandade da Santa Casa de Sertãozinho, Hospital e Maternidade Santa Isabel de Jaboticabal e Santa Casa de misericórdia de Batatais (CNES, 2017). Estes hospitais preenchem os pré-requisitos estruturais e possuem a tomografia operando em regime de urgência, continuamente. Os 
principais desafios para efetivamente transformar estes hospitais em centros de referência para o atendimento de AVC são recursos humanos (neurologista disponível 24h/dia) e a capacitação e treinamento para melhoria da estrutura assistencial vigente, com a implantação de protocolos, pois todos os recursos estruturais (leitos, equipamentos, laboratórios) já se encontram em funcionamento nestes hospitais.

Tendo em vista a quantidade limitada de médicos neurologistas da região e a concentração demográfica dos mesmos nos grandes centros (SCHEFFER; BIANCARELLI; CASSENOTE, 2013), há uma dificuldade importante tanto em termos de disponibilidade quanto de recursos financeiros para remuneração de equipe de neurologia para cobertura de assistência $24 \mathrm{~h} / 7$ dias da semana. Assim, uma rede de telemedicina supriria o pré-requisito da assistência neurológica disponível em até 30 minutos dos critérios para habilitação de Unidades de AVC, criando quatro novos centros de referência para o tratamento trombolítico do AVC nesta macrorregião de saúde, já que a central de telemedicina a ser instalada na UE HCFMRP-USP conta com médicos neurologistas presenciais com expertise em atendimento de AVC agudo em tempo integral, e poderia oferecer este suporte aos hospitais da rede.

\subsection{ANÁLISE DOS ASPECTOS ÉTICOS E JURÍDICOS DA TELEMEDICINA PARA O AVC}

\subsubsection{Questões da telemedicina no atendimento do AVC agudo}

Tendo em vista a implantação de um serviço de colaboração à distância para o atendimento do AVC agudo, serão aplicadas as seguintes modalidades de telemedicina:

(1) interação entre dois médicos em unidades de saúde diferentes;

(2) interação em tempo real entre o médico do centro consultor e o paciente em unidade de saúde distante;

(3) compartilhamento de informações do paciente escritas em formulário de registro eletrônico; 
(4) transmissão de exames de imagem (tomografia) e análise das imagens pelo neurologista à distância;

(5) transmissão de resultados de exames laboratoriais do paciente;

(6) análise diagnóstica do quadro do paciente e decisão terapêutica compartilhada entre as equipes de saúde.

Portanto, há muitas questões éticas e jurídicas a serem respondidas sobre este atendimento, dentre elas: a responsabilidade do ato médico, a confidencialidade e respeito à privacidade do paciente, a necessidade de consentimento livre e esclarecido do paciente, a segurança das informações transmitidas e a responsabilização legal de cada parte envolvida no atendimento em possíveis conflitos jurídicos.

\subsubsection{Regulamentação internacional da telemedicina}

No âmbito internacional, a Associação Médica Mundial, em sua 51 ${ }^{\mathrm{a}}$ Assembleia Geral, em outubro de 1999, em Tel Aviv, Israel, adotou e divulgou a "Declaração de Tel Aviv sobre responsabilidades e normas éticas na utilização da Telemedicina"(WORLD MEDICAL ASSOCIATION, 1999), documento que foi utilizado pelas associações médicas de vários países para o direcionamento de políticas e normas.

Em 2008, a Comissão das Comunidades Europeias em sua "Comunicação da Comissão ao Parlamento europeu, ao conselho, ao comitê econômico e social europeu e ao comitê das regiões sobre os benefícios da telemedicina para os doentes, os sistemas de saúde e a sociedade", definiu que uma das iniciativas a serem tomadas pelos Estados-Membros era a clarificação jurídica sobre o assunto (COMISSÃO DAS COMUNIDADES EUROPÉIAS, 2008). Assim, em 2012 a mesma comissão lançou um documento sobre a aplicabilidade da legislação existente na União Europeia para os serviços de telemedicina, definindo suas estruturas legais, como as diretrizes dos direitos dos cidadãos entre as fronteiras, o licenciamento e registro de profissionais e serviços de telemedicina, condições para processamento e proteção de informações, jurisdições e regras de reembolso (COMISSÃO DAS COMUNIDADES EUROPÉIAS, 2012). 


\subsubsection{Regulamentação da telemedicina no Brasil}

Iniciativas públicas e privadas envolvendo o desenvolvimento da telemedicina no Brasil se iniciaram na década de 1990 (EL KHOURI, 2003); entretanto, a regulamentação jurídica para sua prática ainda está em desenvolvimento.

No Brasil, as principais iniciativas para regulamentação da telemedicina têm sido realizadas pelos Conselhos Federal e Regionais de Medicina (por eventos científicos, resoluções e pareceres éticos) e pelo governo federal (por portarias do Ministério da Saúde). Na busca realizada no site do Supremo Tribunal Federal não constam, até o momento, tópicos com os temas "telemedicina" ou "telessaúde" entre as jurisprudências disponíveis para consulta.

\subsubsection{Privacidade, Sigilo e Confidencialidade}

A Constituição Federal de 1988 não aborda especificamente o tema de telemedicina, entretanto devem ser respeitados os artigos que tratam do direito ao sigilo, à privacidade e à confidencialidade, conforme instituído em seu artigo V, parágrafo X: "são invioláveis a intimidade, a vida privada, a honra e a imagem das pessoas, assegurado o direito de indenização pelo dano material ou moral decorrente de sua violação"; e ainda, no parágrafo XVI: "é assegurado a todos o acesso à informação e resguardado o sigilo da fonte, quando necessário ao exercício profissional”.

No Código Penal Brasileiro, promulgado em 1941, temos uma abordagem sobre revelação segredo, atualizado por legislação sobre invasão de dispositivo informático, incluída em 2012:

Art. 154 - Revelar alguém, sem justa causa, segredo de que tenha ciência, em razão de ministério, ofício ou profissão, e cuja revelação possa produzir dano a outrem: Pena - detenção, de três meses a um ano, ou multa de um conto de réis.

Parágrafo único - somente se procede mediante representação.

Invasão de dispositivo informático (Incluído pela Lei n ${ }^{\circ} 12.737$ de 2012) 
Art. 154 - A. Invadir dispositivo informático alheio, conectado ou não à rede de computadores, mediante violação indevida de mecanismo de segurança e com o fim de obter, adulterar ou destruir dados ou informações sem autorização expressa ou tácita do titular do dispositivo ou instalar vulnerabilidades para obter vantagem ilícita: (Incluído pela Lei $\mathrm{n}^{\circ} 12.737$, de 2012) Vigência. Pena - detenção, de 3 (três) meses a 1 (um) ano, e multa.

O novo código civil brasileiro, de 2002, aborda o tema do sigilo profissional em seu artigo 229: "ninguém pode ser obrigado a depor sobre fato: I - a cujo respeito, por estado ou profissão, deva guardar segredo".

\subsubsection{O papel do Conselho Federal de Medicina}

No Brasil, o Conselho Federal de Medicina (CFM) e os Conselhos Regionais de Medicina (CRM) são os órgãos supervisores da ética profissional em toda a República e ao mesmo tempo, julgadores e disciplinadores da classe médica, cabendo-lhes zelar e trabalhar por todos os meios ao seu alcance, pelo perfeito desempenho ético da medicina e pelo prestígio e bom conceito da profissão e dos que a exerçam legalmente (BRASIL, Lei $n^{\circ} 3.268$, de 30 de setembro de 1957). Cabe ao Conselho Federal de Medicina a elaboração do Código de Ética Médica e dirimir dúvidas levantadas pelos Conselhos Regionais. Com esta última finalidade, o CFM emite pareceres, resoluções, notas técnicas, despachos e informes jurídicos.

Pareceres são respostas que emitem posicionamento técnico e ético sobre questões encaminhadas por diferentes setores da sociedade sobre aspectos relacionados ao exercício da Medicina, emitidos por conselheiros e aprovados pelos plenários do CFM ou CRM. Não tem poder normatizador, mas ajudam no esclarecimento de certas nuances e podem subsidiar a elaboração de resoluções e outros instrumentos legais (CONSELHO FEDERAL DE MEDICINA, 2015).

Conforme definição do site do Conselho Federal de Medicina, resoluções são atos normativos emanados dos plenários do CFM e de alguns dos Conselhos Regionais de Medicina que regulam temas de competência privativa dessas entidades em suas áreas de alcance. Elas resultam do esforço dos órgãos supervisores, normatizadores, disciplinadores, fiscalizadores e julgadores da atividade profissional médica em todo o território nacional. 


\subsubsection{Normas, Resoluções e Pareceres relativos à Telemedicina}

No novo Código de Ética Médica publicado em 2010, em seu capítulo V, sobre a relação com pacientes e familiares, o CFM dispõe:

É vedado ao médico: [...] art. 37. Prescrever tratamento ou outros procedimentos sem exame direto do paciente, salvo em casos de urgência ou emergência e impossibilidade comprovada de realizá-lo, devendo, nesse caso, fazê-lo imediatamente após cessar o impedimento.

Parágrafo único. $\mathrm{O}$ atendimento médico à distância, nos moldes da telemedicina ou de outro método, dar-se-á sob regulamentação do Conselho Federal de Medicina.

Deste modo, nesta nova edição do Código de Ética Médica o CFM acrescenta um parágrafo específico voltado para esta nova modalidade de atendimento médico, atualizando-o e prevendo sua regulamentação específica.

Ainda no Código de Ética Médica, no que tange ao atendimento por telemedicina, é importante observar os artigos:

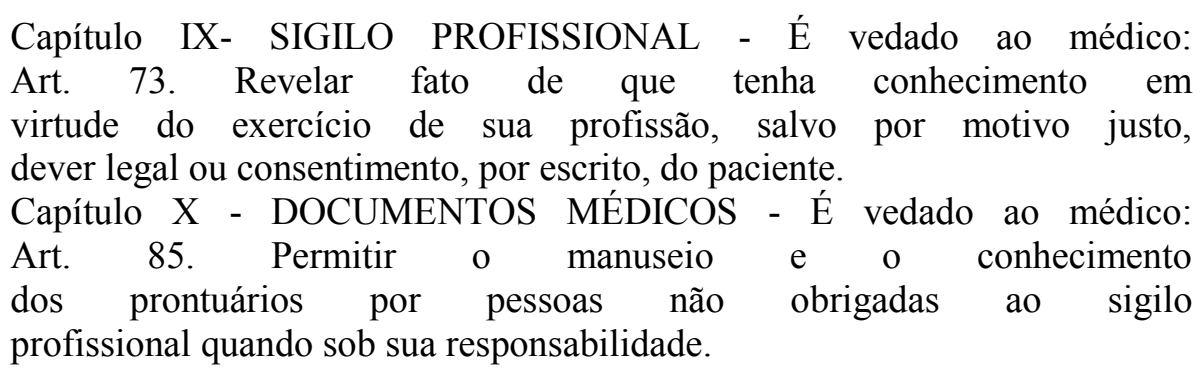

Portanto, segundo recomenda o Código, para que o médico assistente do atendimento presencial transmita as informações do paciente por telemedicina à equipe de neurologia de outro hospital, o paciente (ou seu responsável legal) deverá autorizar por meio de consentimento escrito. Neste projeto será utilizado termo de consentimento livre e esclarecido, previamente apresentado e aprovado por comitê de ética em pesquisa. Além disso, o registro eletrônico criado para compartilhar informações entre as equipes médicas será de acesso restrito aos profissionais de saúde diretamente envolvidos no atendimento (que terão seus nomes e registros profissionais devidamente registrados em prontuário), mantendo 
o sigilo sobre os documentos médicos. Para a criação do registro eletrônico deste atendimento, serão observadas as orientações da Portaria $n^{\circ} 2.073$ do Ministério da Saúde, de 31 de agosto de 2011, que "regulamenta o uso de padrões de interoperabilidade e informação em saúde para sistemas de informação em saúde no âmbito do Sistema Único de Saúde, nos níveis Municipal, Distrital, Estadual e Federal, e para os sistemas privados e do setor de saúde suplementar", e também da resolução no 1.821/07 do Conselho Federal de Medicina, que "aprova as normas técnicas concernentes à digitalização e uso dos sistemas informatizados para a guarda e manuseio dos documentos dos prontuários dos pacientes, autorizando a eliminação do papel e a troca de informação identificada em saúde"(CONSELHO FEDERAL DE MEDICINA, 2007).

Em 2002, o CFM publicou a resolução $\mathrm{n}^{\mathrm{o}}$ 1.643, que define e disciplina a prestação de serviços através da Telemedicina, que é, até o momento, um marco regulatório para estes serviços no País. O documento faz referências à Declaração de Tel Aviv sobre responsabilidades e normas éticas na utilização da Telemedicina, da $51^{\mathrm{a}}$ Assembleia Geral da Associação Médica Mundial, de 1999; às resoluções CFM nº 1.638/2002 e nº 1.639/2002, principalmente no tocante às normas para transmissão de dados identificados, e à Resolução $\mathrm{CFM} \mathrm{n}^{\circ} 1.627 / 2001$, que define e regulamenta o Ato Médico, e resolve:

Art. $1^{\circ}$ - Definir a Telemedicina como o exercício da Medicina através da utilização de metodologias interativas de comunicação áudio - visual e de dados, com o objetivo de assistência, educação e pesquisa em Saúde.

Art. $2^{\circ}$ - Os serviços prestados através da Telemedicina deverão ter a infraestrutura tecnológica apropriada, pertinentes e obedecer às normas técnicas do CFM pertinentes à guarda, manuseio, transmissão de dados, confidencialidade, privacidade e garantia do sigilo profissional.

Art. $3^{\circ}$ - Em caso de emergência, ou quando solicitado pelo médico responsável, o médico que emitir o laudo a distância poderá prestar o devido suporte diagnóstico e terapêutico.

Art. $4^{\circ}$ - A responsabilidade profissional do atendimento cabe ao médico assistente do paciente. Os demais envolvidos responderão solidariamente na proporção em que contribuírem por eventual dano ao mesmo.

Art. $5^{\circ}$ - As pessoas jurídicas que prestarem serviços de Telemedicina deverão inscrever-se no Cadastro de Pessoa Jurídica do Conselho Regional de Medicina do estado onde estão situadas, com a respectiva responsabilidade técnica de um médico regularmente inscrito no Conselho e a apresentação da relação dos médicos que componentes de seus quadros funcionais.

Parágrafo único - No caso de o prestador for pessoa física, o mesmo deverá ser médico e devidamente inscrito no Conselho Regional de Medicina.

Art. $6^{\circ}$ - O Conselho Regional de Medicina deverá estabelecer constante vigilância e avaliação das técnicas de Telemedicina no que concerne à qualidade da atenção, relação médico - paciente e preservação do sigilo profissional. 
Observando o artigo $3^{\circ}$, a telemedicina tem plena aplicabilidade e respalda o atendimento no caso do Acidente Vascular Cerebral hiperagudo, sendo emergência médica em que o tempo para diagnóstico, indicação de exames laboratoriais e sua análise e laudo e decisões diagnósticas e terapêuticas é de extrema importância, dado que o tempo para o tratamento trombolítico do AVC isquêmico é de 4,5 horas decorridas do início dos sintomas, sendo, em muitos casos, necessária a tomada de decisões em áreas geográficas que não dispõe de médico neurologista no local do atendimento e o deslocamento implicaria em esgotamento desta janela terapêutica.

As considerações iniciais desta resolução dão suporte ao artigo $4^{\circ}$, que responsabiliza em primeiro nível o médico assistente do paciente e define responsabilidade solidária dos demais envolvidos, quando descrevem que "CONSIDERANDO que o médico tem liberdade e completa independência para decidir se utiliza ou não recomenda o uso da Telemedicina para seu paciente, e que tal decisão deve basear - se apenas no benefício do paciente" e que "CONSIDERANDO que o médico que exerce a Medicina a distância, sem ver o paciente, deve avaliar cuidadosamente a informação que recebe, só pode emitir opiniões e recomendações ou tomar decisões médicas se a qualidade da informação recebida for suficiente e pertinente para o cerne da questão".

$\mathrm{O}$ artigo $5^{\circ}$ garante a devida identificação do médico e/ou empresa prestadora do serviço de telemedicina, obrigando o registro destes junto ao CRM local.

Especificamente sobre a prática médica de tratamento agudo do acidente vascular cerebral isquêmico (AVCI) via teleconferência e suas possíveis consequências éticas ou legais, há o parecer do relator Conselheiro Luiz Alberto Bacheschi, relativo à consulta $n^{\circ}$ 88.122, de 2008. A questão levantada pelo gerente médico de um hospital de São Paulo ao CRM foi sobre a possibilidade de administração trombolítico em pacientes com AVCI em hospital onde não há neurocirurgião, e que o hospital de referência mais próximo seria distante e sem possibilidade de transferir a tempo o paciente que tivesse um sangramento em função da administração do trombolítico (estimado esse risco em 2 a 3\%); neste sentido, solicitava esclarecimento sobre a prática de tratamento agudo do AVCI via teleconferência e suas possíveis complicações. A câmara técnica de Neurologia, Neurocirurgia e Neurologia Infantil se manifestou a respeito, citando novamente as referências da Declaração de Tel Aviv 
sobre Telemedicina, a resolução $n^{0}$ 1643/2002 do CFM e uma publicação científica internacional sobre telemedicina (AUDEBERT; SCHWAMM, 2009), concluindo que:

\footnotetext{
"Parece-nos que a ausência de suporte neurocirúrgico certamente determinará riscos significativos, embora como diga a própria literatura, em torno de $2-3 \%$. A responsabilidade da conduta determinando tal efeito colateral, certamente recairá sobre o médico assistente dentro da Unidade Assistencial. Portanto, cremos que poderão haver implicações éticas e legais.".
}

De onde podemos concluir que, tendo em vista os riscos de efeitos colaterais do tratamento trombolítico e as implicações éticas e legais, é recomendado que mesmo que a trombólise seja orientada por telemedicina, o serviço onde se encontra o paciente deve ter acesso a suporte neurocirúrgico (e outros recursos para manejo das complicações, como hemoterapia) no local ou a distância viável de centro de referência para tratamento de tais complicações.

Em resumo, as aplicações da telemedicina estão em expansão no Brasil nas últimas duas décadas, e a experiência internacional mostra resultados positivos e consistentes nos setores de assistência especializada e laudos de exames à distância, educação em saúde, monitorização de doenças crônicas e mesmo atendimento médico em áreas remotas, sendo, portanto natural que no nosso país sua utilização seja cada vez maior.

Entretanto, a experiência dos órgãos fiscalizadores e do judiciário ainda é pequena no assunto, não havendo ainda jurisprudência significativa pertinente ao tema. A regulamentação da telemedicina e da telessaúde no Brasil se baseia principalmente em normas, pareceres e resoluções do Conselho Federal de Medicina e em princípios gerais da Constituição e dos Códigos Civil e Penal, provavelmente insuficientes para responder a dilemas ético-legais de responsabilização profissional e institucional em casos que possam gerar processos civis por evolução desfavorável do paciente ou mesmo por erro médico.

É necessário que os profissionais, conselhos e órgãos gestores envolvidos ampliem as discussões sobre os critérios éticos e legais da aplicação da telemedicina e que estes sejam levados em conta na elaboração de qualquer projeto ou atividade na área. A única resolução do CFM que trata diretamente da telemedicina deixa ainda muitas dúvidas e já se passaram 15 anos desde a sua redação, e desde então muitos avanços na área ocorreram.

Finalmente, é indispensável que nos serviços de telessaúde haja a preocupação da produção de protocolos e normas, e que sejam garantidos a segurança, o sigilo e a privacidade 
do paciente, principalmente na transmissão eletrônica de seus dados, para que a experiência nacional com os serviços de telessaúde seja positiva e contribua para o desenvolvimento e a expansão do sistema de saúde, levando atendimento de qualidade a um número cada vez maior de cidadãos.

\subsubsection{Considerações éticas pertinentes ao projeto de pesquisa}

Todos os procedimentos incluídos no presente projeto estão de acordo com as normas éticas e de segurança preconizadas em manuais de boas práticas em pesquisa clínica.

Este projeto é parte integrante do projeto de pesquisa "Avaliação de telemedicina como estratégia para redução da morbimortalidade de pacientes com acidente vascular cerebral”, que já foi submetido ao Comitê de Ética em Pesquisa do Hospital das Clínicas da Faculdade de Medicina de Ribeirão Preto - USP e aprovado.

\subsection{FINANCIAMENTO E CUSTOS DA TELEMEDICINA PARA O AVC NO BRASIL}

\subsubsection{Financiamento}

A regulamentação do financiamento da telemedicina no Brasil ainda é insuficiente, tanto no Sistema Único de Saúde quanto na saúde suplementar.

No âmbito do SUS, em 2009 o Ministério da Saúde iniciou o projeto piloto do programa Telessaúde Brasil, focado no apoio à atenção básica, que envolveu nove Núcleos de Telessaúde localizados em universidades do país. Em 2011, publicou a portaria $\mathrm{n}^{\mathrm{o}} 2.546$ (BRASIL. MINISTÉRIO DA SAÚDE., 2011b), redefinindo e ampliando o programa, que passa a se chamar Telessaúde Brasil Redes, expandindo o financiamento para núcleos intermunicipais e estaduais. Esta portaria cria códigos no Sistema de Cadastro Nacional de 
Estabelecimentos de Saúde (SNCES) relativos à Núcleo Técnico-científico e à Unidade de Telessaúde. Em 2015, o Ministério da Saúde publica o Manual Instrutivo de custeio destes Núcleos de Telessaúde participantes do Programa (BRASIL. MINISTÉRIO DA SAÚDE., 2015b), estabelecendo valores de incentivos financeiros conforme o porte do núcleo de telessaúde e critérios para recebimento do repasse. Entretanto, o Manual de Custeio prevê apenas redes de telessaúde entre núcleos técnicos científicos e unidades de telessaúde de atenção básica, não abrangendo a telessaúde entre hospitais de alta e média complexidade, no modelo pretendido no atendimento da telemedicina para o AVC.

Ainda no contexto do SUS, o Ministério da Saúde fomenta, desde 2009, o Programa de Apoio ao Desenvolvimento Institucional do Sistema Único de Saúde - PROADI SUS, que contribui para o desenvolvimento institucional do SUS por meio de intervenções tecnológicas, gerenciais e capacitação profissional, através de parcerias com entidades de saúde portadoras do Certificado de Entidade Beneficente de Assistência Social em Saúde (CEBAS-SAÚDE) e de Reconhecida Excelência (BRASIL. PRESIDÊNCIA DA REPÚBLICA., 2009; BRASIL. MINISTÉRIO DA SAÚDE., 2011c). Este programa prevê incentivos financeiros de milhões de reais por meio de isenções fiscais aos hospitais, baseados em projetos propostos dentro dos temas prioritários divulgados trienalmente pelo Ministério da Saúde. Todavia, o PROADI SUS prevê apenas parcerias entre hospitais filantrópicos privados de excelência e o SUS, não sendo possível o envio de projetos ou previsão de repasse financeiro a serviços de saúde de administração direta (como o Hospital das Clínicas de Ribeirão Preto, no caso deste projeto de pesquisa).

$\mathrm{Na}$ iniciativa privada, a telemedicina se restringe a contratos de parcerias entre serviços de saúde, não existindo códigos de procedimentos de assistência por telemedicina na Classificação Brasileira Hierarquizada de Procedimentos Médicos (CBHPM) (ASSOCIAÇÃO MÉDICA BRASILEIRA (AMB), 2016), utilizada pela maioria dos convênios e seguros da saúde suplementar como base de cálculo para remuneração.

Internacionalmente, os modelos de financiamento e a custo-efetividade da telemedicina para o AVC tem sido objeto de estudos recentes, com resultados positivos. Em novembro de 2017 foi publicada uma análise de um modelo econômico de rede de telemedicina implantado na França, em que se estabeleceu o pagamento da expertise do hospital central (Hub), distribuindo as cotas de acordo com o uso e pagamentos recebidos pelos hospitais satélites (spokes) e estabelecendo um fluxo de transferência de pacientes e de 
recursos financeiros entre os hospitais (RIOU-COMTE et al., 2017). Neste modelo, há 3 diferentes cenários possíveis de relação entre os hospitais: (1) Paciente admitido no hospital satélite e transferido para o central para manejo específico e tratamento complementar, como trombectomia, sem retornar para o hospital satélite; (2) Paciente admitido no hospital satélite e transferido para o central, depois retorna para o satélite (após estabilização e investigação), com equipe multiprofissional no hospital satélite (fonoaudiólogo e fisioterapeuta); (3) Pacientes são tratados completamente no hospital satélite, sem transferência para o hospital central (geralmente por exclusão do diagnóstico de AVC, recusa da transferência, prognóstico muito reservado ou falta de leitos no hospital central). No cenário 1, geralmente os pagamentos recebidos pelo hospital satélite gerados apenas pela admissão no setor de emergências são baixos e insuficientes para o reembolso do trombolítico utilizado, enquanto os honorários da unidade de AVC do hospital central, quando admitia este paciente, eram muito maiores. Nos cenários 2 e 3, a hospitalização do paciente no hospital satélite gera honorários suficientes para cobrir os custos do trombolítico e o pagamento da consultoria por telemedicina. Nestes cenários, o hospital central é o responsável pelos custos de manutenção da equipe especializada que presta a assessoria por telemedicina. $\mathrm{O}$ modelo econômico desenvolvido permitiu a garantia do recurso para o pagamento da equipe especializada do hospital central, por meio do rateio entre os hospitais da rede, dividindo este custo de forma proporcional, aumentando a sustentabilidade do modelo. Além disso, a definição de fluxos de referência e contra-referência dos pacientes entre os hospitais otimizou o tempo de internação no hospital central, aumentando sua rotatividade.

No Brasil, custeio de sistemas de telemedicina para o AVC ainda dependem da busca de recursos por agências de fomento de pesquisa, parcerias público-privadas ou contratos estabelecidos de modo pontual entre serviços de saúde. Para a proposta do projeto de pesquisa atual, foi firmado contrato de patrocínio com a companhia farmacêutica BoehringerIngelheim para custeio dos equipamentos para instalação do sistema e início das atividades. Os custos de manutenção do sistema serão mantidos pelas unidades de saúde envolvidas inicialmente, discutidos em espaços de gestão estadual de saúde (colegiados intermunicipais) para eventual divisão entre os municípios de abrangência de atendimento e foi iniciado o processo de credenciamento do hospital satélite como Unidade de AVC tipo II para que receba repasses previstos pelo governo federal, contribuindo para cobertura dos custos do trombolítico e manutenção da estrutura dos leitos e equipe local. 


\subsubsection{Custos}

Para a operação da rede de telemedicina entre o hospital central e os hospitais satélites há custos de instalação e custos de manutenção, descritos abaixo.

Instalação:

São necessários equipamentos de informática para a realização da videoconferência, devendo ser portáteis para os hospitais satélites (para que possam ser levados à beira do leito do paciente para exame físico e anamnese) e podendo ser fixos no hospital central (situados em sala de prescrição ou espaço reservado para o neurologista consultor). Buscou-se optar por equipamentos com configurações mínimas necessárias para as tarefas e foram realizados testes, que evidenciaram a possibilidade de efetivação da videoconferência e exame físico do paciente à distância com os equipamentos disponíveis. Na tabela 1 estão dispostos os valores e especificações técnicas dos equipamentos utilizados. Os equipamentos serão custeados com verba de patrocínio privado de pesquisa, realizado por contrato com a companhia farmacêutica Boehringer-Ingelheim.

Também serão necessários treinamentos das equipes dos hospitais quanto ao uso do sistema e treinamentos da equipe do hospital satélite em rotinas de atendimento do AVC agudo. Para este projeto de pesquisa, não haverá custos do treinamento das equipes de saúde, pois serão realizados pela pesquisadora e colaboradores. Caso fosse necessário gasto, estimamos o valor a ser pago baseado na hora de trabalho médico paga aos médicos neurologistas da UE HCFMRP atualmente e estimando 3 horas para cada treinamento, contabilizando o período de transporte, totalizando um valor em torno de $\mathrm{R} \$ 1.400,00$. 


\begin{tabular}{|c|c|c|c|}
\hline Descrição & Quantidade & $\begin{array}{l}\text { Valor } \\
\text { unitário (RS) }\end{array}$ & $\begin{array}{l}\text { Valor total } \\
\text { (RS) }\end{array}$ \\
\hline $\begin{array}{l}\text { Rack para telemedicina com suporte dos monitores, câmera e } \\
\text { computador e acessórios }\end{array}$ & 1 & $\mathrm{R} \$ 3.900,00$ & RS $3.900,00$ \\
\hline $\begin{array}{l}\text { Serviço de instalação dos equipamentos para telemedicina e } \\
\text { treinamento das equipes no sistema }\end{array}$ & 1 & $\mathrm{R} \$ 6.000,00$ & RS $6.000,00$ \\
\hline $\begin{array}{l}\text { Monitor para visualização das tomografias no hospital central } \\
\text { (23" FULL HD Phillips) }\end{array}$ & 1 & $\mathrm{R} \$ 565,76$ & RS 565,76 \\
\hline $\begin{array}{l}\text { Notebook para hospital central (Dell Inspiron 15-5548-C20, } \\
\text { Processador Intel Core i7 8GB 1TB Tela LED 15.6") }\end{array}$ & 1 & $\mathrm{R} \$ 2.900,00$ & RS $2.900,00$ \\
\hline $\begin{array}{l}\text { Notebook para hospital satélite (Notebook Acer Aspire A515-51 } \\
\text { Intel Core i5) }\end{array}$ & 1 & $\mathrm{R} \$ 2.000,00$ & RS $2.000,00$ \\
\hline Câmera para hospital satélite (webcam Logitech 15MP HD) & 1 & $\mathrm{R} \$ 300,83$ & RS 300,83 \\
\hline Headset (fone + microfone) (Microsoft Lifechat LX-3000) & 2 & $\mathrm{R} \$ 129,00$ & RS 258,00 \\
\hline $\begin{array}{l}\text { Access point Wifi (Roteador Wireless } 4 \text { Portas Dual Band Ac } \\
\text { 1.35 Gbps C60 TP Link) }\end{array}$ & 1 & $\mathrm{R} \$ 200,00$ & $\mathrm{RS} 200,00$ \\
\hline $\begin{array}{l}\text { Switch - para montagem do access point na rede local do } \\
\text { hospital satélite (5 PORTAS TP-LINK 10/1000MBPS TL- } \\
\text { SG105) }\end{array}$ & 1 & $\mathrm{R} \$ 140,00$ & RS 140,00 \\
\hline TOTAL & & & $\begin{array}{c}\text { RS } \\
16.264,59 \\
\end{array}$ \\
\hline
\end{tabular}

Tabela 1: Especificação técnica e valores dos equipamentos para montagem de sistema básico de telemedicina para o AVC. Valores em reais, de novembro de 2017.

Internet: é necessário que todos os hospitais tenham rede de internet de banda larga ou fibra óptica. Para este projeto de pesquisa, está prevista a utilização da rede de internet já instalada nos hospitais (embora uma rede dedicada seja preferível, elevará os custos de implantação do projeto, ultrapassando o patrocínio recebido e valor disponível no momento).

Servidor: para armazenamento dos dados dos registros eletrônicos e hospedagem do site desenvolvido; será utilizado servidor da Amazon Web Services, sem custos para utilização inicial.

Sistema de videoconferência (software): há plataformas comerciais disponíveis para chamadas por vídeo e voz, com planos anuais ou licença para uso de software. Na figura 5 encontra-se exemplo de orçamento da empresa Polycom. 


\begin{tabular}{|c|c|c|c|c|c|c|}
\hline \multicolumn{7}{|c|}{ Planilha de Valores do Hospital Matriz } \\
\hline \multicolumn{2}{|c|}{ Item } & \multirow{2}{*}{$\begin{array}{l}\text { Descrição } \\
\text { RealPresence Group 500 - 720p: Group } 500 \text { HD codec EagleEye Acoustic cam. univ. remote } \\
\text { NTSC/PAL. Cables: } 2 \text { HDMI 1.8m 1 CAT 5E LAN 3.6m Power: BRAZIL - Type N. } 1 \text { Yr Premier Srvc }\end{array}$} & \multirow{2}{*}{$\frac{\text { Qtd }}{1}$} & \multicolumn{2}{|c|}{ Vr Unitário } & Vr Total \\
\hline \multirow{2}{*}{1} & HW & & & $\mathrm{R} \$$ & $8.803,00$ & $\mathrm{R} \$ \quad 8.803,00$ \\
\hline & SW & $\begin{array}{l}\text { RealPresence Group 500 - 720p: Group } 500 \text { HD codec EagleEye Acoustic cam. univ. remote } \\
\text { NTSC/PAL. Cables: } 2 \text { HDMI 1.8m } 1 \text { CAT 5E LAN 3.6m Power: BRAZIL - Type N. } 1 \text { Yr Premier Srvc }\end{array}$ & 1 & $\mathrm{R} \$$ & $13.643,00$ & $\mathrm{R} \$ 13.643,00$ \\
\hline 2 & sW & $\begin{array}{l}\text { Group Series Multipoint License-6-way on Group } 500 \text { or 8-way on Group 700. Both support 4-way } \\
\text { HD continuous presence. }\end{array}$ & 1 & $\mathrm{R} \$$ & $8.336,00$ & $\mathrm{R} \$ \mathbf{8 . 3 3 6 , 0 0}$ \\
\hline 4 & $\mathrm{HW}$ & TV Led de 42 polegadas & 1 & $\mathrm{RS}$ & $2.580,00$ & $\mathrm{RS} \quad 2.580,00$ \\
\hline 5 & SW & $\begin{array}{l}\text { Polycom RealPresence Desktop for Windows and Mac OS } 5 \text { users. (Includes } 1 \text { year of Premier } \\
\text { Maintenance) }\end{array}$ & 1 & $\mathrm{R} \$$ & $1.514,00$ & $\mathrm{R} \$ \quad 1.514,00$ \\
\hline \multirow[t]{2}{*}{6} & SV & Serviço de Instalação & 1 & $\mathrm{RSS}$ & $1.980,00$ & $\mathrm{R} \$ \mathbf{T}^{1.980,00}$ \\
\hline & & & & & & $\mathrm{R} \$ \mathbf{3 6 . 8 5 6 , 0 0}$ \\
\hline \multicolumn{7}{|c|}{ Planilha de Valores do Hospitais Remotos } \\
\hline \multicolumn{2}{|c|}{ Item } & Descrição & Qtd & & Unitário & Vr Total \\
\hline \multirow{2}{*}{1} & HW & $\begin{array}{l}\text { RealPresence Group } 300 \text { - 720p: Group } 300 \text { HD codec EagleEye Acoustic cam. univ. remote } \\
\text { NTSC/PAL. Cables: } 1 \text { HDMI 1.8m } 1 \text { CAT 5E LAN 3.6m Power: BRAZIL - Type N. } 1 \text { Yr Premier Srvc }\end{array}$ & 2 & $\mathrm{R} \$$ & $4.327,00$ & $\mathrm{R} \$ \quad 8.654,00$ \\
\hline & SW & $\begin{array}{l}\text { RealPresence Group } 300 \text { - 720p: Group } 300 \mathrm{HD} \text { codec EagleEye Acoustic cam. univ. remote } \\
\text { NTSC/PAL. Cables: } 1 \text { HDMI 1.8m } 1 \text { CAT 5E LAN 3.6m Power: BRAZIL - Type N. } 1 \text { Yr Premier Srvc }\end{array}$ & 2 & $\mathrm{R} \$$ & $6.496,00$ & $\mathrm{R} \$ 12.992,00$ \\
\hline 2 & HW & Rack Audience C150-R & 2 & $\mathrm{RS}$ & $1.650,00$ & $\mathrm{R} \$ \quad 3.300,00$ \\
\hline 3 & HW & TV Led de 32 polegadas & 2 & $\mathrm{RS}$ & $1.850,00$ & $3.700,00$ \\
\hline \multirow[t]{3}{*}{4} & SV & Serviço de Instalação & 2 & $\mathrm{R} \$$ & $1.450,00$ & $2.900,00$ \\
\hline & & & & & & RS $31.546,00$ \\
\hline & & Valor Total do Projeto & & & & $\mathrm{R} \$ \mathbf{6 8 . 4 0 2 , 0 0}$ \\
\hline
\end{tabular}

Figura 5: proposta comercial Polycom equipamentos de videoconferência - valores de abril de 2015.

Para viabilizar a sustentabilidade financeira do sistema de telemedicina, optou-se pelo desenvolvimento de sistema próprio de teleconferência e registro de informações, que não terá custos de licença.

\section{Manutenção:}

$\mathrm{Na}$ fase de manutenção, os principais custos envolvidos em um sistema de telemedicina são os relacionados diretamente à assistência do paciente, como diárias de internação, exames, trombolítico e remuneração médica do hospital satélite e da consultoria pelos médicos do hospital central.

Para início do projeto da rede de telemedicina, foi escolhida a Santa Casa de Batatais como o primeiro hospital satélite, pelo principal motivo do compromisso da administração do hospital e da Secretaria Municipal de Saúde arcarem com o tratamento trombolítico até que seja efetivado o credenciamento e este seja custeado com as verbas previstas para unidade de AVC.

Projetando a incidência do AVC no Brasil, avaliada em torno de 108 casos para cada 100 mil habitantes/ano no município de Matão no estudo de Minelli et al, para a população de toda a sub-região de saúde "Vale das Cachoeiras", na qual está inserida Batatais (135.885 habites, segundo dados de últimos censos do IBGE), há a expectativa de ocorrerem anualmente, nesta sub-região, 147 novos casos de AVC, ou 12,2 AVCs por mês. 
Atualmente, a Santa Casa de Batatais já é o hospital de referência para alguns destes casos de AVC, principalmente para os que não estão em janela de tratamento trombolítico. $\mathrm{O}$ hospital também já dispõe de equipes de plantão médico de pronto socorro e de UTI. Presume-se que não haverá, com o projeto, mudança significativa na quantidade de pacientes com AVC internados neste hospital, mas sim uma mudança no perfil assistencial e um aumento do gasto relacionado ao trombolítico.

O modelo proposto de assistência da rede de telemedicina será preferencialmente o "drip and keep", ou seja, administrar o trombolítico no hospital satélite e manter este paciente internado neste hospital, sem a transferência para o hospital central. Exceções seriam pacientes com oclusão proximal de grandes vasos candidatos a trombectomia mecânica, que teriam sua trombólise iniciada no hospital satélite e em seguida transferidos para o hospital central para o tratamento endovascular. Em um estudo recente sobre custeio de rede de telemedicina francês, o modelo "drip and keep" foi o que demonstrou melhor equilíbrio financeiro (RIOU-COMTE et al., 2017), pois, no modelo "drip and ship", em que após o início da trombólise o paciente já é transferido para continuidade da avaliação e tratamento no hospital central, o hospital satélite perde a remuneração da internação do paciente e fica com a parte mais cara, que é o trombolítico e o primeiro atendimento de urgência. No modelo de financiamento das unidades de AVC brasileiras, o hospital satélite, quando credenciado, receberá 350 reais por dia para cada leito da unidade de AVC, considerando uma ocupação de $90 \%$, além do reembolso do trombolítico.

Devem ser considerados os custos de manutenção da equipe consultora especializada do hospital central que dará suporte aos hospitais satélites, diretamente relacionados à quantidade de horas de disponibilidade do serviço de teleconsultoria. Neste projeto de pesquisa, o atendimento será realizado pela equipe de médicos assistentes e residentes de neurologia vascular da Unidade de Emergência do HCFMRP-USP, sem a previsão de remuneração adicional, com a ciência e parceria da Diretoria da Unidade e do Departamento de Neurociências e Ciências do Comportamento. Entretanto, para efeito de estimativa de custo, considerando a consultoria de 12,2 pacientes/mês, cada um com uma $1^{\text {a }}$ videoconferência em torno de 2 horas e consultas subsequentes de $0,5 \mathrm{~h}$ a cada dia até a alta (média de internação por AVC de 10 dias, com base em estudos de unidades de AVC brasileiras (CABRAL et al., 2003)), temos um custo estimado do suporte especializado no valor de $\mathrm{R} \$ 6.344,00$. Espera-se, também, que com a descentralização do atendimento do 
AVC para outros hospitais, a quantidade de atendimentos locais por AVC da UE HCFMRP caia, pois atualmente a taxa de ocupação da unidade é acima dos 100\% (128\% em 2015, segundo informações do site do HCFMRP), fornecendo portanto tempo hábil para este suporte por telemedicina por parte dos médicos assistentes e residentes em neurologia vascular.

\begin{tabular}{lcc}
\hline ATIVIDADE / ITEM & DESCRIÇÃO & CUSTO \\
\hline \hline $\begin{array}{l}\text { Suporte médico } \\
\text { hospital central }\end{array}$ & $\begin{array}{c}\text { valor hora/médico }(\mathrm{R} \$ 80) \times \text { pacientes com AVC/mês }(12,2) \times \\
\text { horas de teleconsultoria/paciente }(6,5)\end{array}$ & $\begin{array}{c}\mathrm{R} \$ \\
\text { (1) }\end{array}$ \\
\hline
\end{tabular}

Em resumo, muitos dos custos envolvidos na rede de telemedicina já estão sendo gastos nas atividades de rotina do hospital central e do hospital satélite, portanto sem resultar em repercussão orçamentária significativa na manutenção da rede, após serem feitos os gastos iniciais com a instalação. No quadro abaixo foram sintetizados os principais requisitos para manutenção do sistema, a proposta de custeio relativa a cada um e a mudança esperada na rotina assistencial e no orçamento dos hospitais.

\begin{tabular}{|c|c|c|}
\hline ATIVIDADE/ITEM & CUSTO MENSAL ADICIONAL & EFEITO ESPERADO \\
\hline $\begin{array}{l}\text { Suporte médico } \\
\text { especializado } \\
\text { (neurologia vascular) }\end{array}$ & $\begin{array}{c}\text { Realizado pela equipe da UE HCFMRP } \\
\text { dentro das horas já contratadas, sem custeio } \\
\text { adicional }\end{array}$ & $\begin{array}{c}\text { Redução da superlotação da UE } \\
\text { HCFMRP, reduzindo trabalho local da } \\
\text { equipe e possibilitando uso de horas } \\
\text { para telemedicina } \\
\end{array}$ \\
\hline $\begin{array}{l}\text { Internações por AVC } \\
\text { hospital satélite }\end{array}$ & $\begin{array}{c}\text { Já ocorrem na média de } 12,5 \text { internações por } \\
\text { AVC por mês em cada um dos hospitais } \\
\text { satélites do DRS XIII, com remuneração } \\
\text { baseada na tabela SUS }\end{array}$ & $\begin{array}{c}\text { Melhora na remuneração após o } \\
\text { cadastro das unidades de AVC, por } \\
\text { repasses previstos na portaria } \\
\text { no }^{\circ} 800 / 2015\end{array}$ \\
\hline Trombólise endovenosa & $\begin{array}{c}\text { Taxa de trombólise estimada em } 25 \% \text { (3 } \\
\text { pacientes/mês x R } \$ 2.659,26 \text { - valor atual de } \\
1 \text { frasco de Actilyse } 50 \mathrm{mg}+1 \text { frasco de } \\
\text { Actilyse } 20 \mathrm{mg})=\mathrm{R} \$ 7.977,78 \text {. Inicialmente } \\
\text { custeados pelos hospitais satélite e secretarias } \\
\text { municipais de saúde } \\
\end{array}$ & $\begin{array}{c}\text { Reembolso do trombolítico no valor de } \\
\mathrm{R} \$ 1.635,55 \text { por procedimento após o } \\
\text { cadastro da UAVC }=\mathrm{R} \$ 4906,65 \\
\end{array}$ \\
\hline Rede de internet & $\begin{array}{l}\text { Será utilizada a rede já disponível nos } \\
\text { hospitais, sem custeio adicional }\end{array}$ & $\begin{array}{l}\text { Avaliação da efetividade do sistema e } \\
\text { adequação para rede dedicada se } \\
\text { necessária (prejuízo assistencial por } \\
\text { dificuldade de conexão, ausente nos } \\
\text { testes realizados até o momento) }\end{array}$ \\
\hline $\begin{array}{l}\text { Suporte técnico em } \\
\text { informática }\end{array}$ & $\begin{array}{l}\text { Serão envolvidos profissionais de TI dos } \\
\text { hospitais da rede para manutenção }\end{array}$ & $\begin{array}{l}\text { Desenvolvimento das equipes de } \\
\text { técnicos dos hospitais durante a fase de } \\
\text { instalação por meio de treinamento } \\
\text { realizado pelo desenvolvedor do sistema }\end{array}$ \\
\hline
\end{tabular}




\subsection{DESENVOLVIMENTO DO SISTEMA DE REGISTRO ELETRÔNICO E VIDEOCONFERENCIA PARA O ATENDIMENTO DO AVC - TELEAVC}

Durante o planejamento da rede de telemedicina para o atendimento do AVC, observamos que as soluções comerciais disponíveis disponibilizavam separadamente sistemas de videoconferência e sistemas de prontuário eletrônico. Os sistemas de videoconferência avaliados (Polycom ${ }^{\circledR}, \quad$ Skype ${ }^{\circledR}$, Adobe Connect $\left.{ }^{\circledR}\right)$ não possuem ferramentas de compartilhamento de textos escritos que possam ser salvos e registrados de modo seguro, garantindo a documentação da discussão do caso do paciente a ser atendido pela telemedicina.

Portanto, verificamos a necessidade de uma plataforma eletrônica em que fosse possível, dentro do mesmo ambiente virtual, realizar a videoconferência e registrar as informações essenciais do atendimento de casos de AVC agudo. Além disso, as soluções comerciais de videoconferência disponíveis têm um custo elevado de instalação e dependem de licença comercial ou plano de assinatura mensal, sendo um obstáculo para a implantação da rede.

Assim, reunimos uma equipe de engenheiros com experiência em sistemas de informação eletrônicos e neurologistas para desenvolver uma ferramenta que as necessidades acima listadas e que tenha baixo custo de implantação e manutenção.

O sistema de tele-AVC será um site que poderá ser acessado via qualquer navegador de internet com uso de usuário e senha. Está cadastrado no domínio https://www.telestroke.com.br. Para o cadastro do usuário, serão registrados dados pessoais e profissionais (nome completo, CPF, número no conselho profissional, contato de telefone e email) e o usuário aceitará os termos de uso do sistema (que incluirão informações sobre a confidencialidade das informações registradas e transmitidas, respeitando as normas de sigilo médico, a proibição de compartilhamento de usuário e senha com terceiros, a obrigatoriedade de preenchimento de campos mínimos para o atendimento do paciente por telemedicina, dentre outras). Isto garantirá a identificação de cada profissional que acesse e faça modificações no registro eletrônico do paciente, tanto da equipe assistencial do hospital remoto quanto do neurologista do centro de referência, compartilhando a responsabilidade legal pelo atendimento. 
Procuramos desenvolver o site com aspecto visual amigável e com fácil identificação das funcionalidades. A página inicial já mostrará acesso aos principais componentes do sistema: videoconferência (que ficará visível no canto esquerdo da página em tela de vídeo local e remoto, com possibilidade de ampliar para tela cheia o vídeo remoto) e abas para registro de informações do paciente (figura 6).

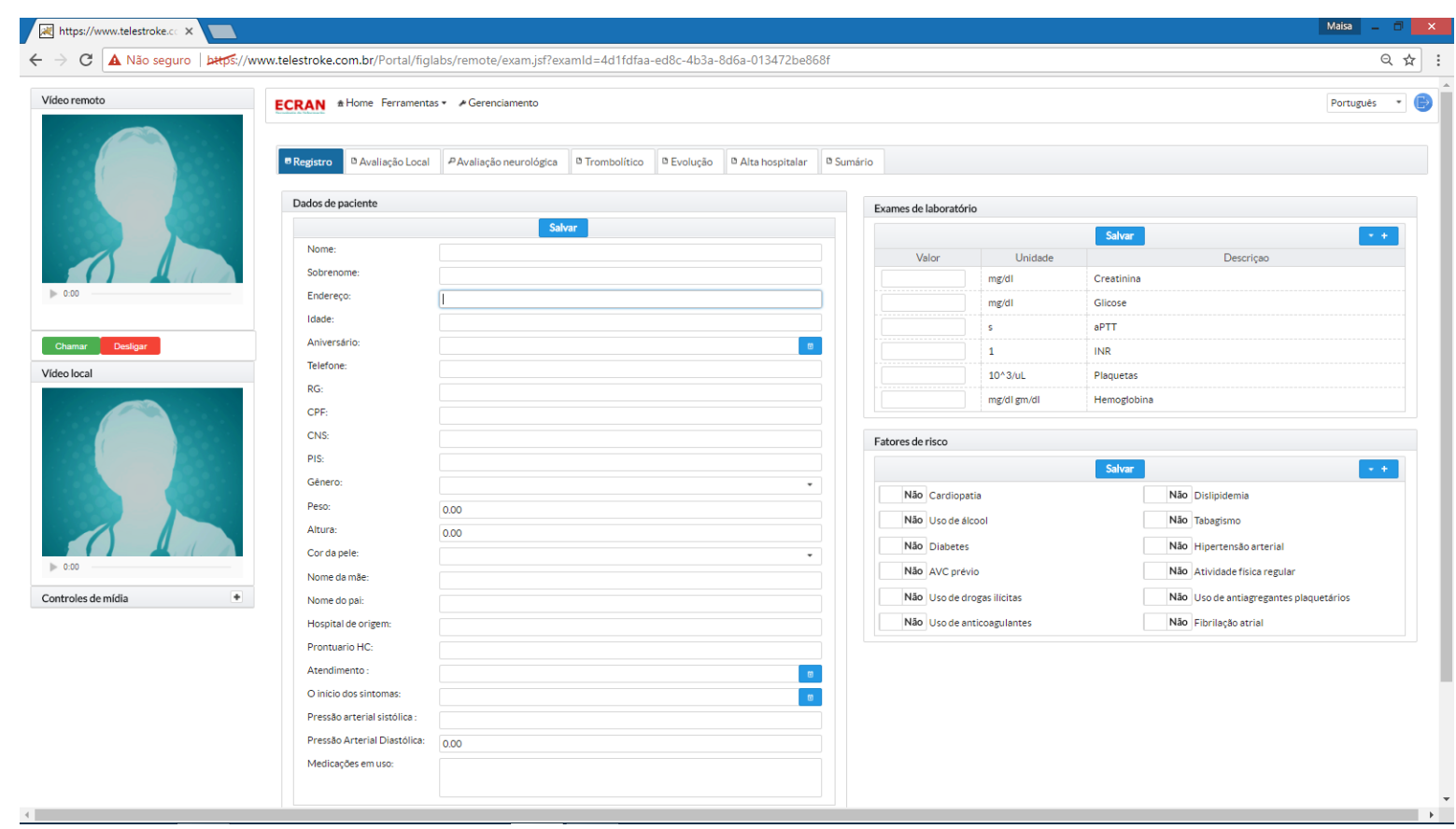

Figura 6: impressão de tela da página inicial do site do sistema de telemedicina para o AVC

Para iniciar a videoconferência o usuário deverá apenas clicar em "chamar" e autorizar o site a utilizar recursos de vídeo e microfone locais. Poderão ser ajustadas configurações de qualidade de vídeo conforme disponibilidade da rede de internet local, reduzindo a qualidade do vídeo para situações em que a rede esteja com baixo fluxo de dados (reduzindo assim as interrupções e o atraso na transmissão), ou aumentando a qualidade em situações em que alta resolução seja necessária (como por exemplo, durante exame físico do paciente).

As informações relativas ao atendimento do paciente com AVC agudo serão divididas em abas: registro, avaliação médica local, avaliação neurológica, trombólise, evolução e alta hospitalar.

$\mathrm{Na}$ primeira aba, registro, a equipe do hospital satélite deverá inserir as anotações básicas para o início da discussão do atendimento ao AVC (conforme visualizado na figura 6): 
- Características do paciente: nome, sobrenome, data de nascimento, telefone, peso, altura, cor da pele, gênero, nome da mãe e do pai, documentos de identificação (RG, CPF, cartão nacional de saúde).

- Características do atendimento: nome do hospital de origem, número do prontuário HC (se houver), data do atendimento, hora do início dos sintomas, pressão arterial da admissão e medicações em uso domiciliar.

- Resultados de exames de sangue: são solicitados nesta primeira tela somente os exames essenciais para decisão do tratamento trombolítico: creatinina, coagulograma (INR, aTTP, plaquetas), hemoglobina e glicemia.

- Fatores de risco para doenças cerebrovasculares: o usuário deverá marcar de modo simples "sim" ou "não" para os antecedentes pessoais potencialmente relacionados a aumento ou redução do risco de AVC (cardiopatia, uso de álcool, diabetes, AVC prévio, uso de drogas ilícitas, uso de anticoagulantes, dislipidemia, tabagismo, hipertensão arterial, atividade física regular, uso de antiagregantes plaquetários, fibrilação atrial).

Assim que o usuário clicar em "salvar", as informações já estarão disponíveis no site para outro usuário que acessar remotamente o atendimento deste paciente.

Após preencher a primeira aba, a equipe do hospital satélite irá preencher a segunda aba, "Avaliação Local" (figura 7), onde anotará a triagem de sinais ou sintomas de AVC, marcando sim ou não para presença de: paralisia facial, alteração de sensibilidade, alteração da visão, alteração do equilíbrio ou coordenação, alteração da força, da fala ou dor de cabeça atípica. Também deverá preencher campo com história clínica resumida.

Com posse destas primeiras informações, e já em videoconferência com o hospital satélite, o expert em neurologia vascular do centro de telemedicina poderá iniciar a consultoria, confirmando dados da anamnese e checando as primeiras contraindicações ao tratamento trombolítico. 


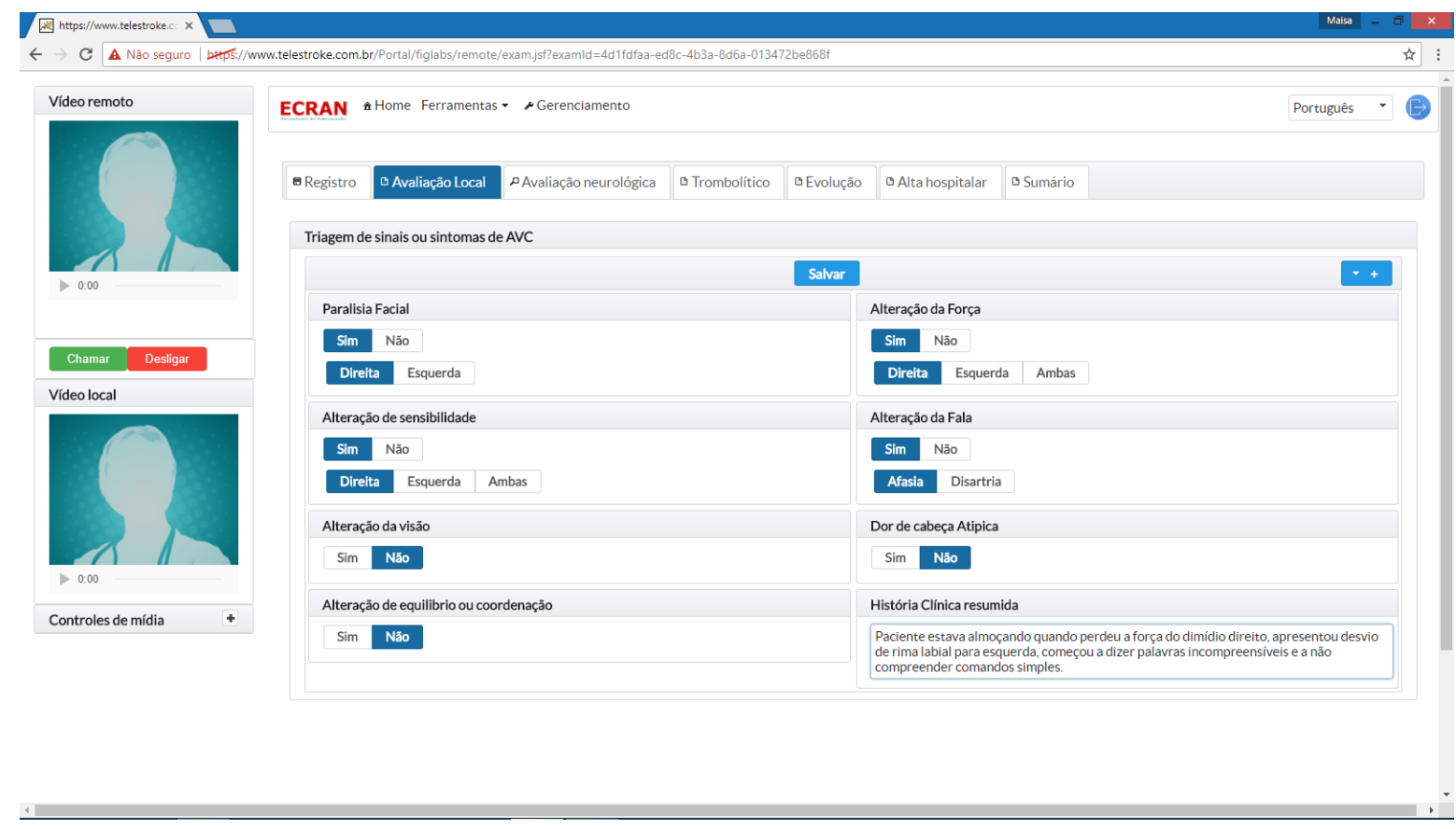

Figura 7: Impressão da tela da segunda aba do site do sistema de telemedicina para o AVC - Avaliação Local.

A terceira aba do site deverá ser preenchida pelo médico neurologista consultor, realizando, em conjunto com a equipe do hospital satélite, por vídeo, o exame físico do paciente por meio da NIHSS (National Institute of Health Stroke Scale). Ao clicar no campo NIHSS abrirá um pop-up para ambos os usuários para realização da escala passo - a - passo, conforme evidenciado nas figuras 8,9 e 10 , abaixo.

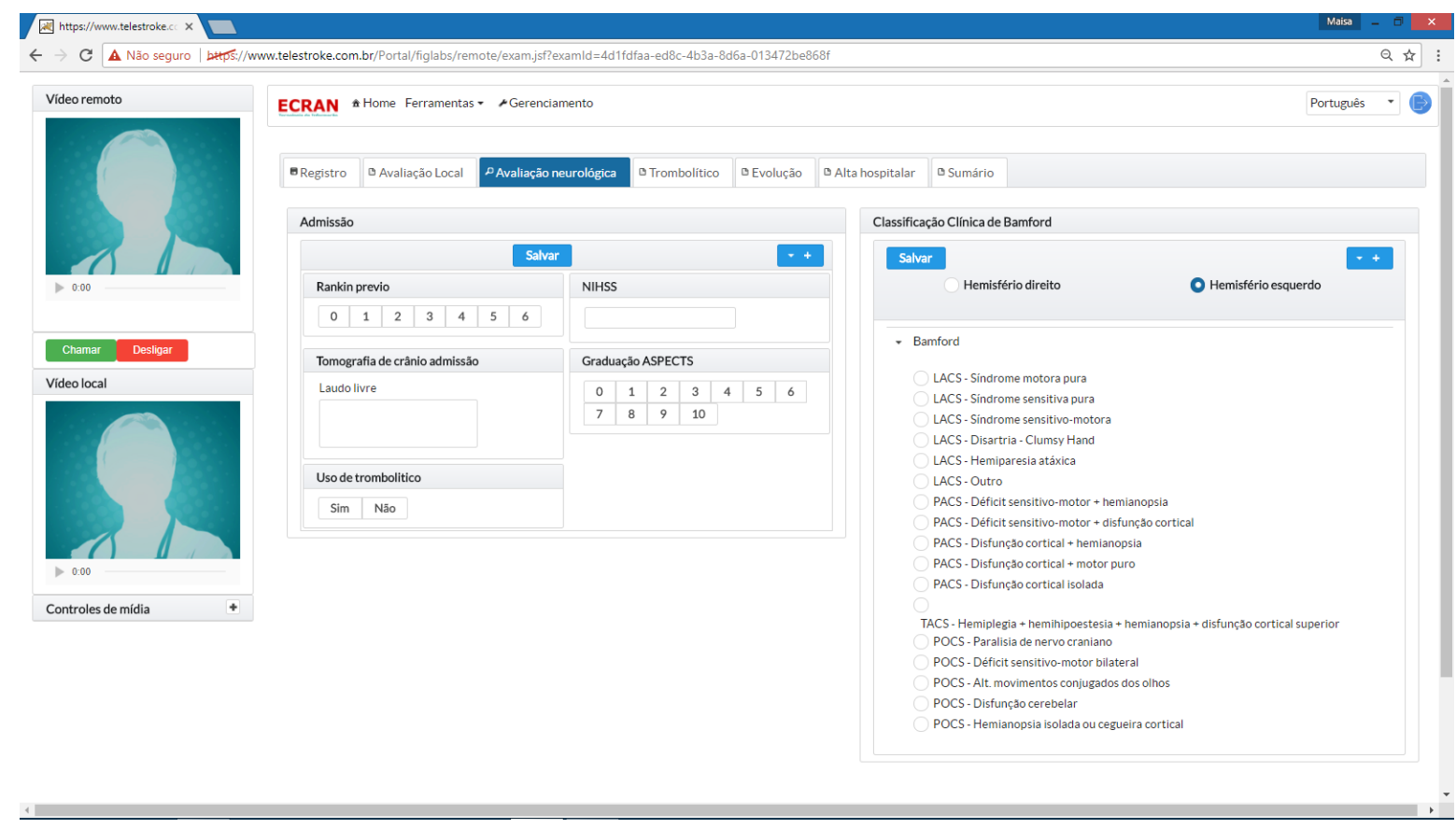

Figura 8: Impressão da tela da terceira aba do site do sistema de telemedicina para o AVC, denominada Avaliação Neurológica. 


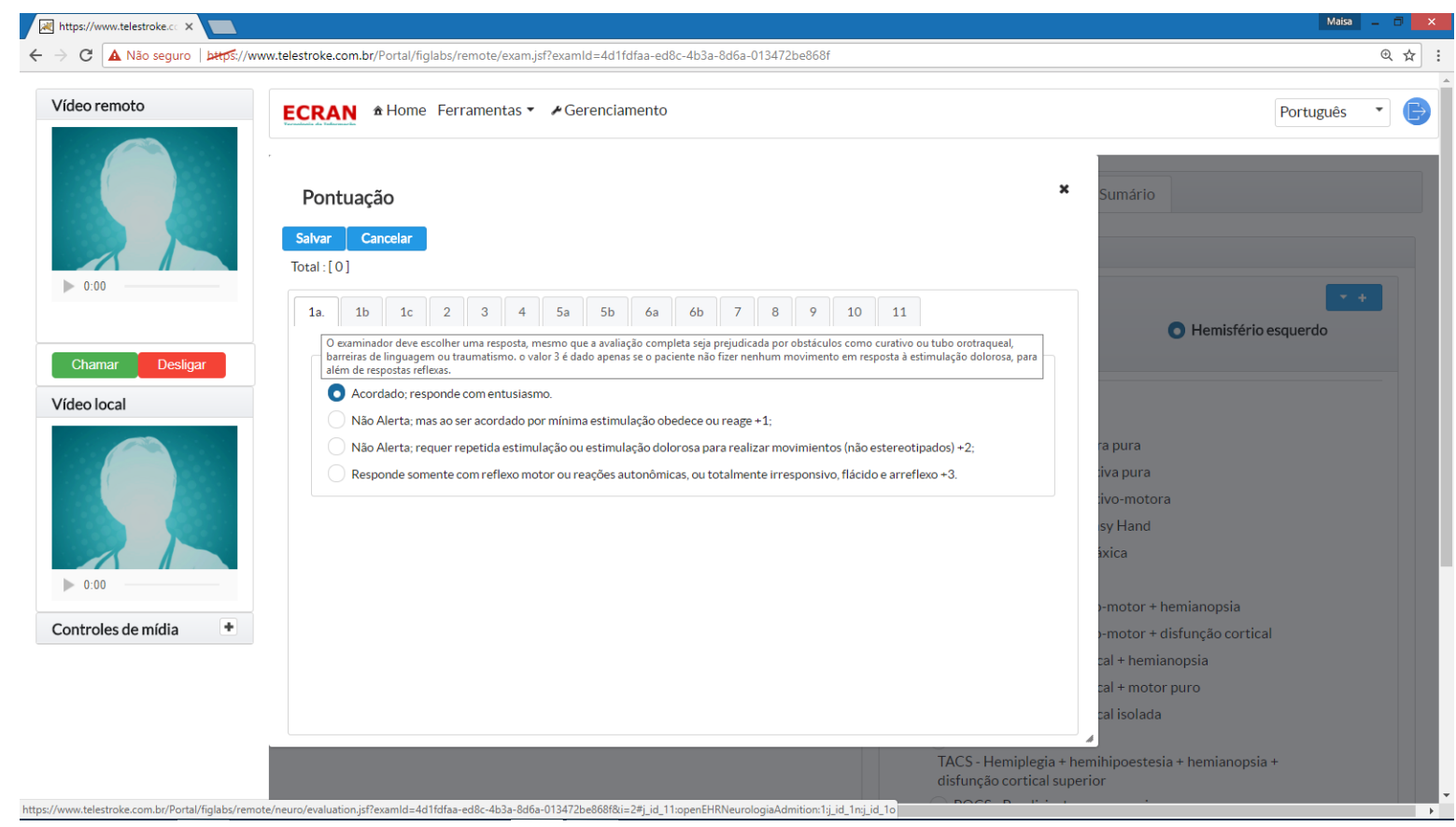

Figura 9: Impressão da tela do sítio eletrônico de telemedicina para o AVC, demonstrando a realização passo-apasso da National Institute of Health Stroke Scale. Ao passar o mouse sobre item (ex. 1a), o usuário recebe a orientação de como realizar a avaliação.

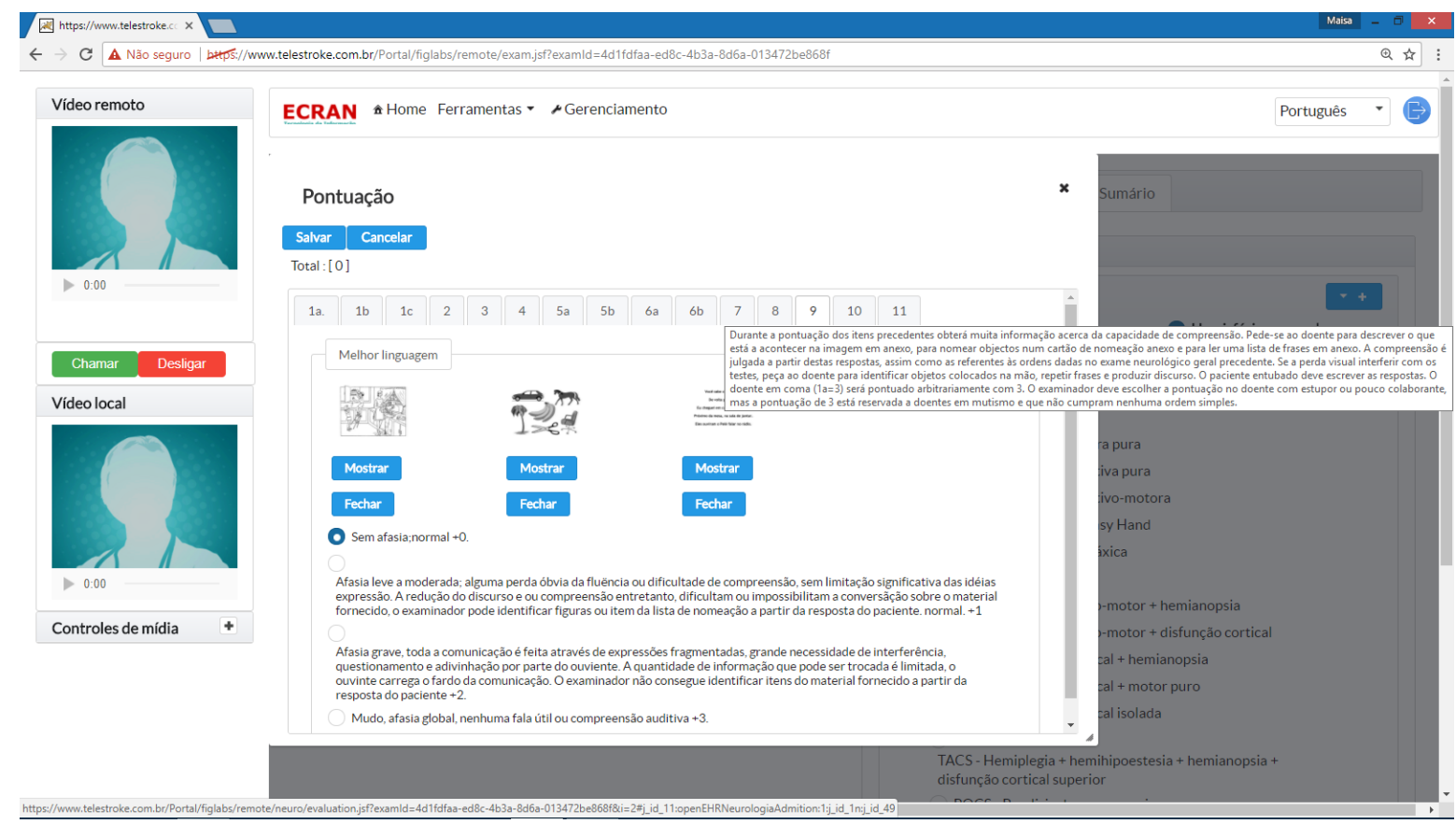

Figura 10: Impressão da tela demonstrando orientações para avaliação do item 9 da National Institute of Health Stroke Scale.

Para avaliação dos itens de linguagem e fala, é possível projetar as figuras e frases padronizadas pela escala para visualização e leitura pelo paciente na tela da videoconferência. 
Ao término da aplicação da escala, a soma dos itens é feita automaticamente e fica registrada no campo NIHSS. Com dados de anamnese e exame físico o neurologista poderá registrar a classificação Bamford (BAMFORD et al., 1991) no campo apropriado, obtendo a classificação clínica de acordo com o provável território vascular do AVC. Dando seguimento ao atendimento do AVC, o neurologista consultor deverá classificar o Rankin prévio do paciente (escala de Rankin modificada, que avalia funcionalidade).

Neste momento, o neurologista consultor acessará as imagens da tomografia computadorizada de crânio do paciente, que serão transmitidas do servidor do aparelho por internet para sistema próprio para laudos de tomografia (conforme o software já utilizado pelo hospital satélite) e em tela com resolução apropriada. Após avaliação da tomografia, o neurologista registrará a pontuação ASPECTS (DEMCHUK; COUTTS, 2005) e sua impressão no campo "Tomografia de Crânio Admissão".

De posse da Classificação Clínica, do ASPECTS, dos exames laboratoriais e da anamnese com registro de tempo de início de sintomas e contra-indicações ao trombolítico, o neurologista consultor poderá indicar ou não a trombólise endovenosa, ou até tomar a decisão de após o início da trombólise transferir o paciente para procedimento de trombectomia mecânica.

A quarta aba do site é destinada ao registro da trombólise, conforme figura 11:

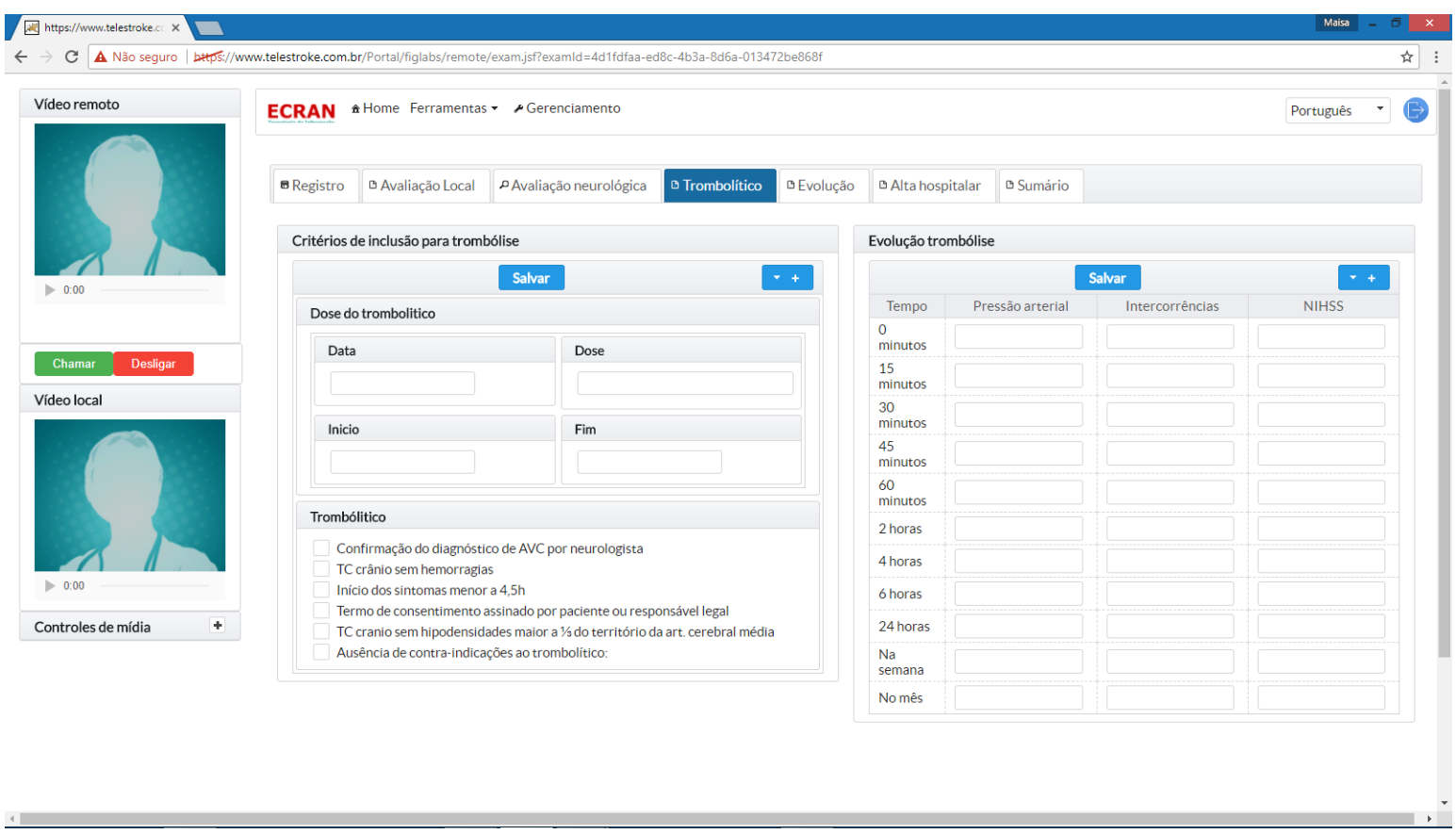

Figura 11: impressão da tela da aba "Trombolítico" do site de telemedicina para o AVC 
A equipe local deverá anotar data, horário exato de início e término da infusão do trombolítico, dose utilizada e a monitorização da pressão arterial, NIHSS e intercorrências durante e após a infusão, seguindo protocolos de atendimento.

Foi disposto uma lista de checagem de critérios de indicação da trombólise (quadro trombolítico):

- Confirmação do diagnóstico de AVC por neurologista;

- TC crânio sem hemorragias;

- Início dos sintomas menor que 4,5h;

- Termo de consentimento assinado por paciente ou responsável legal;

- TC crânio sem hipodensidades maiores que 1/3 do território da art. Cerebral média;

- Ausência de contraindicações ao trombolítico.

Ao clicar neste último item, abrir-se-á uma lista das contraindicações para conferência (figura 12).

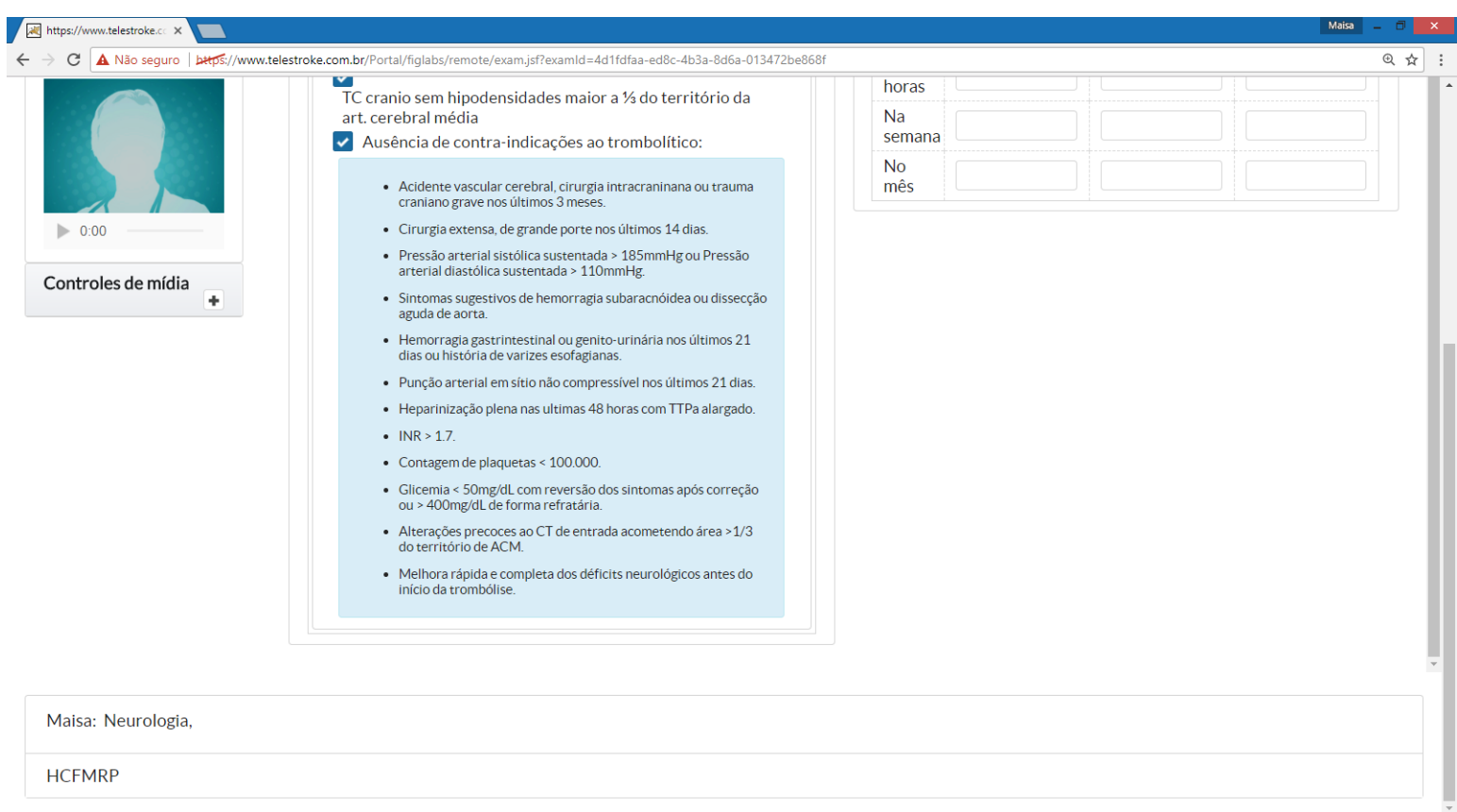

Figura 12: impressão da tela do site de telemedicina para o AVC, demonstrando lista de contraindicações ao trombolítico para conferência.

A próxima aba da tela é denominada "Evolução", que se destina ao registro da investigação etiológica, com resultados dos exames essenciais e complementares, de intercorrências hospitalares e das discussões entre equipes de saúde nos dias subsequentes à admissão (figura 13). 


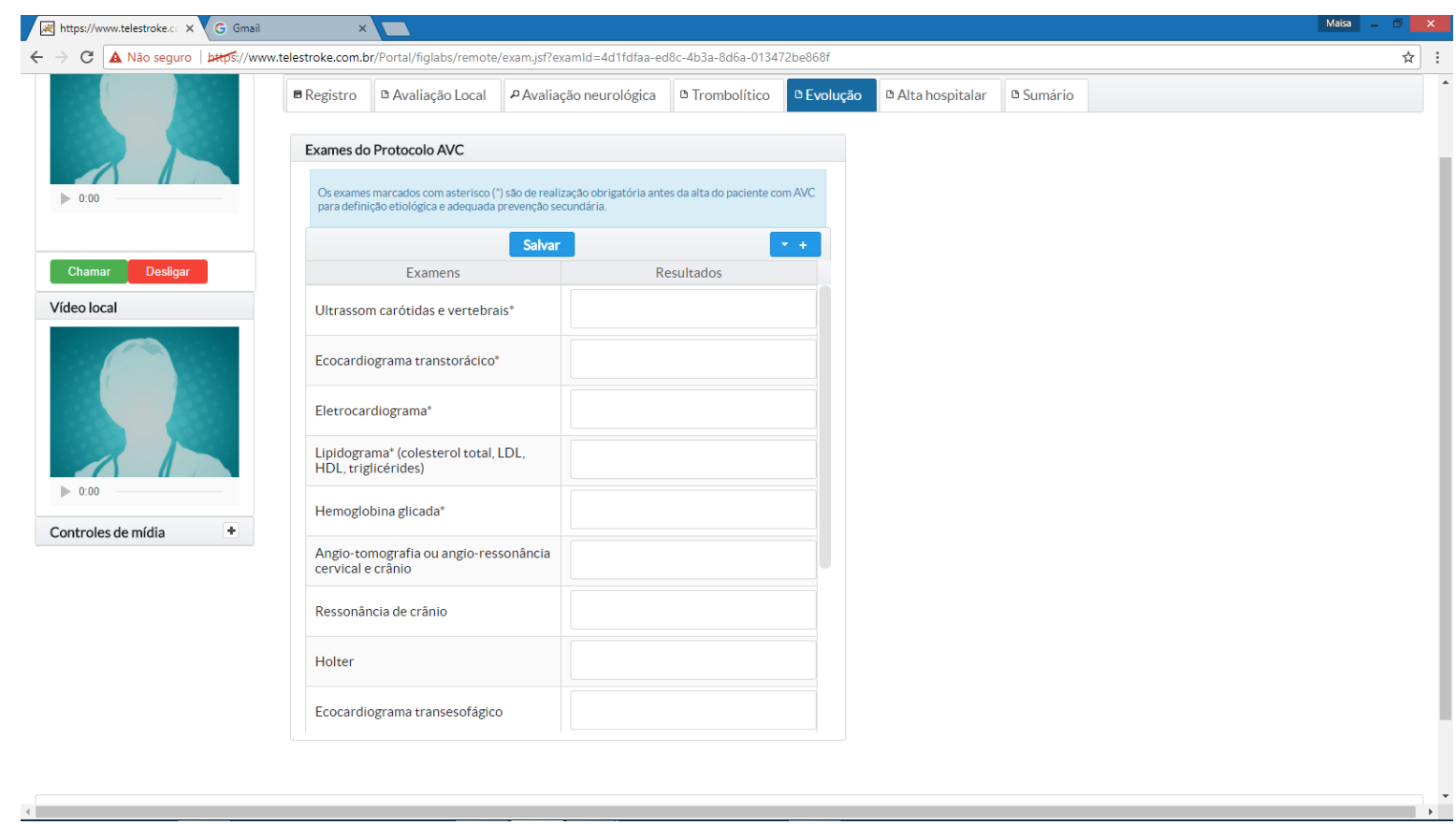

Figura 13: impressão da tela "Evolução" do site de telemedicina para o AVC

Seguindo o raciocínio de função educativa do site, a tabela com os exames do protocolo AVC dispõe os exames necessários para investigação etiológica seguindo o Manual de Rotinas de Atenção ao AVC do Ministério da Saúde (BRASIL. MINISTÉRIO DA SAÚDE., 2013), marcando com asterisco os exames indispensáveis: ultrassom de carótidas e vertebrais, ecocardiograma transtorácico, eletrocardiograma, lipidograma e hemoglobina glicada; além destes, há campos para preenchimento de exames de investigação adicional, como ressonância de crânio, ecocardiograma transesofágico, sorologias e holter.

Finalmente, a última seção do site é a aba "Alta Hospitalar" (figura 14), na qual é feito o registro das conclusões daquela internação por AVC, com as informações:

- Diagnóstico da alta (com opções para marcar sim/não): AVC isquêmico, AVC hemorrágico, AIT, Hemorragia Subaracnóidea, Outros (com possibilidade de escrita livre). Conforme o diagnóstico selecionado, aparecerá na tela uma lista para que se assinale a etiologia, conforme classificação de TOAST (ADAMS et al., 1993) para o AVC isquêmico (figura 15), etiologias mais frequentes de AVC hemorrágico. Quando selecionada a etiologia cardioembólica, abrem-se opções para seleção entre fibrilação atrial, forame oval patente ou miocardiopatia. 
- Intercorrências e procedimentos realizados (com opções para marcar sim/não): neurocirurgia, transformação hemorrágica sintomática, arteriografia ou angioplastia, outro (com escrita livre).

- Grau de independência funcional do paciente no momento da alta (escala de Rankin modificada, com opções para assinalar de 0 a 6) (BAGGIO et al., 2014).

- Óbito (opção para assinalar sim/não).

- Prevenção secundária prescrita (com opções para marcar sim/não): antiagregante plaquetário, estatina, anticoagulante, outro (com campo para escrita livre)

- Data da alta.

- Pontuação da NIHSS da alta.

- Transferência (sim/não e para qual hospital). 


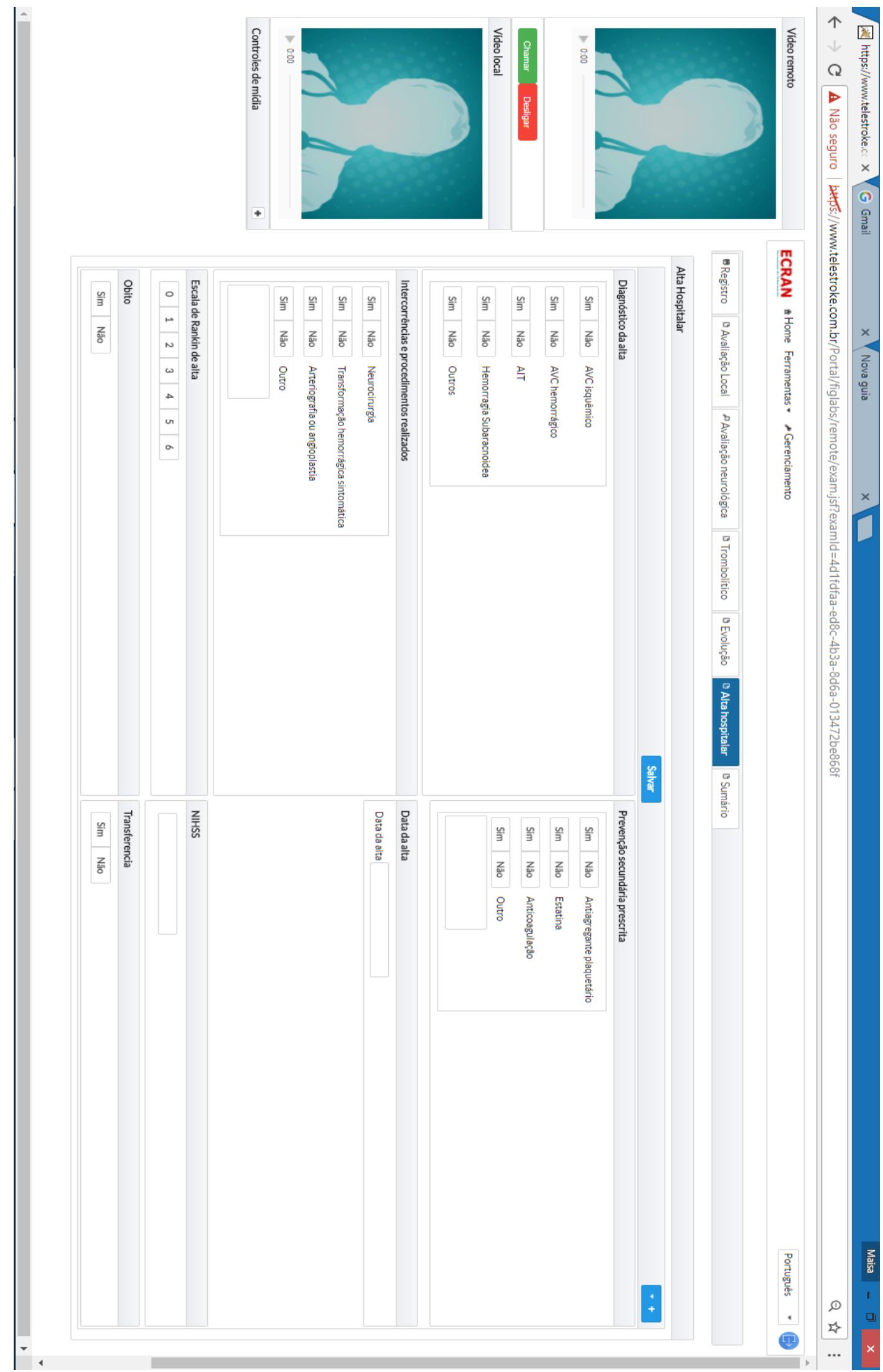

Figura 14: impressão da tela do site de telemedicina para o AVC - aba alta hospitalar. 


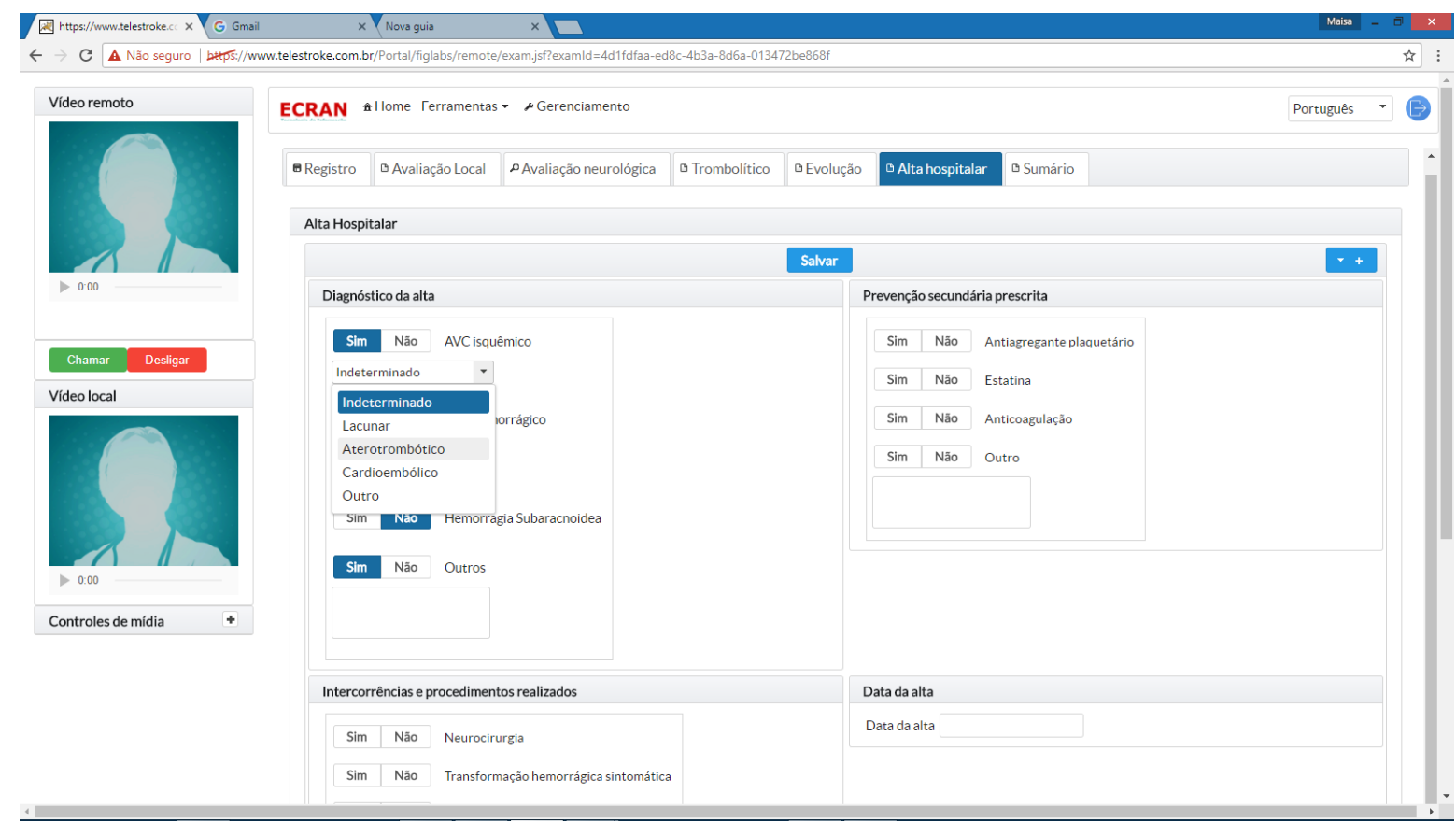

Figura 15: Opções para seleção de diagnóstico etiológico do AVC isquêmico - indeterminado, lacunar, aterotrombótico, cardioembólico e outro.

Novamente, a estrutura da página tem caráter educativo, garantindo que sejam revisados, no momento da alta, o diagnóstico correto, a investigação etiológica e a prevenção secundária correta.

O sistema tem uma ferramenta que permite emitir relatório final, em PDF, com as informações inseridas em cada parte do site, para que, se desejado, seja impresso e anexado ao prontuário físico do paciente.

Além disso, todos os dados inseridos podem ser exportados para planilha em formato Excel®, possibilitando análise estatística para pesquisas acadêmicas (respeitando a necessidade de registro de consentimento informado do paciente para participação de pesquisas).

O sistema está pronto para utilização e começará a ser utilizado a partir do início de 2018, como parte do projeto de pesquisa TEMPO STROKE - Avaliação de Telemedicina como estratégia para redução da morbimortalidade de pacientes com Acidente Vascular Cerebral. 


\section{CONCLUSÕES}

A telemedicina para o AVC é realidade em muitos países, estando em funcionamento nos Estados Unidos há quase 20 anos (LEVINE; GORMAN, 1999; SWITZER; LEVINE; HESS, 2009), sendo estratégica para disseminação do acesso ao tratamento adequado do AVC agudo em países com grandes extensões territoriais e com distribuição desigual de centros de expertise em neurologia vascular. No Brasil, a prática da telemedicina ainda é incipiente, entretanto já existem redes de atendimento em operação e com resultados positivos (MARTINS et al., 2013; STEINMAN et al., 2015).

Este estudo demonstrou que a região de Ribeirão Preto possui potencial para instalação de uma rede de telemedicina interligando um centro de excelência em pesquisa e assistência em neurologia vascular com hospitais de outras quatro cidades da região, que atualmente têm estruturas físicas suficientes para o funcionamento como Unidades de AVC, mas carentes de recursos humanos especializados para a aplicação de protocolos de atendimento que incluam o tratamento trombolítico.

A viabilidade desta rede depende do cadastramento de Unidades de AVC nestes hospitais junto ao Ministério da Saúde (a fim de garantir economicamente o financiamento do trombolítico e aumentar o valor repassado por internação), de financiamento para a compra dos equipamentos necessários (custo baixo, entretanto sem política pública de financiamento bem estabelecida, sendo necessária a busca de recursos junto a gestores locais de saúde e iniciativa privada), de treinamento das equipes dos hospitais da rede e da disponibilidade da equipe do centro de referência em AVC para a consultoria em tempo integral. Em relação a este último item, há interesse institucional da Unidade de Emergência do HCFMRP na prestação desta consultoria, mesmo que inicialmente sem remuneração por financiamento público, pois uma rede maior de atendimento ao AVC reduziria a superlotação desta unidade, além de ampliar quantitativamente o acesso ao tratamento dos pacientes da região, bem como interesse acadêmico, pois o projeto da rede de telemedicina gerará material para publicações científicas no tema.

Após a análise dos aspectos éticos e jurídicos envolvidos, não foram encontradas restrições para este modelo de rede de telemedicina, desde que garantidos a segurança, o sigilo e a privacidade do paciente, principalmente na transmissão eletrônica de seus dados, e o registro da interação por telemedicina em prontuário. 
O sistema eletrônico de telemedicina desenvolvido se apresenta como ferramenta útil para aplicação prática da rede de tele-AVC, pois possibilita o registro seguro das informações discutidas nos atendimentos compartilhados por meio da teleconferência e guia o atendimento, tendo como base protocolos nacionais e internacionais de assistência ao AVC agudo (Manual de Rotinas para atenção ao AVC do Ministério da Saúde e Diretrizes da American Stroke Association). Além do papel assistencial, o uso do site tem valor educativo no treinamento do atendimento do AVC (funcionalidade interativa e descritiva da aplicação da escala NIHSS, direciona anamnese e exame físico, orienta exames de investigação etiológica inicial e a prevenção secundária) e fornece recursos para pesquisa clínica (ferramenta de exportação de dados em formato de planilha, utilização de linguagem LOINC e interoperabilidade com outros sistemas de informação).

Esperamos que esta pesquisa contribua para efetivação deste projeto de rede de telemedicina na região de Ribeirão Preto e sirva de base para o desenvolvimento de projetos semelhantes em outras regiões brasileiras.

\subsection{LIMITAÇÕES DA PESQUISA}

Os dados referentes a serviços de saúde dos municípios do DRS XIII foram coletados pelo DATASUS e CNES, podendo estar desatualizados quanto a algumas informações, por falta de alimentação dos sistemas pelos municípios. Entretanto, a estrutura dos maiores municípios com potencial para instalação de unidades de AVC foi confirmada junto ao DRS e aos hospitais municipais.

O sistema de telemedicina desenvolvido foi submetido a testes, entretanto ainda não foi iniciada sua utilização em larga escala e cotidianamente, o que possivelmente apontará algumas falhas e pontos a serem melhorados.

\subsection{SUGESTÕES PARA TRABALHOS FUTUROS}


A pesquisa realizada nesta dissertação poderá ser utilizada para reorganização da Rede de Urgências e Emergências em Neurologia e AVC no DRS XIII e como base teórica para solicitações de cadastramento das Unidades de AVC nos municípios em que identificou a estrutura necessária para instalação das mesmas.

A autora pretende iniciar em breve a implantação de serviços de telemedicina para o AVC entre o HCFMRP e um hospital secundário da região, realizando ensaio clínico para comparar o uso de Telemedicina para AVC com a Regulação Médica convencional como estratégia para auxílio na triagem, diagnóstico e tratamento dos pacientes com AVC. A utilização do sistema de telemedicina criado permitirá a coleta dos dados de todos os pacientes atendidos para esta e outras pesquisas clínicas futuras em AVC e telemedicina (observando, claro, a necessidade do consentimento livre e esclarecido dos pacientes como participantes de pesquisa). 


\section{REFERÊNCIAS}

ADAMS, H. P.; BENDIXEN, B. H.; KAPPELlE, L. J.; BILLER, J.; LOVE, B. B.; GORDON, D. L.; MARSH, E. E. Classification of subtype of acute ischemic stroke. Definitions for use in a multicenter clinical trial. TOAST. Trial of Org 10172 in Acute Stroke Treatment. Stroke, v. 24, n. 1, p. 35-41, 1993. Disponível em: $<$ http://stroke.ahajournals.org/cgi/doi/10.1161/01.STR.24.1.35>.

ASSOCIAÇÃO MÉDICA BRASILEIRA (AMB). Classificação Brasileira Hierarquizada de Procedimentos Médicos. São Paulo: Manole, 2016.

AUDEBERT, H. J.; SCHWAMM, L. Telestroke: Scientific results. Cerebrovascular Diseases, v. 27, n. SUPPL. 4, p. 15-20, 2009.

BAGGIO, J. A. O.; SANTOS-PONTELLI, T. E. G.; COUGO-PINTO, P. T.; CAMILO, M.; SILVA, N. F.; ANTUNES, P.; MACHADO, L.; LEITE, J. P.; PONTES-NETO, O. M. Validation of a structured interview for telephone assessment of the modified rankin scale in Brazilian stroke patients. Cerebrovascular Diseases, v. 38, n. 4, p. 297-301, 2014.

BAMFORD, J.; SANDERCOCK, P.; DENNIS, M.; BURN, J.; WARLOW, C. Classification and natural history of clinically identifiable subtypes of cerebral infarction. Lancet, v. 337, p. 1521-26, 1991.

BRASIL. MINISTÉRIO DA SAÚDE. Resumo do Projeto Nacional de Atendimento ao Acidente Vascular Cerebral. Disponível em: $<$ http://pwweb2.procempa.com.br/pmpa/prefpoa/redebrasilavc/usu_doc/resultadosprojetonaci onal.pdf $>$. Acesso em: 3 jul. 2017.

BRASIL. MINISTÉRIO DA SAÚDE. Portaria $n^{\circ}$ 2.073, de 31 de agosto de 2011. Regulamenta o uso de padrões de interoperabilidade e informação em saúde para sistemas de informação em saúde no âmbito do Sistema Único de Saúde, nos níveis Municipal, Distrital, Estadual e Federal, e para os s. Diário Oficial da União, 2011a. Disponível em: $<$ http://bvsms.saude.gov.br/bvs/saudelegis/gm/2011/prt2073_31_08_2011.html>.

BRASIL. MINISTÉRIO DA SAÚDE. PORTARIA No 2.546, de 27 de outubro de 2011. Redefine e amplia o Programa Telessaúde Brasil, que passa a ser denominado Programa Nacional Telessaúde Brasil Redes (Telessaúde Brasil Redes). Diário Oficial da União, p. 17, 2011b. Disponível em: <http://bvsms.saude.gov.br/bvs/saudelegis/gm/2011/prt2546_27_10_2011_comp.html>. 
BRASIL. MINISTÉRIO DA SAÚDE. Portaria nº 936, de 27 de abril de 2011. Dispõe sobre as regras e critérios para apresentação, monitoramento, acompanhamento e avaliação de projetos do Programa de Apoio ao Desenvolvimento Institucional doSistema Único de Saúde (PROADI-SUS). Diário Oficial da União, p. 1-9, 2011c.

BRASIL. MINISTÉRIO DA SAÚDE. Portaria $n^{\circ} 664$ de 12 de abril de 2012. Aprova o Protocolo Clínico e Diretrizes Terapêuticas - Trombólise no Acidente Vascular Cerebral Isquêmico Agudo. Diário Oficial da União, v. 164, n. 1, p. 205, 2012a.

BRASIL. MINISTÉRIO DA SAÚDE. PORTARIA Nº. 665, DE 12 DE ABRIL DE 2012. Dispõe sobre os critérios de habilitação dos estabelecimentos hospitalares como Centro de Atendimento de Urgência aos Pacientes com Acidente Vascular Cerebral (AVC), no âmbito do Sistema Único de Saúde (SUS),insti. Diário Oficial da União, p. 206, 2012 b.

BRASIL. MINISTÉRIO DA SAÚDE. Manual de rotinas para atenção ao AVC. Brasília, DF: Editora Ministério da Saúde, 2013.

BRASIL. MINISTÉRIO DA SAÚDE. Portaria $n^{\circ} 800$, de 17 de junho de 2015. Altera, acresce e revoga dispositivos da Portaria ${ }^{\circ}$ 665/GM/MS, de 12 de abril de 2012, que dispõe sobre os critérios de habilitação dos estabelecimentos hospitalares como Centro de Atendimento de Urgência aos Paci. Diário Oficial da União, v. 1, n. 115, p. 34-38, 2015a. Disponível em: $<$ http://bvsms.saude.gov.br/bvs/saudelegis/gm/2015/prt0800_17_06_2015.html>. BRASIL. MINISTÉRIO DA SAÚDE. Custeio dos Núcleos de Telessaúde - Manual Instrutivo. Brasília: Ministério da Saúde, 2015b.

CABRAL, N. L.; GONCALVES, A. R. R.; LONGO, A. L.; MORO, C. H. C.; COSTA, G.; AMARAL, C. H.; SOUZA, M. V; ELUF-NETO, J.; FONSECA, L. A. M. Trends in stroke incidence, mortality and case fatality rates in Joinville, Brazil: 1995-2006. Journal of Neurology, Neurosurgery \& Psychiatry, v. 80, n. 7, p. 749-754, 2009. Disponível em: $<$ http://jnnp.bmj.com/cgi/doi/10.1136/jnnp.2008.164475>.

CABRAL, N. L.; MORO, C.; SILVA, G. R.; SCOLA, R. H.; WERNECK, L. C. Study comparing the stroke unit outcome and conventional ward treatment: A randomized study in Joinville, Brazil. Arquivos de Neuro-Psiquiatria, v. 61, n. 2 A, p. 188-193, 2003.

CAPELI, R. D. Apresentação FÓRUM “ URGÊNCIAS E EMERGÊNCIAS " Estrutura / Cenário Regional. Disponível em: $<$ http://www.cremesp.org.br/pdfs/eventos/eve_05122014_103555_Estrutura Cenario 
Regional de Ribeirao Preto - Ronaldo Dias Capeli.pdf>. Acesso em: 19 jul. 2017.

COMISSÃO DAS COMUNIDADES EUROPÉIAS. Comunicação da comissão ao parlamento europeu, ao conselho, ao comitê econômico e social europeu e ao comitê das regiões sobre os benefícios da telemedicina para os doentes, os sistemas de saúde e a sociedade. [s.l: s.n.].

COMISSÃO DAS COMUNIDADES EUROPÉIAS. Comission Staff working document on the applicabiliby of the existing EU legal framework to telemedicine servicesComission Staff Working Document on the applicability of the existing EU legal framework to telemedicine services. [s.l: $\mathrm{s.n}$.]. Disponível em: <https://ec.europa.eu/digital-singlemarket/en/news/commission-staff-working-document-applicability-existing-eu-legalframework-telemedicine $>$.

CONSELHO FEDERAL DE MEDICINA. Resolução CFM n ${ }^{\circ}$ 1.640/2002 Define e disciplina a prestação de serviços através da telemedicina. Diário Oficial da União, v. 1, p. 205, 2002. Disponível em: <http://www.portalmedico.org.br/resolucoes/CFM/2002/1643_2002.pdf>.

CONSELHO FEDERAL DE MEDICINA. Resolução CFM Nº1.821/07. Aprova as normas técnicas concernentes à digitalização e uso dos sistemas informatizados para a guarda e manuseio dos documentos dos prontuários dos pacientes, autorizando a eliminação do papel e a troca de informação identificad. Diário Oficial da União, v. 1, p. 252, 2007. Disponível em: <http://www.portalmedico.org.br/resolucoes/cfm/2007/1821_2007.htm>.

CULEBRAS, A.; CHATURVEDI, S. Standard strategies for acute ischemic stroke within the rtPA therapeutic window. Neurology: Clinical Practice, v. 3, n. 3, p. 202-204, 2013. Disponível em: $<$ http://ovidsp.ovid.com/ovidweb.cgi?T $=$ JS\&PAGE=reference $\& D=e m e d 11 \& N E W S=N \& A N$ $=2013445871>$.

DEMCHUK, A. M.; COUTTS, S. B. Alberta stroke program early CT score in acute stroke triage. Neuroimaging Clinics of North America, v. 15, n. 2, p. 409-419, 2005.

DONNAN, G. A. Stroke in developing countries: The looming epidemic. International Journal of Stroke, v. 6, n. 2, p. 97-97, 2011.

EL KHOURI, S. G. Telemedicina : análise da sua evolução no Brasil. 2003. Universidade de São Paulo, 2003.

FERNANDES, T. G.; BANDO, D. H.; ALENCAR, A. P.; BENSEÑOR, I. M.; LOTUFO, P. A. Income inequalities and stroke mortality trends in Sao Paulo, Brazil, 1996-2011. 
International Journal of Stroke, v. 10, n. A100, p. 34-37, 2015.

KAUP, A. O.; DOS SANTOS, B. F. C.; VICTOR, E. S.; CYPRIANO, A. S.; LOTTENBERG, C. L.; CENDOROGLO NETO, M.; SILVA, G. S. Georeferencing deaths from stroke in São Paulo: An intra-city stroke belt? International Journal of Stroke, v. 10, n. A100, p. 69-74, 2015.

KOH, G. C.-H.; YEN, S. C.; TAY, A.; CHEONG, A.; NG, Y. S.; DE SILVA, D. A.; PNG, C.; CAVES, K.; KOH, K.; KUMAR, Y.; PHAN, S. W.; TAI, B. C.; CHEN, C.; CHEW, E.; CHAO, Z.; CHUA, C. E.; KOH, Y. S.; HOENIG, H. Singapore Tele-technology Aided Rehabilitation in Stroke (STARS) trial: protocol of a randomized clinical trial on telerehabilitation for stroke patients. BMC Neurology, v. 15, n. 1, p. 161, 2015. Disponível em: $<\mathrm{http}: / /$ bmcneurol.biomedcentral.com/articles/10.1186/s12883-015-0420-3>.

LEVINE, S. R.; GORMAN, M. "Telestroke": the application of telemedicine for stroke. Stroke, v. 30, n. 2, p. 464-9, 1 fev. 1999. Disponível em: $<$ http://stroke.ahajournals.org/cgi/doi/10.1161/01.STR.0000102044.27905.B5>.

MARTINS, S. C. O.; PONTES-NETO, O. M.; ALVES, C. V.; DE FREITAS, G. R.; FILHO, J. O.; TOSTA, E. D.; CABRAL, N. L. Past, present, and future of stroke in middle-income countries: The Brazilian experience. International Journal of Stroke, v. 8, n. 100 A, p. 106$111,2013$.

MEDEIROS DE BUSTOS, E.; VUILLIER, F.; CHAVOT, D.; MOULIN, T. Telemedicine in stroke: Organizing a network - Rationale and baseline principles. Cerebrovascular Diseases, v. 27, n. SUPPL. 4, p. 1-8, 2009.

MINELLI, C.; FEN, L. F.; MINELLI, D. P. C. Stroke incidence, prognosis, 30-day, and 1year case fatality rates in Matão, Brazil: A population-based prospective study. Stroke, v. 38, n. 11, p. 2906-2911, 2007.

PEDRAGOSA, A.; ALVAREZ-SABIN, J.; MOLINA, C. A.; SANCLEMENTE, C.; MARTIN, M. C.; ALONSO, F.; RIBO, M. Impact of a telemedicine system on acute stroke care in a community hospital. J Telemed Telecare, v. 15, n. 5, p. 260-263, 2009. Disponível em:

$<$ http://ovidsp.ovid.com/ovidweb.cgi?T $=\mathrm{JS} \& \mathrm{PAGE}=$ reference $\& \mathrm{D}=$ med5\&NEWS=N\&AN $=1$ 9590033>.

PONTES-NETO, O. M.; SILVA, G. S.; FEITOSA, M. R.; DE FIGUEIREDO, N. L.; FIOROT, J. A.; ROCHA, T. N.; MASSARO, A. R.; LEITE, J. P. Stroke awareness in Brazil: 
Alarming results in a community-based study. Stroke, v. 39, n. 2, p. 292-296, 2008.

RIOU-COMTE, N.; MIONE, G.; HUMBERTJEAN, L.; BRUNNER, A.; VEZAIN, A.; LAVANDIER, K.; MARCHAL, S.; BRACARD, S.; DEBOUVERIE, M.; RICHARD, S. Implementation and evaluation of an economic model for telestroke: Experience from Virtuall, France. Frontiers in Neurology, v. 8, n. NOV, p. 1-9, 2017.

SCHEFFER, M. (coordenação); BIANCARELLI, A.; CASSENOTE, A. Demografia Médica No Brasil: dados gerais e descrições de desigualdades. São Paulo: Conselho Regional de Medicina do Estado de São Paulo e Conselho Federal de Medicina, 2013. v. 1

SCHWAMM, L. H.; ALI, S. F.; REEVES, M. J.; SMITH, E. E.; SAVER, J. L.; MESSE, S.; BHATT, D. L.; GRAU-SEPULVEDA, M. V.; PETERSON, E. D.; FONAROW, G. C. Temporal Trends in Patient Characteristics and Treatment With Intravenous Thrombolysis Among Acute Ischemic Stroke Patients at Get With the Guidelines-Stroke Hospitals. Circulation: Cardiovascular Quality and Outcomes, v. 6, n. 5, p. 543-549, 2013. Disponível em: $<$ http://circoutcomes.ahajournals.org/cgi/doi/10.1161/CIRCOUTCOMES.111.000095>.

SCHWAMM, L. H.; AUDEBERT, H. J.; AMARENCO, P.; CHUMBLER, N. R.; FRANKEL, M. R.; GEORGE, M. G.; GORELICK, P. B.; HORTON, K. B.; KASTE, M.; LACKLAND, D. T.; LEVINE, S. R.; MEYER, B. C.; MEYERS, P. M.; PATTERSON, V.; STRANNE, S. K.; WHITE, C. J. Recommendations for the implementation of telemedicine within stroke systems of care: A policy statement from the American heart association. Stroke, v. 40, n. 7, p. 2635-2660, 2009.

SILVA, G. S.; FARRELL, S.; SHANDRA, E.; VISWANATHAN, A.; SCHWAMM, L. H. The status of telestroke in the united states: A survey of currently active stroke telemedicine programs. Stroke, v. 43, n. 8, p. 2078-2085, 2012.

STEINMAN, M.; MORBECK, R. A.; PIRES, P. V.; ABREU FILHO, C. A. C.; ANDRADE, A. H. V.; TERRA, J. C. C.; TEIXEIRA JUNIOR, J. C.; KANAMURA, A. H. Impact of telemedicine in hospital culture and its consequences on quality of care and safety. Einstein (São Paulo), v. 13, n. 4, p. 580-586, 2015. Disponível em: $<$ http://www.scielo.br/scielo.php?script=sci_arttext\&pid=S167945082015000400580\&lng=en \&tlng $=\mathrm{en}>$.

SWITZER, J. A.; LEVINE, S. R.; HESS, D. C. Telestroke 10 years later - "telestroke 2.0". Cerebrovascular Diseases, v. 28, n. 4, p. 323-330, 2009. 
TATLISUMAK, T.; SOINILA, S.; KASTE, M. Telestroke networking offers multiple benefits beyond thrombolysis. Cerebrovascular Diseases, v. 27, n. SUPPL. 4, p. 21-27, 2009.

WAHLGREN, N.; AHMED, N.; DÁVAlOS, A.; HACKE, W.; MILlÁN, M.; MUIR, K.; ROINE, R. O.; TONI, D.; LEES, K. R. Thrombolysis with alteplase 3-4.5 h after acute ischaemic stroke (SITS-ISTR): an observational study. The Lancet, v. 372, n. 9646, p. 13031309, 2008. Disponível em: <http://dx.doi.org/10.1016/S0140-6736(08)61339-2>.

WEN, C. L. Telemedicina e Telessaúde - Um panorama no Brasil. Informatica Pública, v. 10, n. 2, p. 07-15, 2008.

WORLD HEALTH ORGANIZATION (WHO). Global Health Estimates 2015 Summary Tables. October. Disponível em: $<$ http://www.who.int/mediacentre/factsheets/fs310/en/index1.html $>$. Acesso em: 3 jul. 2017a.

WORLD HEALTH ORGANIZATION (WHO). Global Health Estimates 2015: Disease burden by Cause, Age, Sex, by Country and by Region, 2000-2015. Disponível em: $<$ http://www.who.int/healthinfo/global_burden_disease/estimates/en/index1.html $>$. Acesso em: 3 jul. $2017 b$.

WORLD MEDICAL ASSOCIATION. WMA statement on accountability, responsibilities and ethical guidelines in the practice of telemedicine. World Medical Assembly, PIlanesberg, South Africa, n. October, p. 1-6, 1999. 


\section{ANEXO TÉCNICO \\ DESCRIÇÃO TÉCNICA DO SISTEMA DE TELEMEDICINA PARA O AVC}

A Telemedicina é uma tecnologia emergente a qual reúne: Telecomunicações, Ciência da computação e Saúde[1]. O objetivo da telemedicina é estender os serviços de saúde, desde centros desenvolvidos para áreas geograficamente distantes (lugares que não possuam atendimento médico especializado). Esta tecnologia trouxe importantes avanços em consultas médicas e até telecirurgias sendo feitas remotamente pelos médicos especialistas [12]. Além disso, tem como valor agregado melhorar a educação e à pesquisa médica para estudantes e médicos que se encontram em regiões distantes.

As especialidades em telemedicina são variadas. A tecnologia tem sido aplicada em muitas especialidades da medicina convencional, as quais geralmente são denominadas pelo prefixo "Tele" acompanhado da área de estudo [1]. O desenvolvimento desta tecnologia além da videoconferência gera informação associada na observação do paciente. Estas informações são armazenadas em registros eletrônicos de Saúde (RES), como um meio para agilizar o registro e acesso à informação clínica. Porém, geralmente os registros encontram-se em bases de dados diferentes em cada serviço de saúde, que na maioria das vezes não podem ser acessados de outro serviço, impossibilitando a troca de informações sobre um mesmo paciente. Deste problema, adveio o esforço mundial em tornar a interoperabilidades entre esses sistemas uma realidade. Dentro desses paradigmas, o OpenEHR visa permitir a interoperabilidade entre sistemas de RES [2].

Descreveremos a utilidade de OpenEHR no desenvolvimento do sistema de Telemedicina para o atendimento do acidente vascular cerebral (AVC). Ao final, teceremos algumas conclusões do aprendizado desta experiência.

\section{METODOLOGIA}

A telemedicina compreende dois componentes importantes:

a) Módulo de visualização: pelo qual duas pessoas interagem, por exemplo, um especialista e um auxiliar de lugares geográficos distantes de atendimento;

b) Módulo de administração de dados: armazenam os dados observados do paciente. 
Para o módulo de administração de dados, foi utilizado o OpenEHR, que é um conjunto de especificações e ferramentas livres cujo propósito é permitir construções de sistemas RES (Registros eletrônicos de Saúde) que possam comunicar-se entre eles sem que aconteça perda de significado, conseguindo uma interoperabilidade semântica. As principais características da metodologia OpenEHR são a independência tecnológica e a separação da complexidade em dois níveis: um modelo de informação genérico (modelo de referência) e um modelo de domínio de conhecimento, mais próximo do especialista de domínio (pessoal não de computação)[9]. A informação, que dificilmente muda com o passar do tempo, é modelada pelo modelo de referência (Reference Model - RM), enquanto o conhecimento, parte dinâmica do sistema, é modelado usando o Modelo de objetos de arquétipos (Archetype Object Model-MOA).

Seguindo os lineamentos do openEHR, foi realizado um planejamento para incorporar as características no desenvolvimento do sistema de telemedicina. Primeiramente foi realizada uma elicitação de requisitos para ter um panorama geral da complexidade do sistema. Assim, foram realizadas reuniões frequentes com a médica especialista em AVC e nestas, realizadas mudanças nos requerimentos já feitos e desenvolvidos novos requerimentos. Desta maneira, aplicabilidade do sistema foi melhorando em cada um dos pontos de forma incremental. Por trabalhar com openEHR, o fato de definir os requerimentos nos arquétipos permitiu muitas facilidades. Os arquétipos segundo [2] definem a as estruturas do sistema por conter os conceitos clínicos definidos pelos especialistas (neurologistas). Este esquema realizado em essa mistura de requerimentos e desenvolvimento (Figura 16).

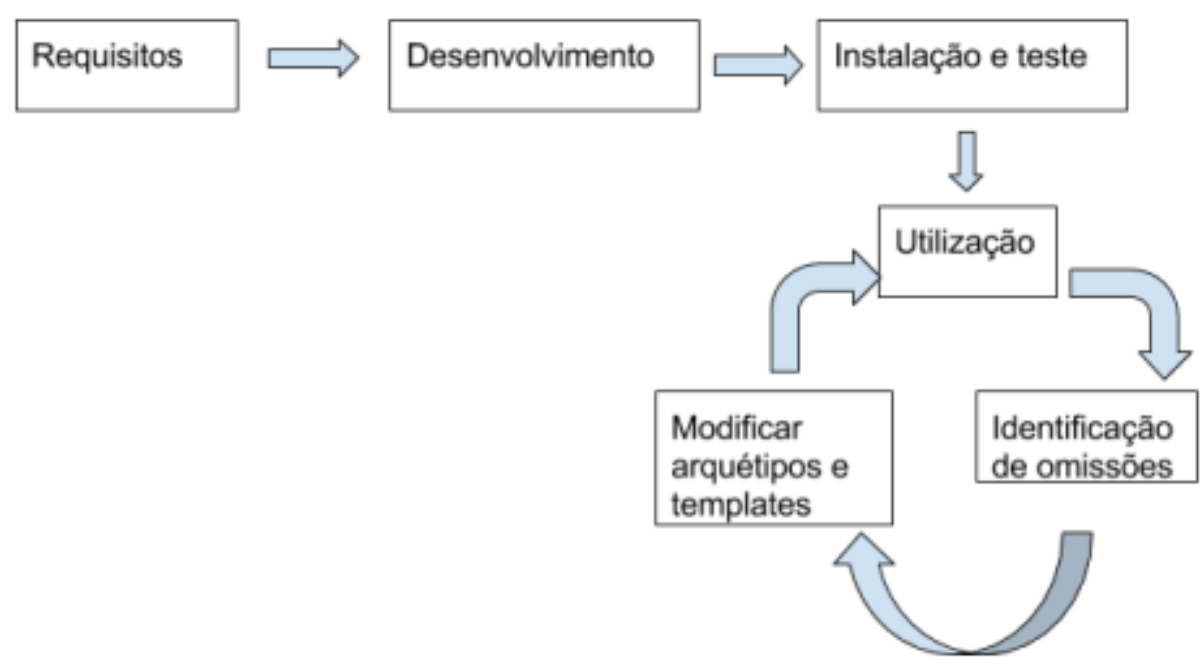

Figura 16: Metodologia de desenvolvimento de softwares com OpenEHR 
A importância da modelagem openEHR é a flexibilidade, porque as mudanças não repercutiram drasticamente no sistema. O esquema envolvido com modelamento de arquétipos [2] (Figura 17) pode ser visualizado em um modelador de domínio (informação clínica) e o modelo de desenvolvedor o que permite independência com a parte informática.

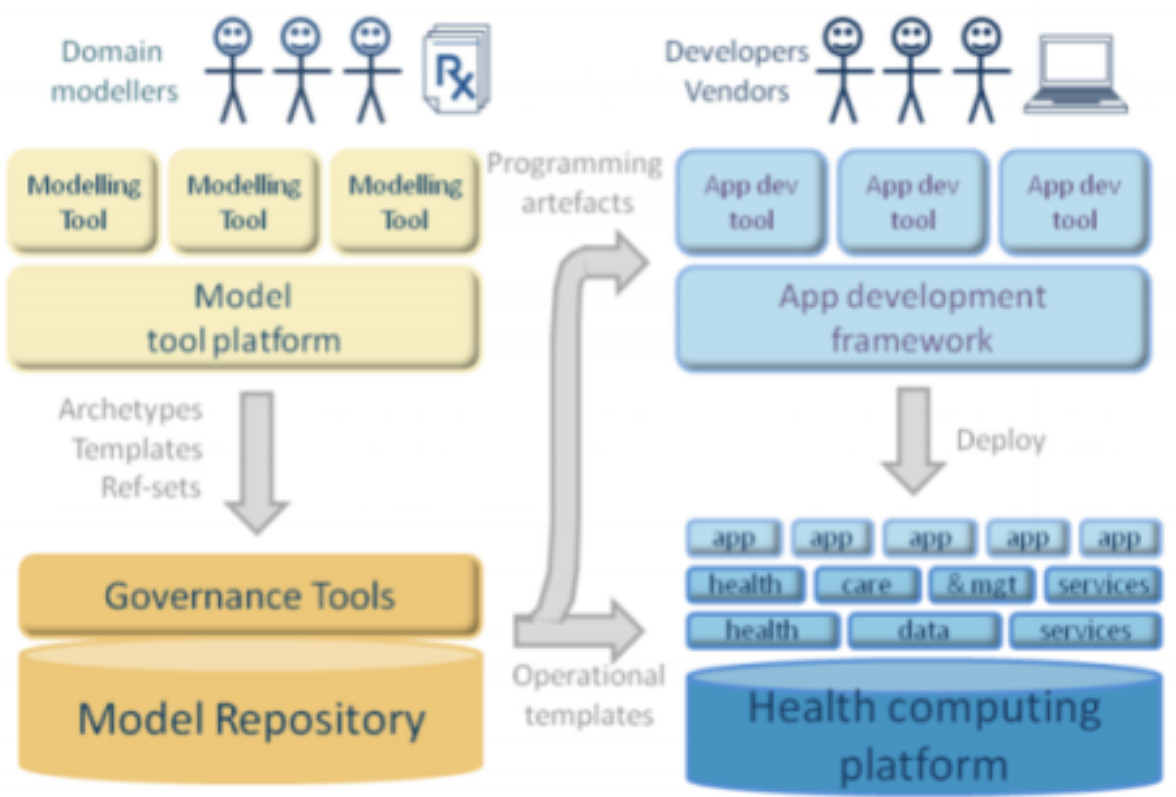

Figura 17: Nível clínico (conhecimento) e técnico no desenho de um sistema de saúde com OpenEHR

Planejou-se um modelo de passos para transição dos conhecimentos clínicos em arquétipos e templates. $\mathrm{Na}$ figura 4 descreveremos os seguintes estágios: a) Desenho de arquétipo, b) Formação do arquétipo, c) Geração de template, d) Parseador Python, e) Arquivo Json, e) Interface Gráfica. 


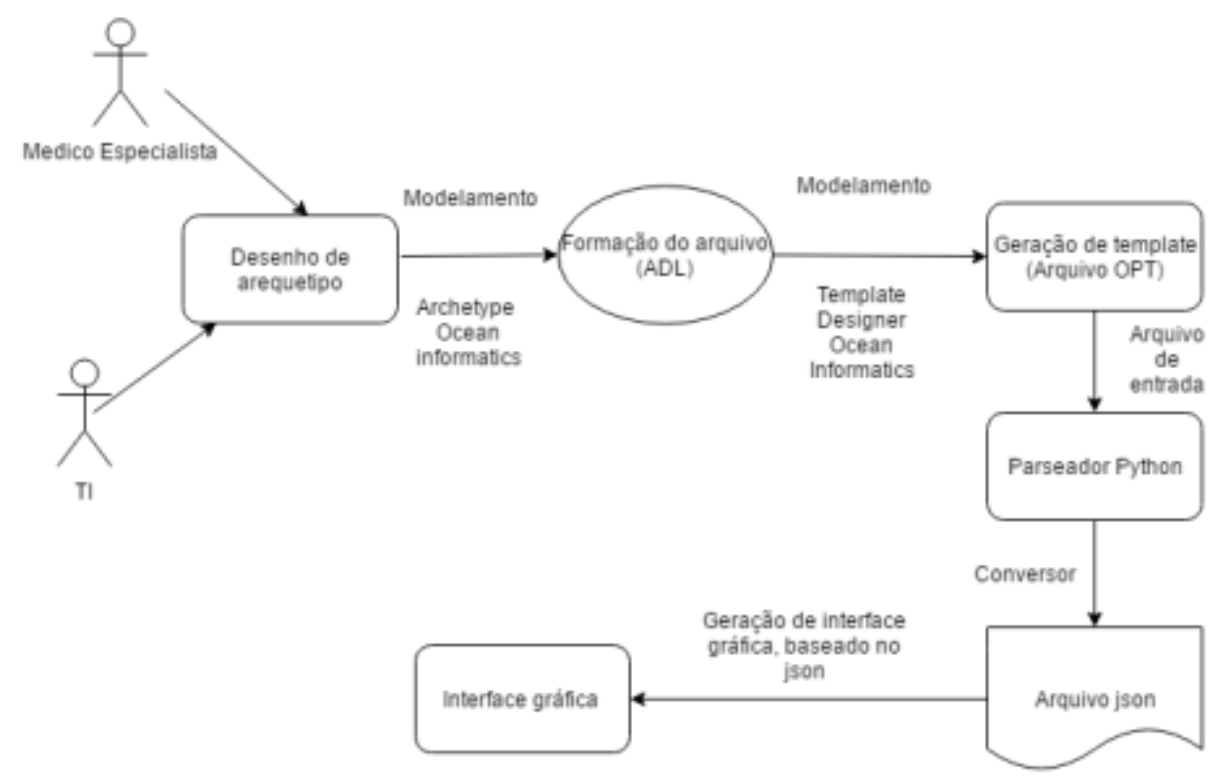

Figura 18: Diagrama contextual da metodologia utilizada na aplicação do openEHR no sistema de telemedicina

\section{DESENHO DOS ARQUÉTIPOS}

Como foi dito anteriormente, o conhecimento clínico é importante, e os arquétipos podem ser entendidos como metadados para definir os padrões que caracterizam essa informação.

Para desenhar os arquétipos foram utilizadas ferramentas livres, proporcionadas pela Ocean Informatics [10], utilizando o Archetype Editor e Template designer. Os arquétipos possuem distintos tipos de aplicabilidade e são classificados como se visualiza na Figura 6.

\section{COMPOSIÇÄO}

\section{SECÇÃO}

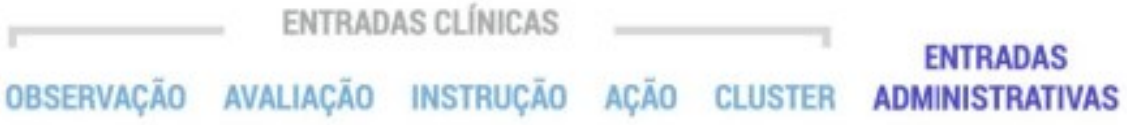

Figura 19: Tipos de arquétipos

Composição: Documento clínico, por exemplo, um relatório de alta hospitalar. É composto por outros arquétipos e tem duas naturezas eventual (dados de uma consulta) ou persistente (medicações em uso ou história familiar).

Secção: Estes arquétipos auxiliam a organização e navegação dentro dos RES. Organizam o conteúdo do documento em compartimentos específicos separando-o em seções ou subseções. É possível inserir um arquétipo section dentro de outro arquétipos section. 
Entradas Clínicas (Arquétipos não relevantes clinicamente) Armazenam informação administrativa sobre o processo clínico, exemplo: dados administrativos da admissão hospitalar. (p. ex. seguro de saúde).

Arquétipos que modelam dados clínicos:

Observação: Informação (crua, livre de interpretação). Engloba tudo o que foi dito pelo paciente (sintoma, evento, preocupação). Uma observação está composta por 4 partes : Data (dados), Protocol (protocolo), State (estado do paciente), Events (eventos).

Avaliação: Este arquétipo registra as interpretações das observações. Estão incluídos os achados interpretados clinicamente, opiniões e resumos clínicos. (Ideias, rotulações ou visões a partir da mente do clínico). Exemplos: Diagnóstico, avaliação do risco. Conteúdo composto por dados e protocolo.

Instrução: Informações relativas ao seguimento dos cuidados de saúde são modeladas por este arquétipo. Exemplos Prescrições, Solicitação de exames, Recomendações.

Ação: São associados a uma intervenção e geralmente precedidos por uma instrução. Cluster: Os arquétipos desta classe possuem uma característica especial: eles podem ser reutilizados dentro de outros dos tipos descritos anteriormente. Na verdade, o Cluster é um fragmento de arquétipo.

Os arquétipos desenvolvidos são classificados segundo a descrição da tabela abaixo:

\begin{tabular}{|l|c|c|}
\hline Arquétipo & Contexto & Tipo de arquétipo \\
\hline Trombolítico & AVC & Cluster \\
\hline Bamford & AVC & Evaluation \\
\hline Score avaliação & AVC & Evaluation \\
\hline Fatores de risco & AVC & Evaluation \\
\hline Examen protocolo & AVC & Evaluation \\
\hline avc & & Cluster \\
\hline Local Avaliação & AVC & AVC \\
\hline
\end{tabular}




\begin{tabular}{|c|c|c|}
\hline laboratório & & \\
\hline Alta hospitalar & AVC & Cluster \\
\hline Complicações & AVC & Cluster \\
médicas & & \\
\hline
\end{tabular}

\section{FORMAČ̃̃O DO ARQUIVO (ADL)}

As informações ditas foram modeladas com a ferramenta archetype editors [3], que é um compilador, editor e visualizador. Um exemplo pode ser visualizado na Figura 20; a ferramenta permite estabelecer o tipo de arquétipo (cluster, evaluation, etc), e permite colocar distintos tipos de dados para definir os elementos (texto, quantidade, numéricos, booleanos, data, clusters, slots).

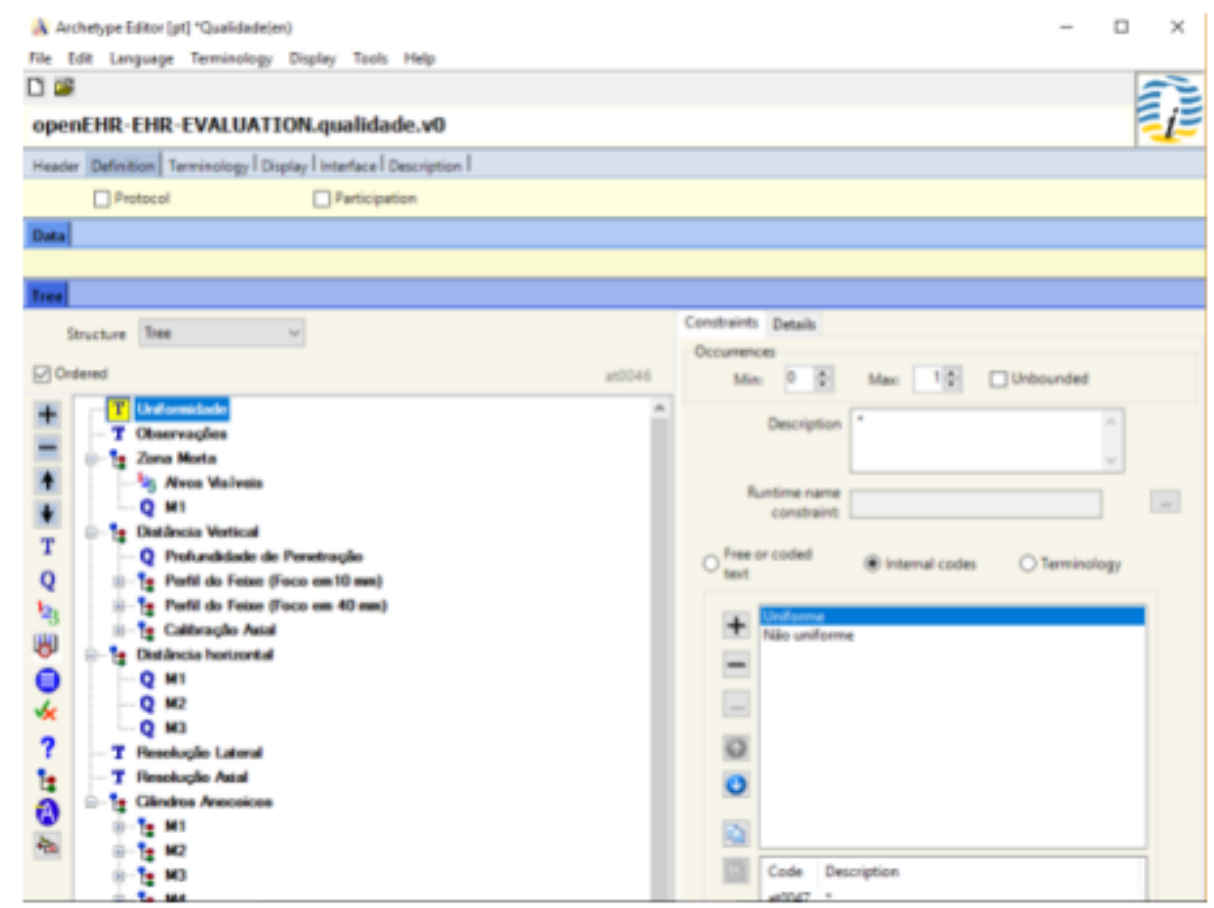

Figura 20: Desenho de arquétipo Qualidade (desenhado no Archetype Editor)

A linguagem ADL (Archetype definition Language) é um modelo eletrônico computável de um arquétipo que se encontra estruturado e detalhado. Utiliza-se a ferramenta Archetype Editor do Ocean Informatics, este permite exportar o desenho feito manualmente 
dos arquétipos na linguagem ADL (Figura 21). Os arquivos gerados serão depois utilizados pelos templates para a formação de seu conteúdo.

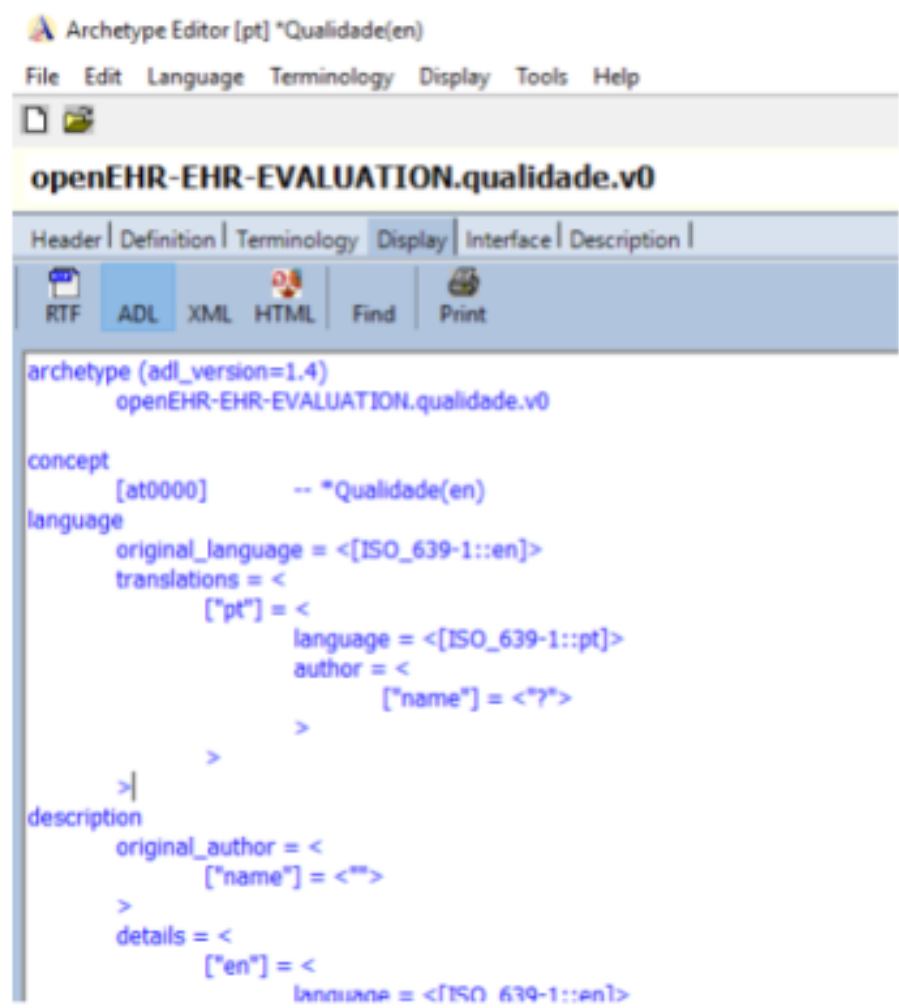

Figura 21: Desenho de linguagem ADL gerado pela ferramenta Archetype

\section{GERAÇÃO DO OPERATIONAL TEMPLATE}

O template é utilizado para criar definições de conteúdo assim como um particular relatório. O template pode estar vazio ou ter um ou mais arquétipos. A estrutura de um arquivo opt segue o seguinte esquema:

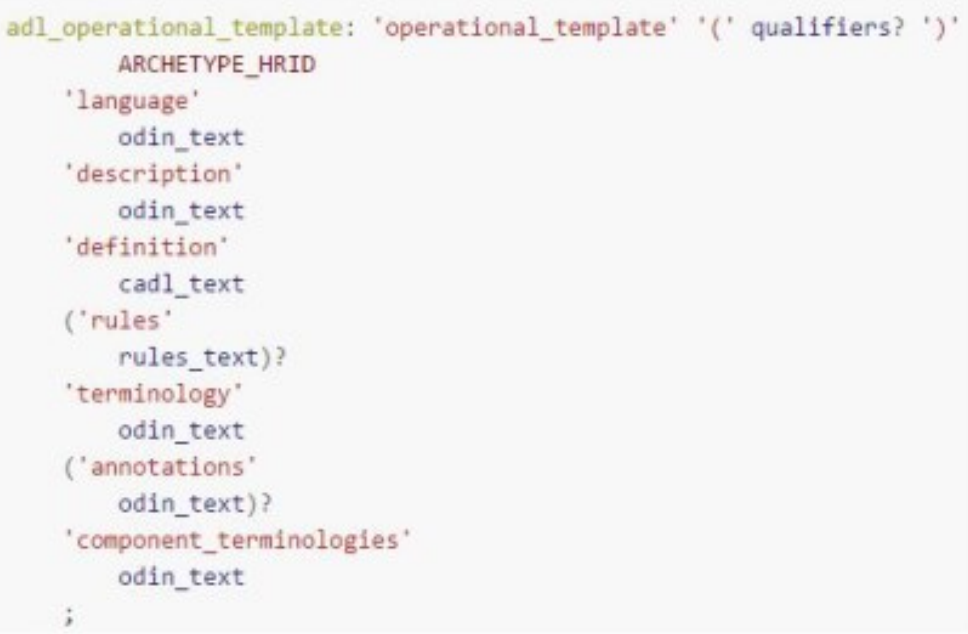

Figura 22: Estrutura do arquivo opt 
Na figura 23, mostra-se um exemplo no qual tem um template chamado trombolítico. Este está formado por dois arquétipos: análise de trombólise e evolução trombólise.

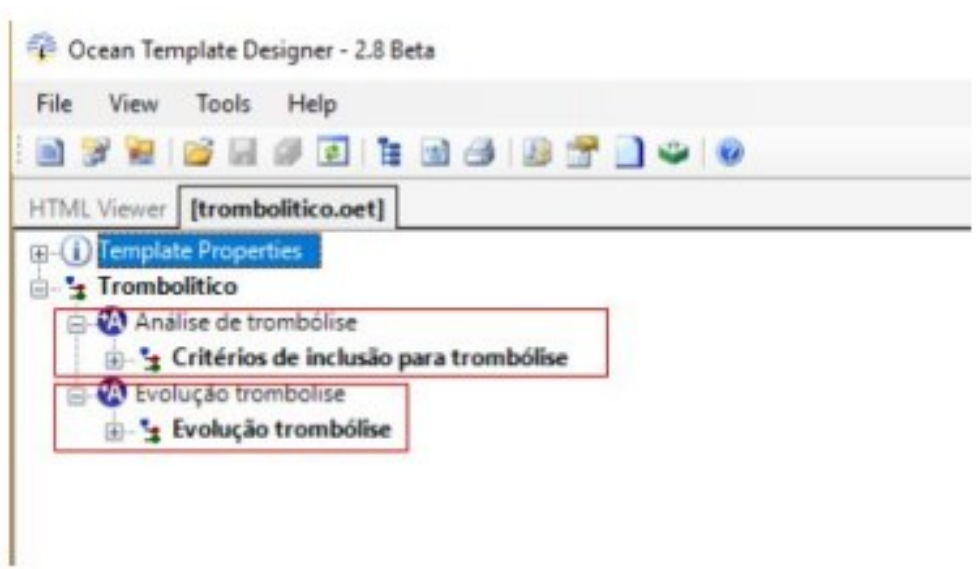

Figura 23: O template trombolítico está composto por dois arquétipos

Em seguida, a ferramenta template designer [4], permite exportar o arquivo num formato operational template. O operational template define um arquivo em formato xml.

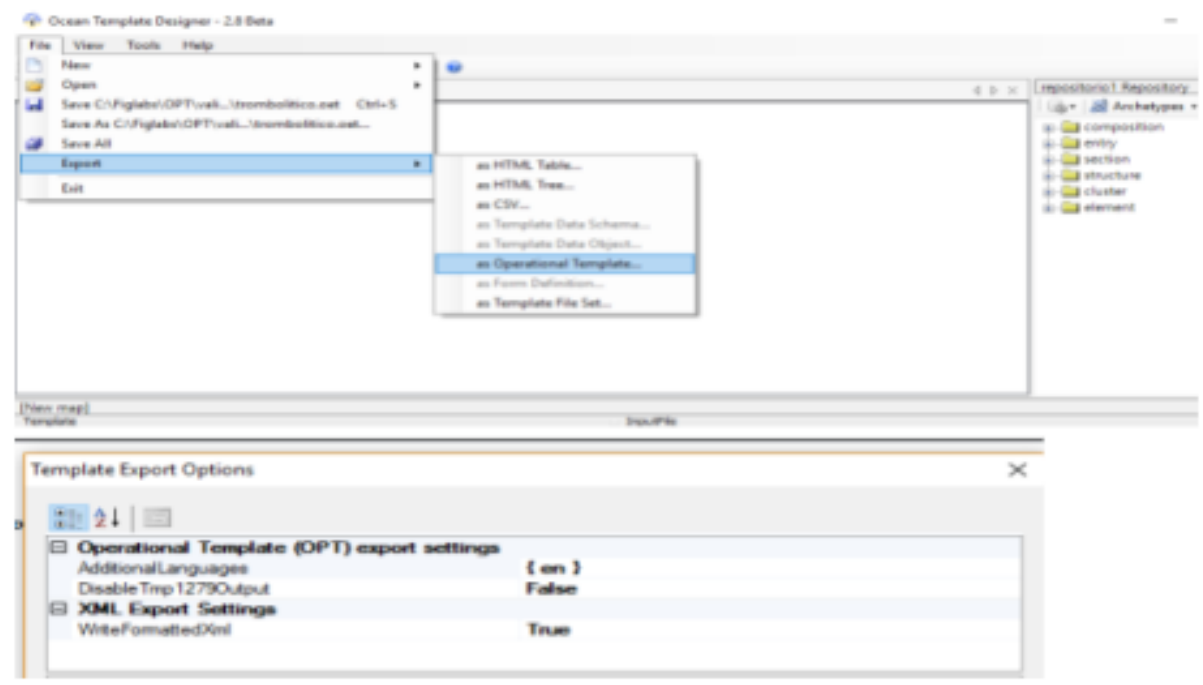

Figura 24: Exporte do arquivo do template para um operational template

\section{PARSER CÓDIGO FORMATO Json}

O xml é utilizado para representar objetos com características complexas. Utiliza-se um parser desenvolvido em python, este converte um arquivo xml em um formato json. O Python contém rotinas para tokenizar arquivos xml. A conversão é importante porque utilizaremos os arquivos json dos arquétipos para ser armazenados em nosso Banco de Dados Orientado a Documentos MongoDb. 
O Json é um modelo para armazenamento e transmissão de informações no formato texto. Apesar de ser muitos simples tem sido bastante utilizado por aplicações Web devido a sua capacidade de estruturar informações de uma forma bem mais compacta do que a conseguida pelo modelo Xml, tornando mais rápido o parsing das informações [11]. Na figura 25 , mostramos um exemplo da comparativa entre o xml e json.
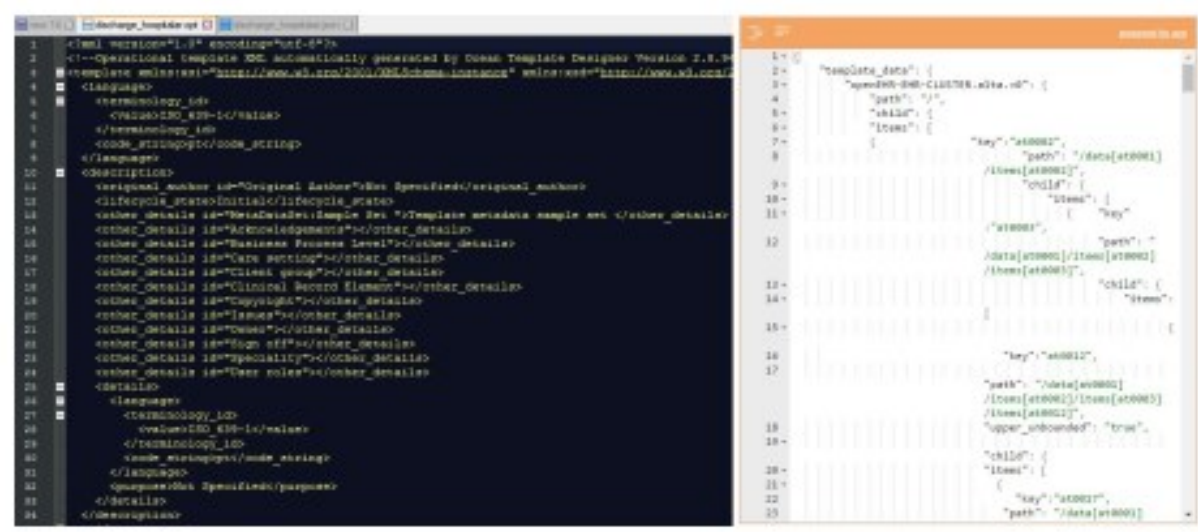

Figura 25: À esquerda, encontra-se o template em xml (opt) e à direita, sua versão em arquivo json

Os arquivos json são utilizados como coleções de objetos pelo mongoDB, no sistema podem-se adicionar ou atualizar cada um deles (Fig.26).

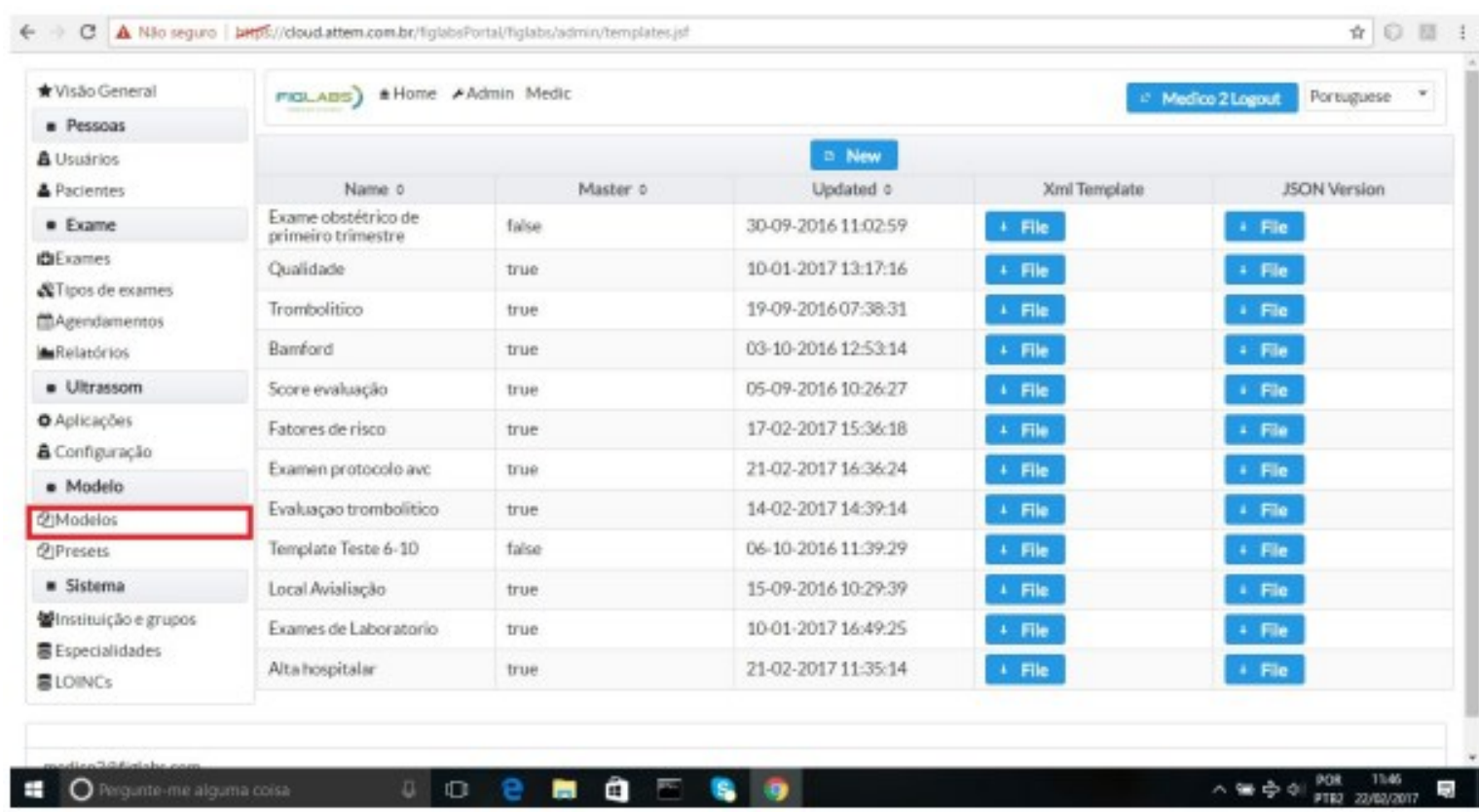

Figura 26: interface gráfica para adicionar e atualizar os arquétipos 


\section{INTERFACE GRÁFICA}

A construção da interface gráfica foi desenvolvido em java utilizando o framework primeface. Primefaces é um popular framework para projetos JSF que pode ser usado para desenvolver rapidamente aplicações sofisticadas para empresas ou sites padrão. Provê um conjunto de componentes de interface gráfica para aplicações JSF. A interface gráfica desenvolvida é um espelho das informações ditas nos arquétipos. Dessa maneira o pessoal especializado está em direto contato com o desenho. Assim no código estabelecemos rotinas necessárias para esquematizar as informações. Por exemplo, na figura 27 mostramos uma parte da informação de prevenção secundária do arquétipo Alta hospitalar.

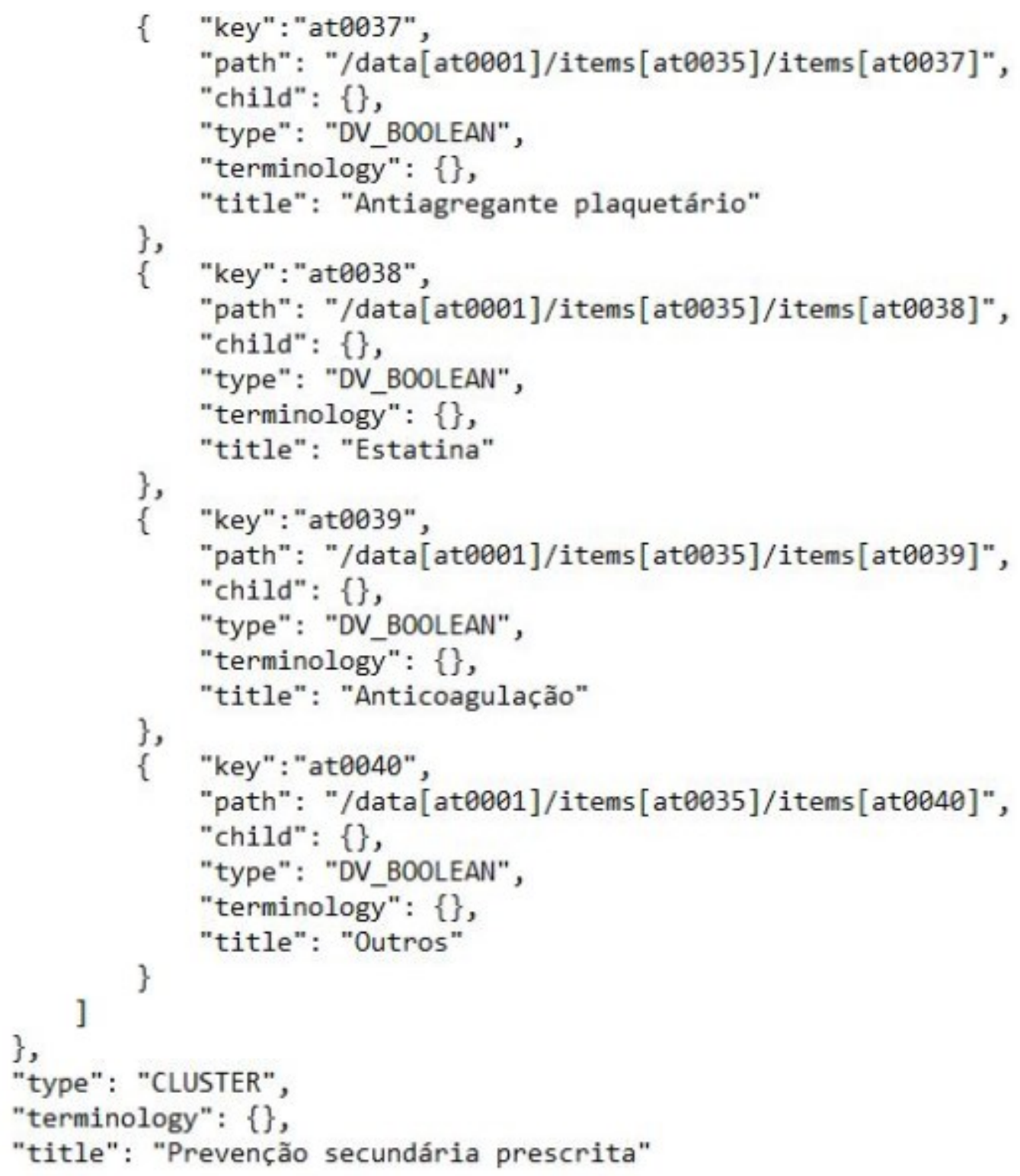

Figura 27: arquétipo alta hospitalar, parte prevenção secundária 
$\mathrm{Na}$ figura 28, podemos observar a representação na interface dos componentes booleanos descritos no arquétipo. Podemos observar que "OUTROS", além de ser booleano, possui um campo escrito associado a um texto. $\mathrm{Na}$ implementação, as informações dos arquétipos são carregadas pelas funções da classe RemoteBean como getListFromItem entre outras que percorrem os arquivos (figura 29). A função encontra-se sempre no cabeçalho da implantação dos arquétipos.

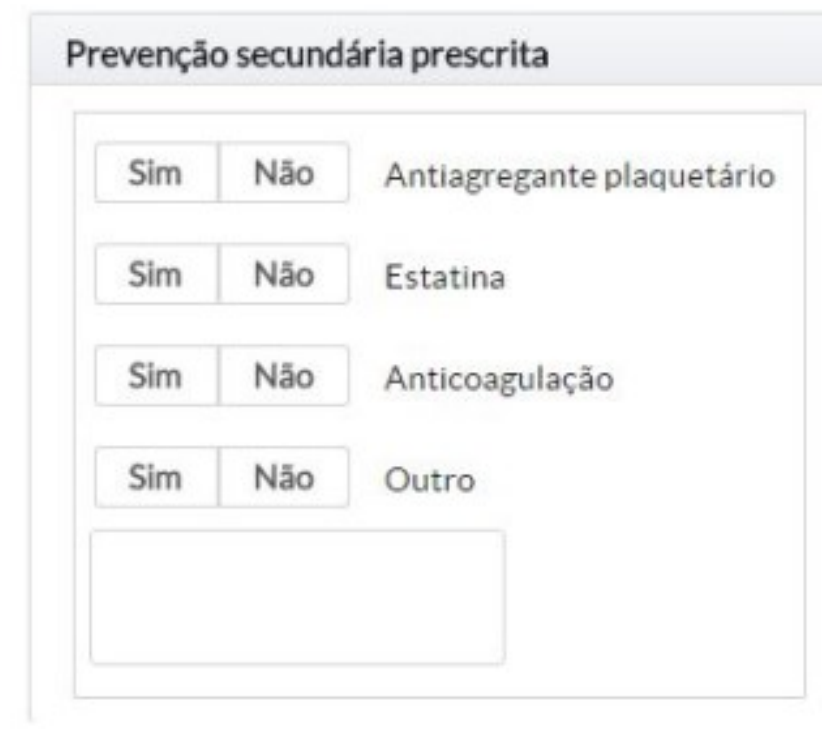

Figura 28: representação da informação booleana

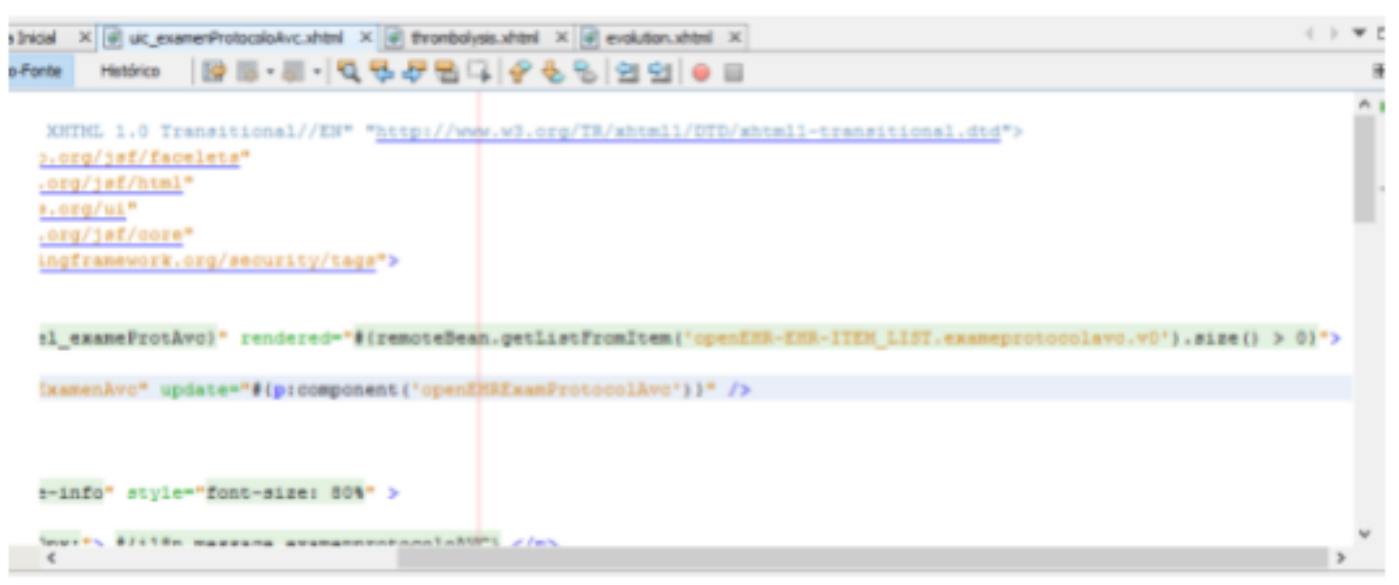

Figura 29: A função getListFromItem lê a informação do arquétipo 


\section{GERENCIAMENTO DE ARQUÉTIPOS}

$\mathrm{Na}$ figura abaixo, o quadro vermelho indica a opção para gerenciar os arquivos. $\mathrm{Na}$ tabela de fundo foi selecionada a opção "Avaliação AVC", obtendo um quadro com a opção "templates", onde poderão ser adicionados os arquétipos carregados na plataforma.

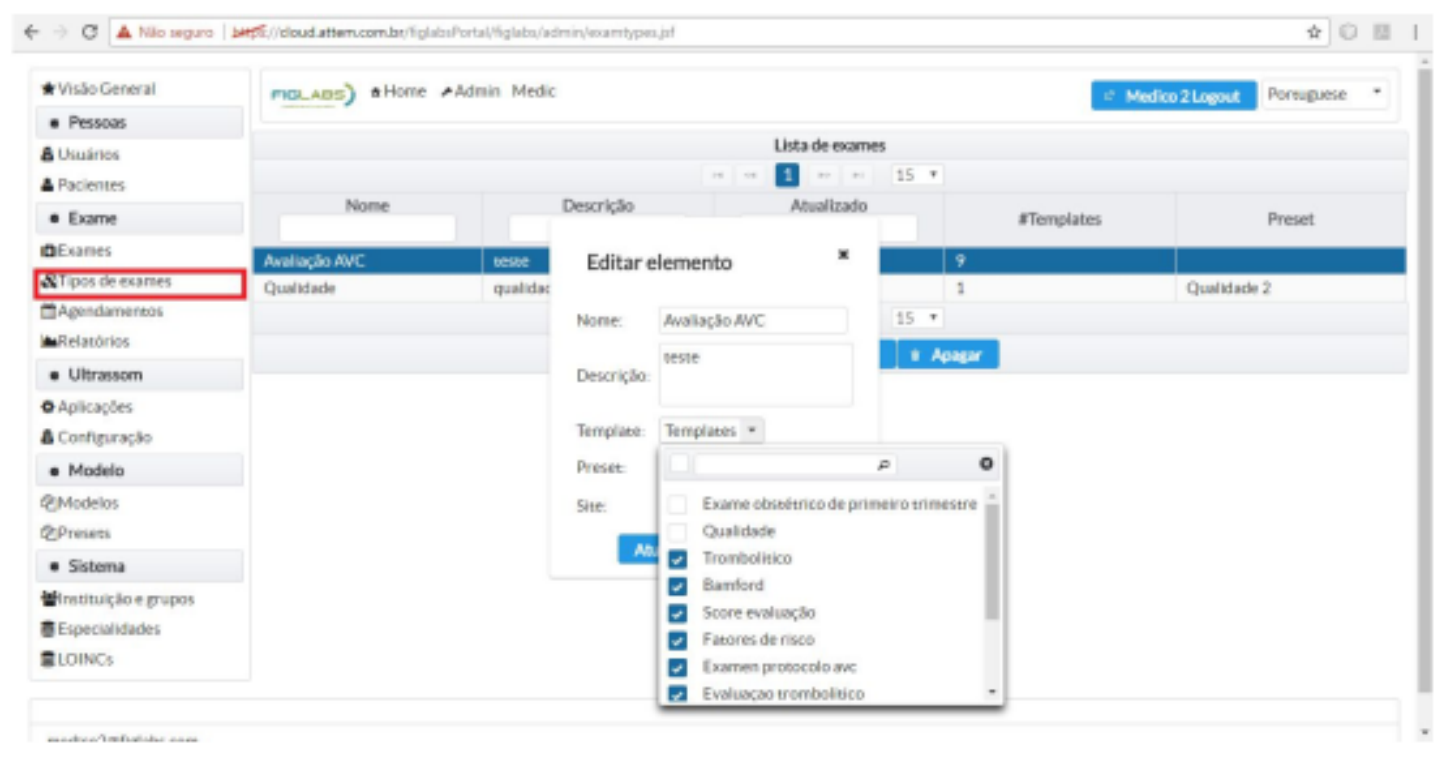

Figura 30: Exemplo de gerenciamento de arquétipos

\section{CONCLUSÃO}

A interoperabilidade de dados é importante para a integração de sistemas desenvolvidos em plataformas distintas. Para o caso desenvolvido, foi utilizado e estudado a metodologia OpenEHR. Esta metodologia apresenta vários benefícios, como a separabilidade da complexidade. Esta característica permite ao usuário estabelecer os requisitos sem ter conhecimentos em tecnologia de informação. Durante o projeto foram utilizadas as ferramentas desenvolvidas pela Ocean Informatics para desenvolver os arquétipos. Porém, o especialista precisa de uma capacitação nessas ferramentas para modelar os requerimentos. Então foram estudadas as ferramentas e metodologias dos arquétipos do OpenEHR para fornecer acesso das características aos usuários médicos.

Durante o projeto, o equipe de tecnologia de informação ajudou no desenho dos arquétipos para agilizar o processo de conhecimento de informação clínica. $\mathrm{O}$ fato de modelar as informações clínicas nos arquétipos ajudou bastante na manutenção do sistema, 
diferentemente de alguns sistemas tradicionais. Além de definir os dados de armazenamento, os arquétipos orientam o desenho da interface de usuário. Também podemos destacar que o armazenamento da informação num banco de dados NoSql Mongodb orientado a documentos facilitou bastante a integração dos arquétipos com o sistema.

$\mathrm{Na}$ medida em que foram ocorrendo as reuniões com os especialistas, percebeu-se que a abstração do modelagem em OpenEHR, consegue satisfazer os requerimentos desde um nível básico até um nível complexo. Esta ferramenta tem muitas opções de desenvolvimento, e neste trabalho foi utilizada apenas uma parte de todo o contexto que envolve este interessante paradigma para solucionar o problema de interoperabilidade de dados nos sistemas de saúde. Durante o transcurso do projeto foram apreendidas, além da metodologia OpenEHR, metodologias para construção de interfaces usando primefaces e utilização de modelos de dados baseados em documentos MongoDb chamados também tecnologias NoSql.

\section{REFERÊNCIAS}

[1] Nielsen, Marilyn, and Jodi Saracino. "Telemedicine in the intensive care unit." Critical care nursing clinics of North America 24.3 (2012): 491-500.

[2] OpenEHR : http://www.openEHR.org

[3] Archeytipe editor : http://www.openEHR.org

[4] Template editor : http://www.openEHR.org

[5] Beale, T. Archetypes: Constraint-based Domain Models for Future-proof Information. Systems. OOPSLA 2002 workshop on behavioural semantics, 2002.

[6] Primefaces : https://www.primefaces.org/

[7] Bacelar, Gustavo, and Ricardo Correia. "openEHR." (2015).

[8] Kalra, Dipak. Electronic Health Record Standards. IMIA, 2006.

[9] Santos, Marcelo R., and Marcello Peixoto Bax. "Modelagem de um Repositório Central Baseado em Arquétipos para Sistemas de RES Federados." Anais do XII Congresso Brasileiro de Informática em Saúde-CBIS. Porto de Galinhas: Pernambuco. 2010.

[10] Ocean informatics, site online http://oceanhealthsystems.com/ , visto :23/03/2016 
[11] Json site http://www.devmedia.com.br/introducao-ao-formato-json/25275, visto $23 / 03 / 2016$

[12] Satava, Richard M. "Telesurgery, robotics, and the future of telemedicine." European surgery 37.5 (2005): 304-307. 